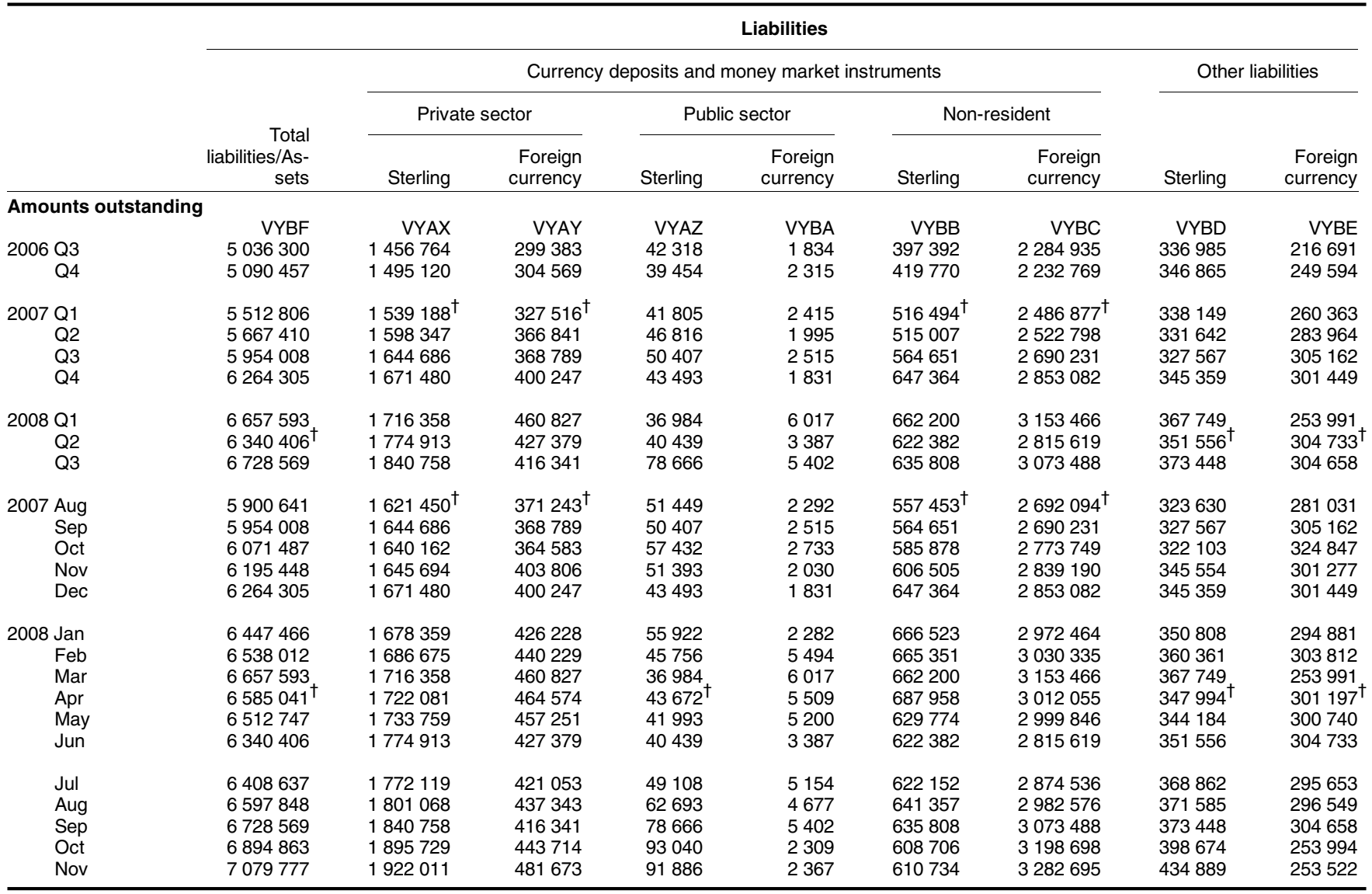

\begin{tabular}{|c|c|c|c|c|c|c|c|c|c|c|c|c|c|c|}
\hline & \multicolumn{14}{|c|}{ Assets } \\
\hline & \multicolumn{6}{|c|}{ Loans } & \multicolumn{6}{|c|}{ Securities (other than derivatives) } & \multicolumn{2}{|c|}{ Other assets } \\
\hline & \multicolumn{2}{|c|}{ Private sector } & \multicolumn{2}{|c|}{ Public sector } & \multicolumn{2}{|c|}{ Non-resident } & \multicolumn{2}{|c|}{ Private sector } & \multicolumn{2}{|c|}{ Public sector } & \multicolumn{2}{|c|}{ Non-resident } & \multirow[b]{2}{*}{ Sterling } & \multirow[b]{2}{*}{$\begin{array}{r}\text { Foreign } \\
\text { currency }\end{array}$} \\
\hline & Sterling & $\begin{array}{l}\text { Foreign } \\
\text { currency }\end{array}$ & Sterling & $\begin{array}{l}\text { Foreign } \\
\text { currency }\end{array}$ & Sterling & $\begin{array}{l}\text { Foreign } \\
\text { currency }\end{array}$ & Sterling & $\begin{array}{l}\text { Foreign } \\
\text { currency }\end{array}$ & Sterling & $\begin{array}{l}\text { Foreign } \\
\text { currency }\end{array}$ & Sterling & $\begin{array}{l}\text { Foreign } \\
\text { currency }\end{array}$ & & \\
\hline \multicolumn{15}{|c|}{ Amounts outstanding } \\
\hline & VYBG & VYBH & VYBI & VYBJ & VYBK & VYBL & VYBM & VYBN & VYBO & VYBP & VYBQ & VYBR & VYBS & VYBT \\
\hline 2006 Q3 & 1679678 & 318410 & 38981 & 1465 & 258534 & 1845777 & 157863 & 55914 & -2629 & 132 & 39108 & 527937 & 71691 & 43439 \\
\hline Q4 & 1698705 & 342203 & 42785 & 106 & 291348 & 1751183 & 169394 & 58127 & -7572 & 105 & 40954 & 577207 & 78659 & 47252 \\
\hline 2007 Q1 & 1785214 & 386861 & 37650 & 1196 & 380130 & 1944693 & 144260 & 62288 & -16337 & 97 & 43218 & 616000 & 78615 & 48921 \\
\hline Q2 & 1827272 & 405419 & 35294 & 321 & 376891 & 2005419 & 158191 & 53576 & -9829 & 18 & 48671 & 638512 & 78437 & 49217 \\
\hline Q3 & 1917229 & 418246 & 30355 & 827 & 385467 & 2162534 & 160776 & 61378 & -8023 & - & 48754 & 639590 & 80237 & 56638 \\
\hline Q4 & 1936977 & 454890 & 36486 & 1605 & 428897 & 2301717 & 169899 & 69727 & -5459 & 9 & 48727 & 675412 & 88310 & 57107 \\
\hline 2008 Q1 & 1982320 & 537083 & 28774 & 1405 & 438650 & 2590605 & 180737 & 79263 & -3139 & - & 51251 & 621595 & 84866 & $0410<+$ \\
\hline Q2 & $2030369^{\dagger}$ & $464966^{\dagger}$ & 18584 & 232 & $393002^{\dagger}$ & $2360387^{\dagger}$ & 217993 & 88544 & -3046 & 15 & 47284 & 579128 & 83531 & $59418^{\dagger}$ \\
\hline Q3 & 2066046 & 483351 & 42693 & 1840 & 402694 & 2573581 & 260015 & 91153 & 2683 & 4 & 46724 & 590314 & 100014 & 67457 \\
\hline 2007 Aug & 1881689 & 416361 & 30457 & 420 & 396814 & 2128661 & 158979 & 58398 & -6320 & -4 & 46941 & 651546 & 82528 & 54171 \\
\hline Sep & 1917229 & 418246 & 30355 & 827 & 385467 & 2162534 & 160776 & 61378 & -8023 & - & 48754 & 639590 & 80237 & 56638 \\
\hline Oct & 1933004 & 431467 & 29237 & 1040 & 382237 & 2235486 & 160895 & 61347 & -1900 & 15 & 49576 & 651968 & 82850 & 54267 \\
\hline Nov & 1930373 & 455589 & 30790 & 1137 & 392608 & 2291486 & 170680 & 57620 & 1265 & -3 & 53010 & 668206 & 86259 & 56428 \\
\hline Dec & 1936977 & 454890 & 36486 & 1605 & 428897 & 2301717 & 169899 & 69727 & -5459 & 9 & 48727 & 675412 & 88310 & 57107 \\
\hline 2008 Jan & 194 & & & 5 & & & 1894 & & -2434 & 79 & & & & 57414 \\
\hline Feb & 1964999 & 496420 & 28503 & 1833 & 463848 & 2479059 & 185171 & 72594 & -3165 & 43 & 49619 & 649207 & 87721 & 62160 \\
\hline Mar & 1982320 & 537083 & 28774 & 1405 & 438650 & 2590605 & 180737 & 79263 & -3139 & - & 51251 & 621595 & 84866 & 64182 \\
\hline Apr & $1999083^{\dagger}$ & $483251^{\dagger}$ & 27129 & 961 & $456287^{\dagger}$ & $2504271^{\dagger}$ & 191066 & 96137 & -3094 & 6 & 46325 & 642259 & 81650 & $59712^{\dagger}$ \\
\hline May & 2008008 & 482301 & 25197 & 775 & 400509 & 2516172 & 184380 & 88954 & -2377 & 7 & 50166 & 612344 & $83876^{\dagger}$ & 62434 \\
\hline Jun & 2030369 & 464966 & 18584 & 232 & 393002 & 2360387 & 217993 & 88544 & -3046 & 15 & 47284 & 579128 & 83531 & 59418 \\
\hline Jul & 2032768 & 452340 & 18326 & 1239 & 389032 & 2396195 & 228105 & 88963 & -1377 & 94 & 48676 & & 96779 & 62280 \\
\hline Aug & 2040832 & 505268 & 31745 & 1103 & 392436 & 2480634 & 247945 & 89819 & -1281 & 98 & 48157 & 606357 & 98781 & 55953 \\
\hline Sep & 2066046 & 483351 & 42693 & 1840 & 402694 & 2573581 & 260015 & 91153 & 2683 & 4 & 46724 & 590314 & 100014 & 67457 \\
\hline Oct & 2114752 & 511894 & 35864 & 1971 & 397692 & 2673053 & 260535 & 90474 & 9710 & 5 & 44336 & $581553^{\dagger}$ & 100185 & 72841 \\
\hline Nov & 2121121 & 543963 & 34117 & 2502 & 414287 & 2752113 & 261360 & 99121 & 25679 & 5 & 44741 & 596177 & 106714 & 77878 \\
\hline
\end{tabular}


\begin{tabular}{ll}
\hline Liabilities & L
\end{tabular}

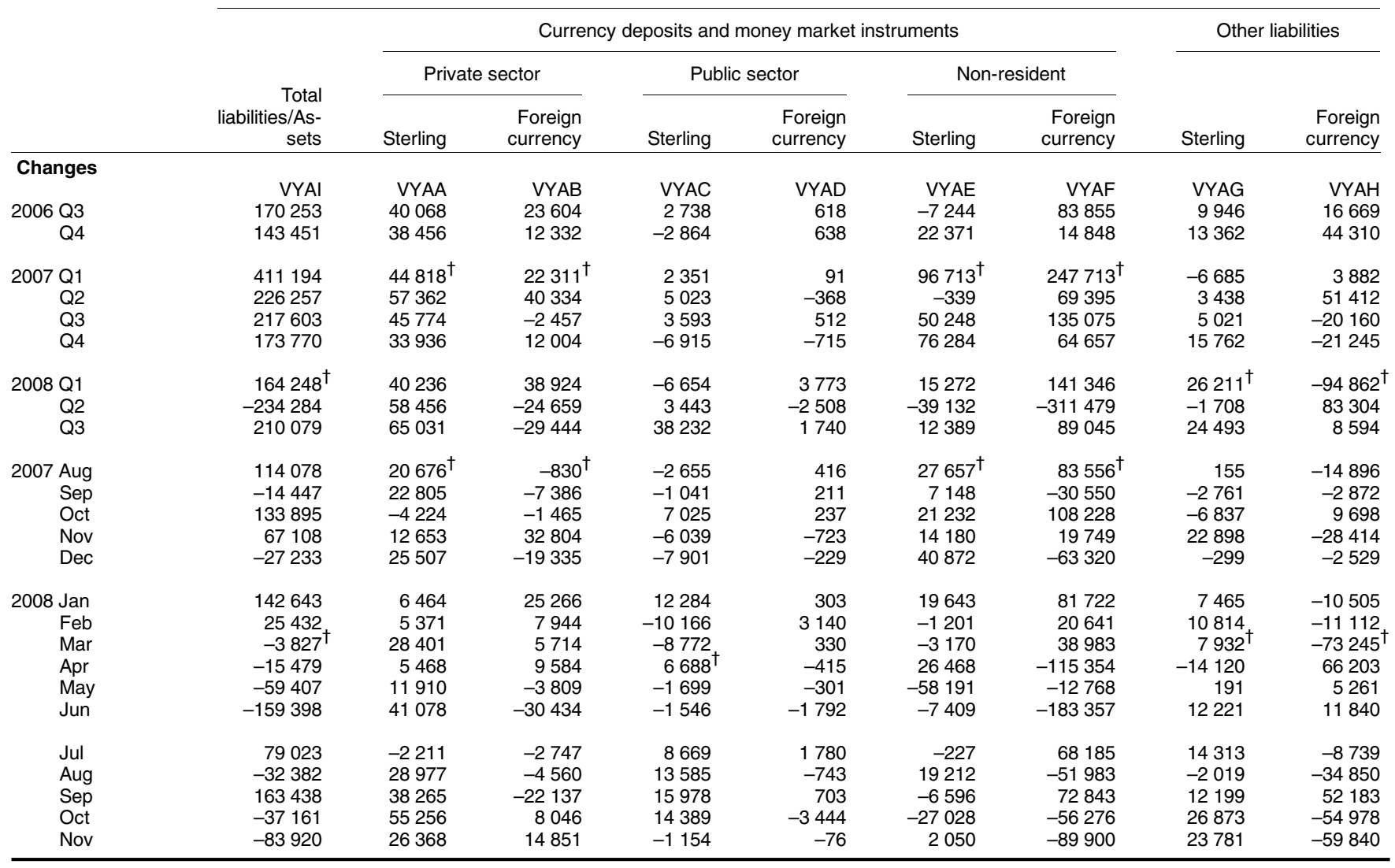

\begin{tabular}{|c|c|c|c|c|c|c|c|c|c|c|c|c|c|c|}
\hline & \multicolumn{14}{|c|}{ Assets } \\
\hline & \multicolumn{6}{|c|}{ Loans } & \multicolumn{6}{|c|}{ Securities (other than derivatives) } & \multicolumn{2}{|c|}{ Other assets } \\
\hline & \multicolumn{2}{|c|}{ Private sector } & \multicolumn{2}{|c|}{ Public sector } & \multicolumn{2}{|c|}{ Non-resident } & \multicolumn{2}{|c|}{ Private sector } & \multicolumn{2}{|c|}{ Public sector } & \multicolumn{2}{|c|}{ Non-resident } & \multirow[b]{2}{*}{ Sterling } & \multirow[b]{2}{*}{$\begin{array}{c}\text { Foreign } \\
\text { currency }\end{array}$} \\
\hline & Sterling & $\begin{array}{l}\text { Foreign } \\
\text { currency }\end{array}$ & Sterling & $\begin{array}{l}\text { Foreign } \\
\text { currency }\end{array}$ & Sterling & $\begin{array}{l}\text { Foreign } \\
\text { currency }\end{array}$ & Sterling & $\begin{array}{c}\text { Foreign } \\
\text { currency }\end{array}$ & Sterling & $\begin{array}{c}\text { Foreign } \\
\text { currency }\end{array}$ & Sterling & $\begin{array}{r}\text { Foreign } \\
\text { currency }\end{array}$ & & \\
\hline \multicolumn{15}{|l|}{ Changes } \\
\hline & VYAJ & VYAK & VYAL & VYAM & VYAN & VYAO & VYAP & VYAQ & VYAR & VYAS & VYAT & VYAU & VYAV & VYAW \\
\hline 2006 Q3 & 49534 & -7808 & 1696 & 243 & -5248 & 102103 & 553 & 5002 & -2545 & -20 & -2617 & 25329 & -580 & 4612 \\
\hline Q4 & 21628 & 33273 & 3805 & -1322 & 33757 & -40737 & 10646 & 3629 & -4969 & -23 & 2823 & 68952 & 6929 & 5058 \\
\hline 2007 Q1 & 57034 & 43393 & -4980 & 1047 & 88806 & 187735 & 7163 & 3931 & -8951 & -8 & 2151 & 32322 & 22 & 1527 \\
\hline Q2 & 43109 & 31233 & -2356 & -856 & -2492 & 94016 & 15039 & -6885 & 5977 & -78 & 6460 & 42008 & -52 & 1136 \\
\hline Q3 & 87167 & 6706 & -4992 & 506 & 8657 & 126973 & 465 & 6620 & 2088 & -19 & -814 & -26666 & 4224 & 6688 \\
\hline Q4 & 21215 & 22203 & 6131 & 764 & 44069 & 64632 & 7302 & 5502 & 2727 & 9 & -1808 & -5813 & 8334 & -1500 \\
\hline & 67659 & 56040 & & -261 & 9546 & 163201 & -11561 & 421 & 2538 & -11 & $9^{\dagger}$ & $-118138^{\dagger}$ & -2006 & \\
\hline Q2 & $50244^{\dagger}$ & $-62198^{\dagger}$ & -10190 & -1163 & $-43060^{\dagger}$ & $-199160^{\dagger}$ & 45271 & 9899 & -246 & 16 & -2433 & -17207 & $-277^{\dagger}$ & $-3780^{\dagger}$ \\
\hline & 33531 & -13655 & 24160 & 1509 & 10369 & 81045 & $43529^{\dagger}$ & 4762 & 5976 & -16 & -1064 & -3143 & 17386 & 5690 \\
\hline 2007 Aug & 34394 & 1201 & -738 & -108 & 7787 & 49791 & -3653 & -599 & 1935 & -280 & -892 & 17327 & 2761 & 5153 \\
\hline Sep & 30674 & -3892 & -170 & 410 & -11326 & 4504 & 758 & 1898 & -1710 & 4 & 1177 & -38502 & -84 & 1811 \\
\hline Oct & 15611 & 16823 & -1118 & 213 & -3229 & 87208 & -673 & 59 & 6209 & 15 & 901 & 11121 & 2568 & -1814 \\
\hline Nov & -2164 & 17250 & 1553 & 93 & 11100 & 21756 & 9082 & -4613 & 3183 & -18 & 2864 & 2195 & 3592 & 1233 \\
\hline Dec & 7768 & -11870 & 5696 & 458 & 36198 & -44332 & -1107 & 10056 & -6665 & 12 & -5573 & -19129 & 2174 & -919 \\
\hline 2008 Jan & 28279 & 27997 & -10039 & -59 & 11989 & 102558 & 1282 & 3472 & 3246 & 70 & -1557 & -25008 & 393 & 20 \\
\hline Feb & 21523 & 1905 & 2034 & 256 & 21751 & 14335 & -7371 & -2903 & -789 & -37 & 1326 & -30989 & 379 & 4012 \\
\hline Mar & 17857 & 26138 & 271 & -458 & -24194 & 46308 & -5472 & -148 & 81 & -44 & $240^{\dagger}$ & $-62141^{\dagger}$ & -2778 & 513 \\
\hline Apr & $17773^{\dagger}$ & $-43436^{\dagger}$ & -1645 & -434 & $17883^{\dagger}$ & $-57824^{\dagger}$ & 14880 & 17828 & -72 & 7 & -4524 & 30999 & -3226 & $-3687^{\dagger}$ \\
\hline May & 9450 & -1006 & -1932 & -186 & -54068 & 15716 & -4882 & -7276 & 515 & 1 & 4220 & -24892 & 2221 & 2712 \\
\hline Jun & 23021 & -17756 & -6613 & -543 & -6875 & -157052 & 35273 & -653 & -689 & 8 & -2129 & -23314 & $728^{\dagger}$ & -2805 \\
\hline Jul & 1756 & -11910 & -258 & 1011 & -3359 & 47794 & 7654 & 649 & 1832 & 79 & 1299 & 16281 & 13261 & 2935 \\
\hline Aug & 8570 & 23260 & 13470 & -215 & 3438 & -54511 & 17319 & 2191 & 151 & -1 & -3039 & -35949 & 1677 & -8743 \\
\hline Sep & 23205 & -25005 & 10948 & 713 & 10290 & 87762 & $18556^{\dagger}$ & 1922 & 3993 & -94 & 676 & 16525 & 2448 & 11498 \\
\hline Oct & 51220 & 4843 & -6829 & -92 & -4969 & -39949 & 589 & -3888 & 7036 & - & -3682 & -44433 & 832 & 2162 \\
\hline Nov & 7055 & 3855 & -1746 & 382 & 16628 & -67583 & -8678 & 3786 & 15850 & - & -2883 & -58624 & 6366 & 1673 \\
\hline
\end{tabular}




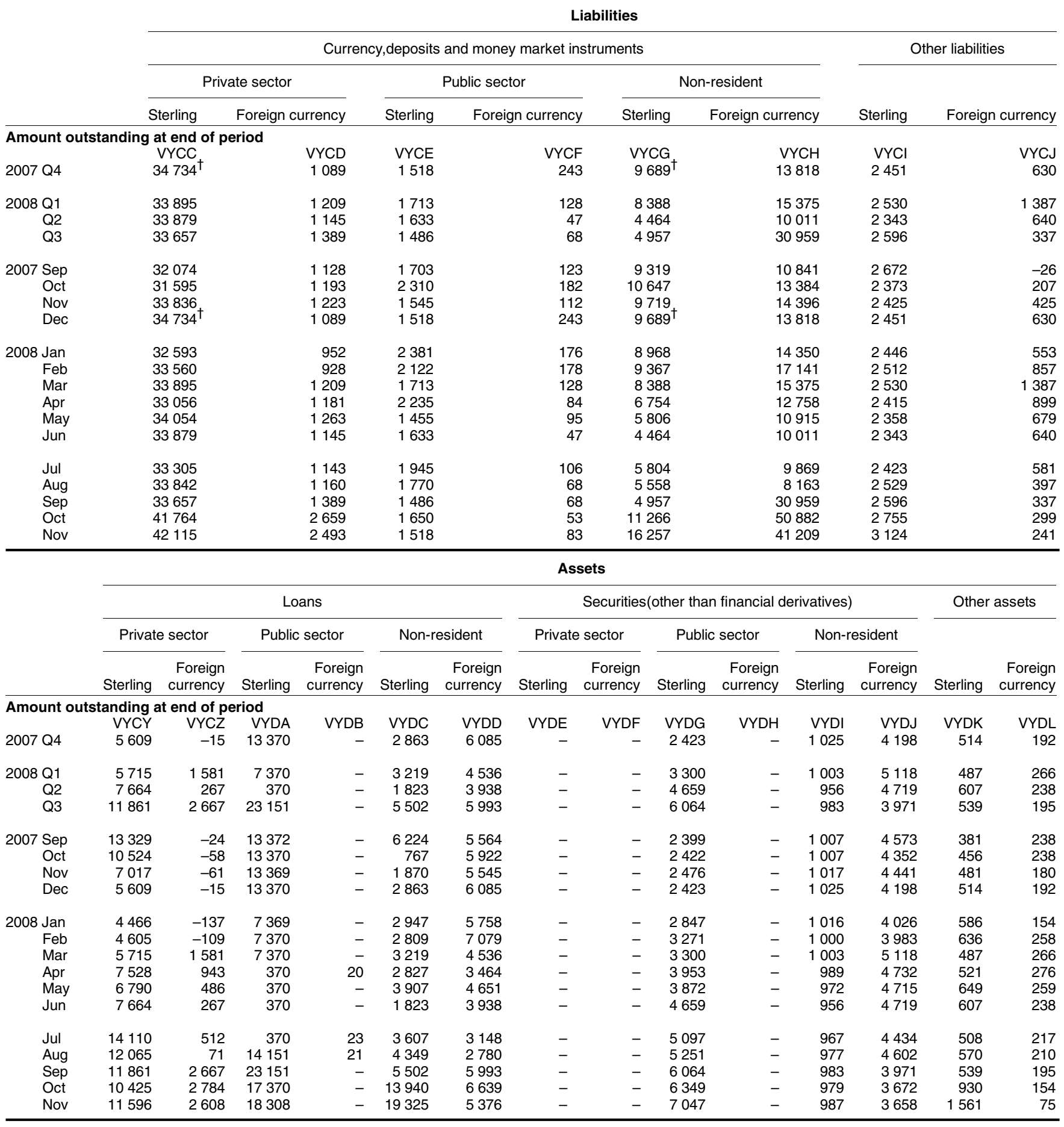




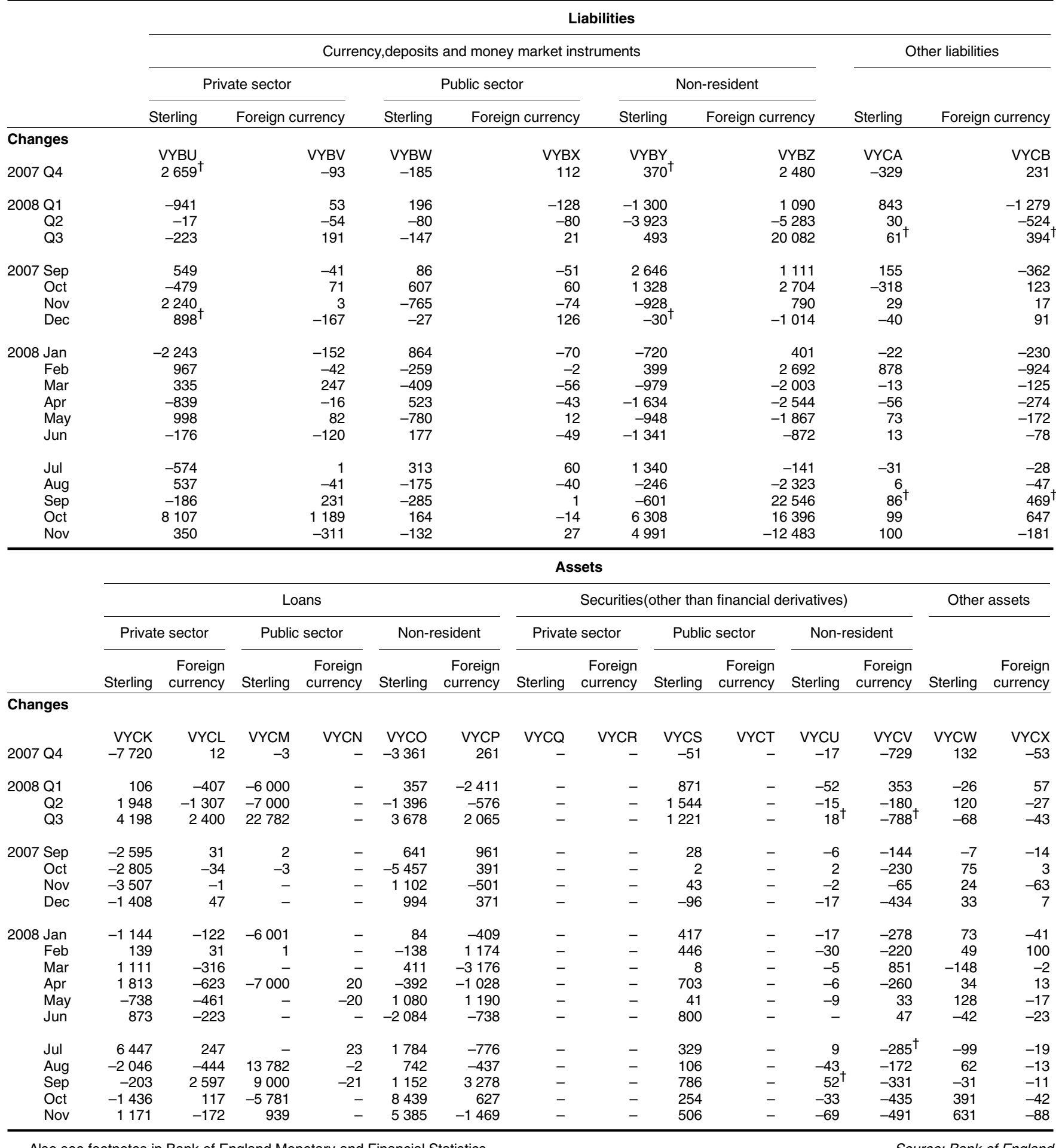




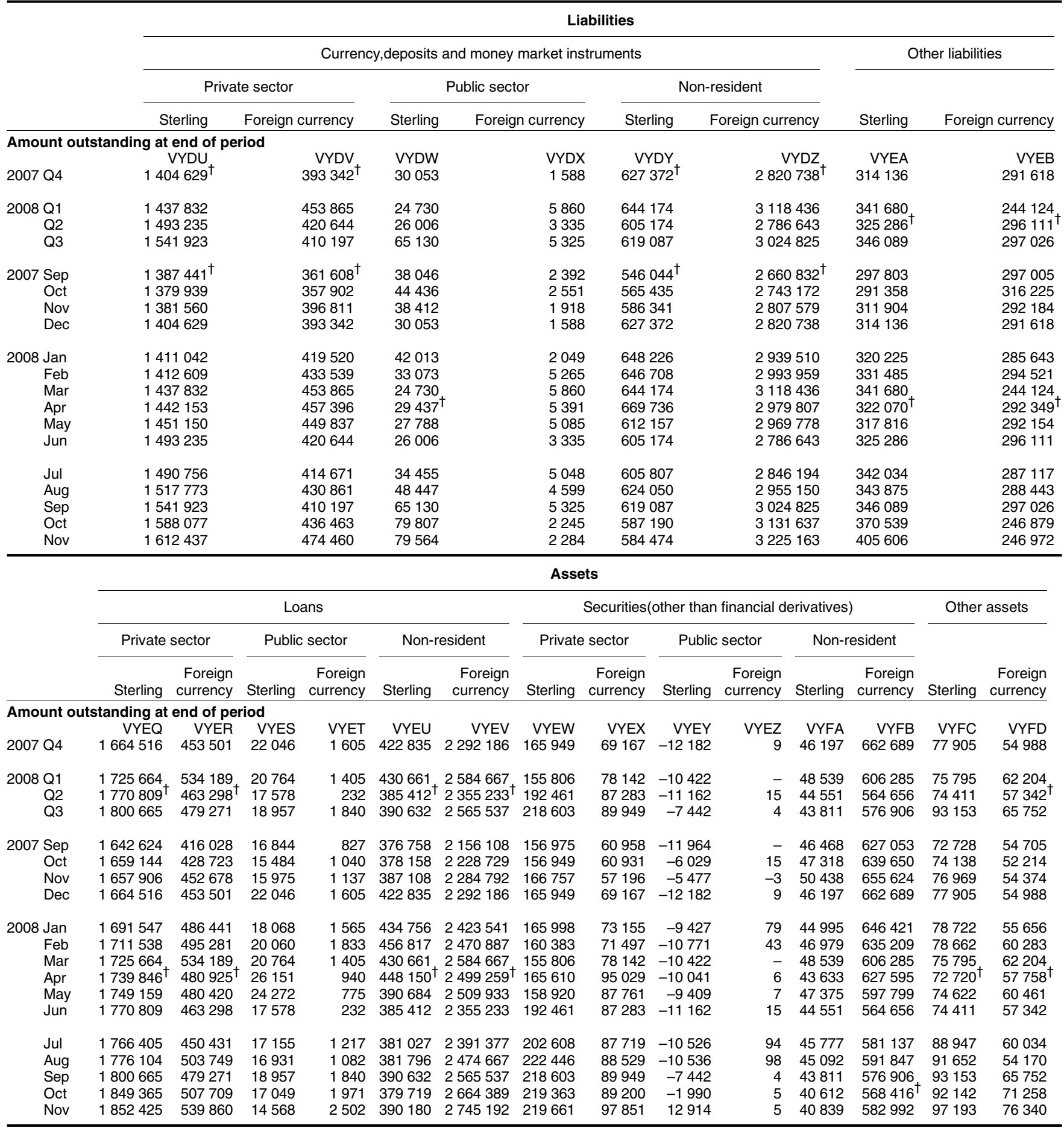




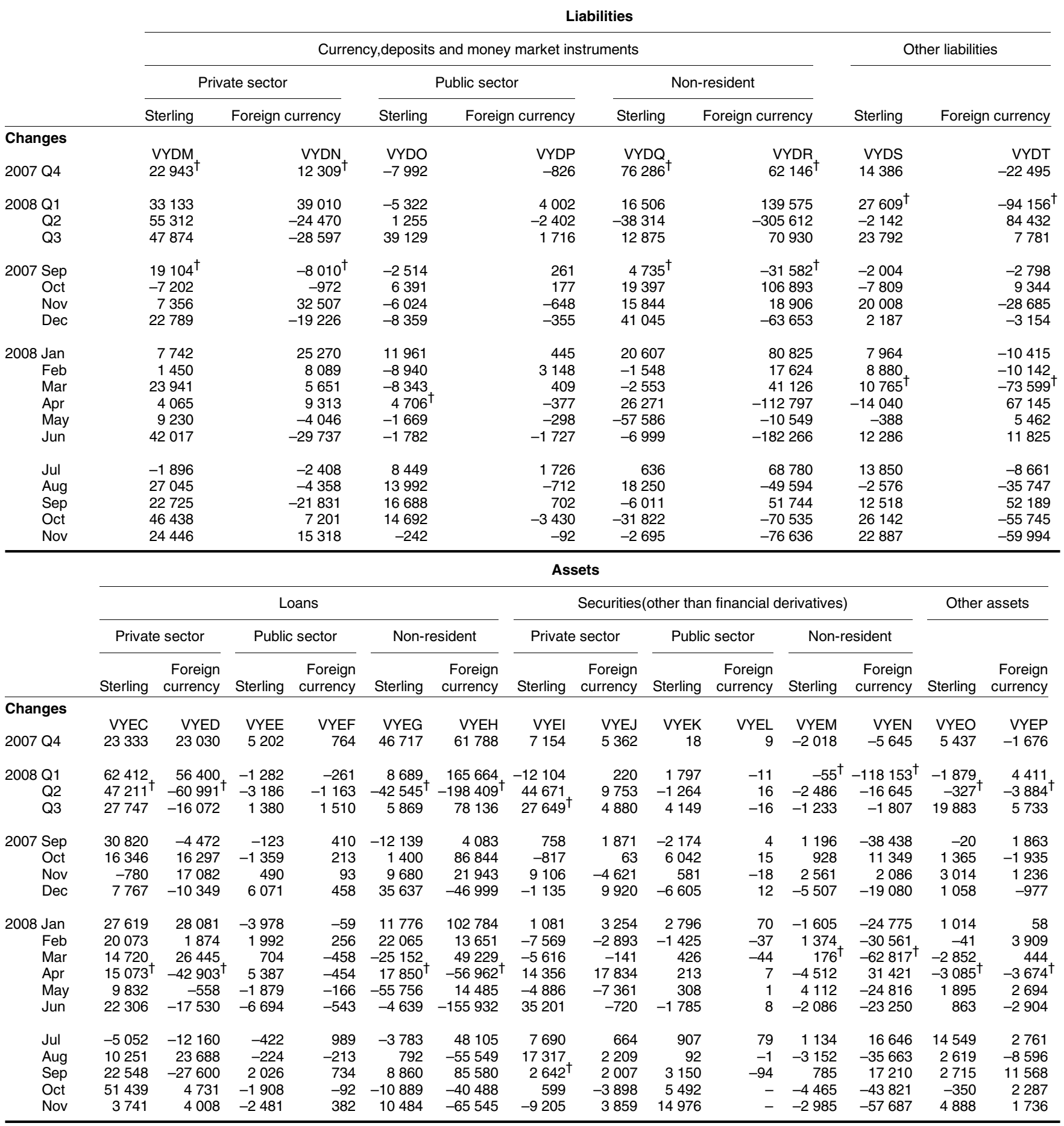









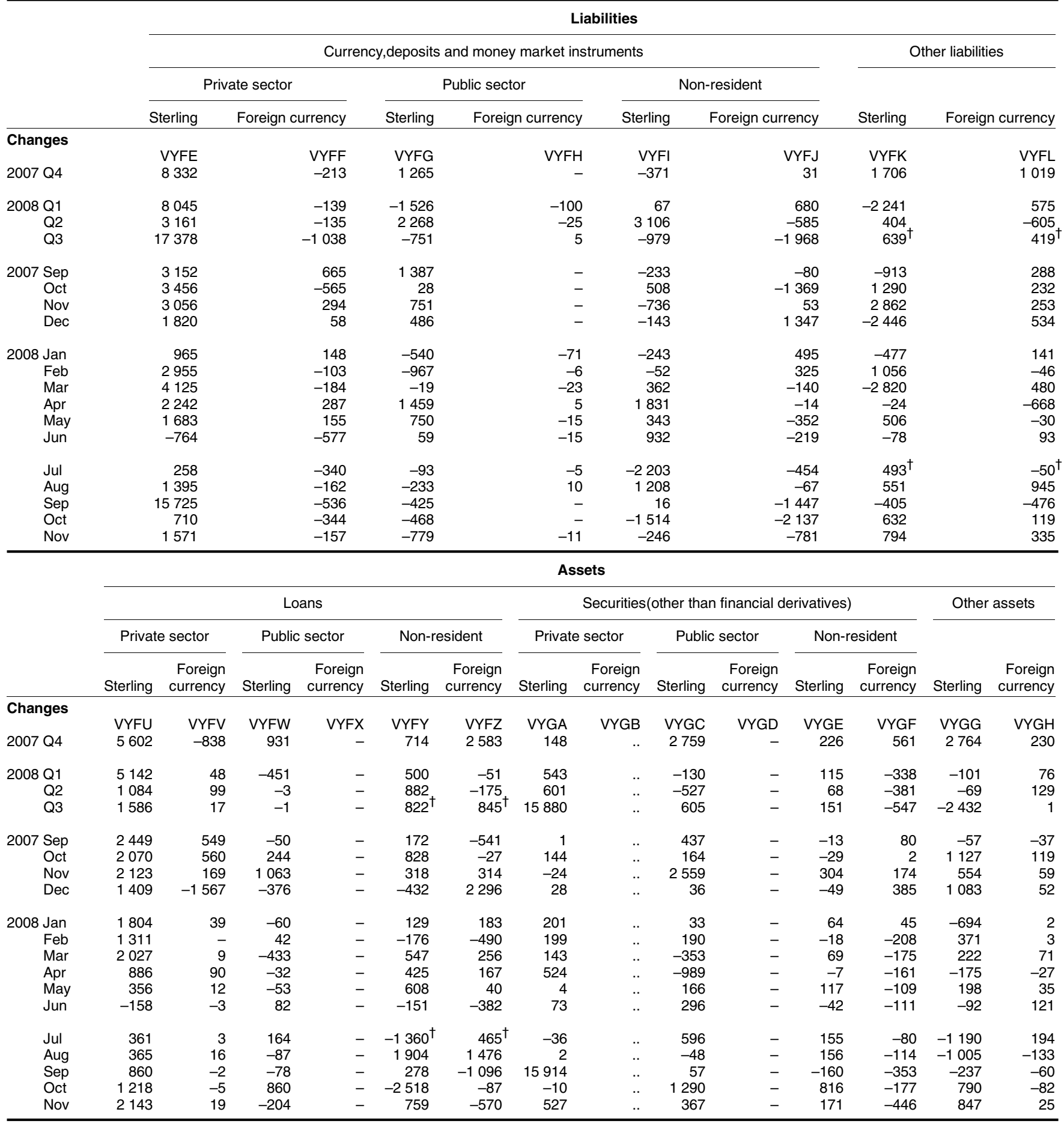




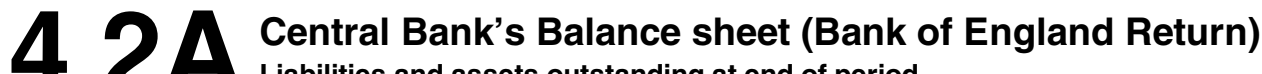 \\ Liabilities and assets outstanding at end of period}

$£$ million

\begin{tabular}{|c|c|c|c|c|c|c|c|c|c|c|c|c|c|c|c|c|c|}
\hline & \multicolumn{17}{|c|}{ Consolidated statement } \\
\hline & \multicolumn{7}{|c|}{ Liabilities } & \multicolumn{9}{|c|}{ Assets } & $\begin{array}{r}\text { Total } \\
r \\
\text { assets- } \\
\text { /liabil }\end{array}$ \\
\hline 2007 & $\begin{array}{r}\text { B55A } \\
43862\end{array}$ & $\begin{array}{r}\text { B56A } \\
24608\end{array}$ & $\begin{array}{r}\text { B57A } \\
-\end{array}$ & $\begin{array}{r}\mathrm{B} 58 \mathrm{~A} \\
-\end{array}$ & $\begin{array}{l}\text { B59A } \\
4667\end{array}$ & $\begin{array}{l}\text { B62A } \\
2936\end{array}$ & $\begin{array}{r}\text { B63A } \\
31523\end{array}$ & ${ }^{\mathrm{B} 65 \mathrm{~A}}$ & $\begin{array}{r}\text { B66A } \\
10000\end{array}$ & $\begin{array}{r}\text { B67A } \\
10000\end{array}$ & $\begin{array}{r}\mathrm{B} 68 \mathrm{~A} \\
-\end{array}$ & $\begin{array}{r}\text { BL59 } \\
9998\end{array}$ & $\begin{array}{r}\text { B69A } \\
13500\end{array}$ & $\begin{array}{r}\text { B72A } \\
13370\end{array}$ & $\begin{array}{l}\text { B73A } \\
7763\end{array}$ & $\begin{array}{r}\text { B74A } \\
42965\end{array}$ & $\begin{array}{r}\text { B75A } \\
87597\end{array}$ \\
\hline $2007 \mathrm{Dec}$ & 43862 & 24608 & - & - & 4667 & 2936 & 31523 & - & 10000 & 10000 & - & 9998 & 13500 & 13370 & 7763 & 42965 & 87597 \\
\hline $\begin{array}{r}2008 \text { Jan } \\
\text { Feb } \\
\text { Mar } \\
\text { Apr } \\
\text { May } \\
\text { Jun }\end{array}$ & $\begin{array}{l}41327 \\
40933 \\
42255 \\
41452 \\
41902 \\
42029\end{array}$ & $\begin{array}{ll}21 & 447 \\
23 & 824 \\
27 & 196 \\
28 & 241 \\
26 & 300 \\
23 & 216\end{array}$ & $\begin{array}{l}- \\
- \\
- \\
- \\
- \\
-\end{array}$ & $\begin{array}{l}- \\
- \\
- \\
\overline{-} \\
-\end{array}$ & $\begin{array}{l}4872 \\
3327 \\
4422 \\
4477 \\
4469 \\
4419\end{array}$ & $\begin{array}{l}2936 \\
2936 \\
2936 \\
2936 \\
2936 \\
2275\end{array}$ & $\begin{array}{l}26005 \\
26595 \\
25369 \\
22382 \\
18758 \\
15009\end{array}$ & $\begin{array}{l}- \\
- \\
- \\
- \\
-\end{array}$ & $\begin{array}{r}8039 \\
6609 \\
12769 \\
11009 \\
13779 \\
16149\end{array}$ & $\begin{array}{r}8039 \\
6609 \\
7769 \\
11009 \\
13779 \\
16149\end{array}$ & $\begin{array}{r}- \\
- \\
4999 \\
- \\
- \\
-\end{array}$ & $\begin{array}{l}- \\
- \\
- \\
- \\
-\end{array}$ & $\begin{array}{l}14419 \\
12000 \\
12000 \\
12000 \\
11999 \\
11999\end{array}$ & $\begin{array}{r}13370 \\
7370 \\
7370 \\
7370 \\
370 \\
370\end{array}$ & $\begin{array}{l}7356 \\
7219 \\
8413 \\
8462 \\
8049 \\
7931\end{array}$ & $\begin{array}{l}43402 \\
44020 \\
40835 \\
34574 \\
33696 \\
28687\end{array}$ & $\begin{array}{l}86586 \\
77617 \\
82179 \\
74488 \\
69367 \\
66951\end{array}$ \\
\hline $\begin{array}{l}\text { Jul } \\
\text { Aug } \\
\text { Sep } \\
\text { Oct } \\
\text { Nov }\end{array}$ & $\begin{array}{l}42403 \\
42530 \\
42618 \\
43304 \\
44103\end{array}$ & $\begin{array}{r}27943 \\
29126 \\
50847 \\
52568 \\
-\end{array}$ & $\begin{array}{r}- \\
- \\
860 \\
-\end{array}$ & $\begin{array}{r}- \\
- \\
\overline{-} \\
3700\end{array}$ & $\begin{array}{l}4413 \\
4576 \\
4669 \\
4702 \\
5274\end{array}$ & $\begin{array}{r}2280 \\
2280 \\
2280 \\
2280 \\
-\end{array}$ & $\begin{array}{r}13853 \\
14916 \\
17617 \\
149482 \\
121486\end{array}$ & $\begin{array}{l}- \\
- \\
- \\
-\end{array}$ & $\begin{array}{r}31878 \\
33919 \\
62519 \\
7082\end{array}$ & $\begin{array}{r}21879 \\
33919 \\
37521 \\
- \\
-\end{array}$ & $\begin{array}{r}10000 \\
24999 \\
7082\end{array}$ & $\begin{array}{l}- \\
- \\
- \\
-\end{array}$ & $\begin{array}{l}12048 \\
12047 \\
12046 \\
12046 \\
10446\end{array}$ & $\begin{array}{l}370 \\
370 \\
370 \\
370 \\
370\end{array}$ & $\begin{array}{l}7714 \\
7871 \\
7907 \\
6712 \\
7082\end{array}$ & $\begin{array}{r}26669 \\
26609 \\
22063 \\
161859 \\
105936\end{array}$ & $\begin{array}{r}80892 \\
83429 \\
108031 \\
184508 \\
134877\end{array}$ \\
\hline
\end{tabular}




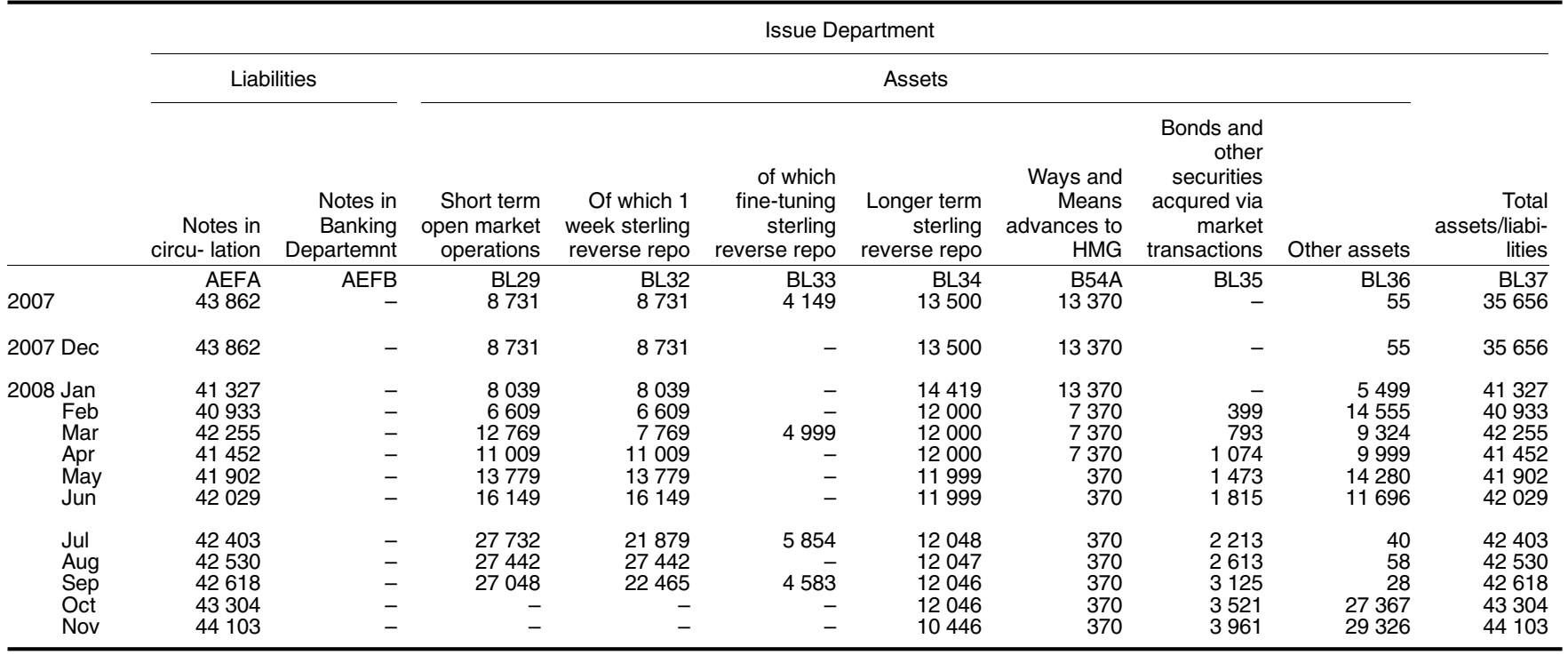

Banking Department

\begin{tabular}{|c|c|c|c|c|c|c|c|c|c|c|c|c|c|c|c|}
\hline & \multicolumn{6}{|c|}{ Liabilities } & \multicolumn{8}{|c|}{ Assets } & \multirow[b]{2}{*}{$\begin{array}{r}\text { Tota } \\
\text { assets/l- } \\
\text { iabilitie }\end{array}$} \\
\hline & $\begin{array}{r}\text { Reserve } \\
\text { balances }\end{array}$ & $\begin{array}{r}\text { Standing } \\
\text { facility } \\
\text { deposits }\end{array}$ & $\begin{array}{r}\text { Short } \\
\text { term open } \\
\text { market } \\
\text { operatio- } \\
\text { ns }\end{array}$ & $\begin{array}{r}\text { Foreign } \\
\text { currency } \\
\text { public } \\
\text { securiti- } \\
\text { es issued }\end{array}$ & $\begin{array}{r}\text { Cash } \\
\text { ratio } \\
\text { deposits }\end{array}$ & $\begin{array}{r}\text { Other } \\
\text { liabilit- } \\
\text { ies }\end{array}$ & $\begin{array}{r}\text { Standing } \\
\text { facility } \\
\text { assets }\end{array}$ & $\begin{array}{r}\text { Short } \\
\text { term open } \\
\text { market } \\
\text { operatio- } \\
\text { ns }\end{array}$ & $\begin{array}{r}\text { Of which } \\
1 \text { week } \\
\text { sterling } \\
\text { reverse } \\
\text { repo }\end{array}$ & $\begin{array}{r}\text { of which } \\
\text { fine-tru- } \\
\text { ning } \\
\text { sterling } \\
\text { reverse } \\
\text { repo }\end{array}$ & $\begin{array}{r}\text { Longer } \\
\text { term } \\
\text { sterling } \\
\text { reverse } \\
\text { repo }\end{array}$ & $\begin{array}{r}\text { Bonds and } \\
\text { other } \\
\text { securiti- } \\
\text { es } \\
\text { acqured } \\
\text { via } \\
\text { market } \\
\text { transact- } \\
\text { ions }\end{array}$ & $\begin{array}{r}\text { Bank of } \\
\text { England } \\
\text { notes }\end{array}$ & $\begin{array}{r}\text { Other } \\
\text { assets }\end{array}$ & \\
\hline 2007 & $\begin{array}{r}\text { BL38 } \\
24608\end{array}$ & $\begin{array}{r}\text { BL39 } \\
-\end{array}$ & $\begin{array}{r}\mathrm{BL} 42 \\
-\end{array}$ & $\begin{array}{l}\text { BL43 } \\
4667\end{array}$ & $\begin{array}{r}\text { BL44 } \\
2936\end{array}$ & $\begin{array}{r}\text { BL45 } \\
31578\end{array}$ & $\begin{array}{r}\text { BL47 } \\
-\end{array}$ & $\begin{array}{r}B L 48 \\
1269\end{array}$ & $\begin{array}{l}\text { BL49 } \\
1269\end{array}$ & $\begin{array}{r}\mathrm{BL} 52 \\
-\end{array}$ & $\begin{array}{r}\text { B3J2 } \\
10000\end{array}$ & $\begin{array}{l}\text { BL53 } \\
7763\end{array}$ & $\begin{array}{r}\text { BL54 } \\
-\end{array}$ & $\begin{array}{r}\text { BL55 } \\
42965\end{array}$ & $\begin{array}{r}\text { BL56 } \\
51996\end{array}$ \\
\hline $2007 \mathrm{Dec}$ & 24608 & - & - & 4667 & 2936 & 31578 & - & 1269 & 1269 & - & 10000 & 7763 & - & 42965 & 51996 \\
\hline $\begin{array}{r}2008 \text { Jan } \\
\text { Feb } \\
\text { Mar } \\
\text { Apr } \\
\text { May } \\
\text { Jun }\end{array}$ & $\begin{array}{ll}21 & 447 \\
23 & 824 \\
27 & 196 \\
28241 \\
26300 \\
23216\end{array}$ & $\begin{array}{l}- \\
- \\
- \\
- \\
-\end{array}$ & $\begin{array}{l}- \\
- \\
- \\
- \\
-\end{array}$ & $\begin{array}{l}4872 \\
3327 \\
4422 \\
4477 \\
4469 \\
4419\end{array}$ & $\begin{array}{l}2936 \\
2936 \\
2936 \\
2936 \\
2936 \\
2275\end{array}$ & $\begin{array}{l}31504 \\
41151 \\
34694 \\
32381 \\
33039 \\
26705\end{array}$ & $\begin{array}{l}- \\
- \\
- \\
- \\
- \\
-\end{array}$ & $\begin{array}{l}- \\
- \\
- \\
- \\
- \\
-\end{array}$ & $\begin{array}{l}- \\
- \\
- \\
- \\
- \\
-\end{array}$ & $\begin{array}{l}- \\
- \\
- \\
- \\
-\end{array}$ & $\begin{array}{l}10000 \\
19999 \\
19999 \\
24999 \\
24999 \\
19998\end{array}$ & $\begin{array}{l}7356 \\
7219 \\
8413 \\
8462 \\
8049 \\
7931\end{array}$ & $\begin{array}{l}- \\
- \\
- \\
- \\
-\end{array}$ & $\begin{array}{l}43402 \\
44020 \\
40835 \\
34574 \\
33696 \\
28687\end{array}$ & $\begin{array}{l}50758 \\
51239 \\
49248 \\
43036 \\
41745 \\
36617\end{array}$ \\
\hline $\begin{array}{l}\text { Jul } \\
\text { Aug } \\
\text { Sep } \\
\text { Oct } \\
\text { Nov }\end{array}$ & $\begin{array}{r}27943 \\
29126 \\
50847 \\
52568 \\
-\end{array}$ & $\begin{array}{r}- \\
- \\
\overline{-} \\
-\end{array}$ & $\begin{array}{r}- \\
- \\
- \\
3700 \\
-\end{array}$ & $\begin{array}{l}4413 \\
4576 \\
4669 \\
4702 \\
5274\end{array}$ & $\begin{array}{r}2280 \\
2280 \\
2280 \\
2280 \\
-\end{array}$ & $\begin{array}{r}13892 \\
14974 \\
17646 \\
176849 \\
150812\end{array}$ & $\begin{array}{l}- \\
- \\
- \\
- \\
-\end{array}$ & $\begin{array}{r}4146 \\
6477 \\
35472 \\
7082\end{array}$ & $\begin{array}{r}647 \overline{7} \\
15056 \\
- \\
-\end{array}$ & $\begin{array}{r}4146 \\
20416 \\
708 \overline{-}\end{array}$ & $\begin{array}{r}9999 \\
9999 \\
10000 \\
92239 \\
134768\end{array}$ & $\begin{array}{l}7714 \\
7871 \\
7907 \\
6712 \\
7082\end{array}$ & $\begin{array}{l}- \\
- \\
- \\
-\end{array}$ & $\begin{array}{r}26669 \\
26609 \\
22063 \\
161859 \\
105936\end{array}$ & $\begin{array}{r}38529 \\
40957 \\
65442 \\
168571 \\
120100\end{array}$ \\
\hline
\end{tabular}




\begin{tabular}{|c|c|c|c|c|c|c|c|c|c|c|c|c|c|c|}
\hline & \multicolumn{14}{|c|}{ Sterling liabilities } \\
\hline & \multicolumn{5}{|c|}{ Sterling liabilities:(UK)Sight deposits } & \multicolumn{7}{|c|}{ Sterling liabilities: (UK) Time deposit } & \multicolumn{2}{|c|}{$\begin{array}{c}\text { Sterling } \\
\text { liabilities }\end{array}$} \\
\hline & Banks & $\begin{array}{l}\text { Building } \\
\text { societies }\end{array}$ & $\begin{array}{l}\text { Public } \\
\text { sector }\end{array}$ & $\begin{array}{l}\text { Other UK } \\
\text { residents }\end{array}$ & $\begin{array}{r}\text { Non-resi- } \\
\text { dents }\end{array}$ & Banks & $\begin{array}{l}\text { Building } \\
\text { societies }\end{array}$ & $\begin{array}{l}\text { Public } \\
\text { sector }\end{array}$ & $\begin{array}{l}\text { Other UK } \\
\text { residents }\end{array}$ & $\begin{array}{l}\text { Of which } \\
\text { TESSAs }\end{array}$ & $\begin{array}{l}\text { Of which } \\
\text { SAYE }\end{array}$ & $\begin{array}{r}\text { Non-resi- } \\
\text { dents }\end{array}$ & $\begin{array}{r}\text { Notes } \\
\text { outstand- } \\
\text { ing } \\
\text { and cash } \\
\text { loaded } \\
\text { cards }\end{array}$ & $\begin{array}{r}\text { Acceptan- } \\
\text { ces } \\
\text { granted }\end{array}$ \\
\hline $\begin{array}{r}2007 \text { Sep } \\
\text { Oct } \\
\text { Nov } \\
\text { Dec }\end{array}$ & $\begin{array}{r}\text { TBFB } \\
108146 \\
95312 \\
99189 \\
91480\end{array}$ & $\begin{array}{l}\text { TBFC } \\
35466 \\
33392 \\
35151 \\
2653\end{array}$ & $\begin{array}{l}\text { TBFD } \\
9494 \\
8601 \\
8529 \\
8190\end{array}$ & $\begin{array}{r}\text { TBFE } \\
767483 \\
763229 \\
763177 \\
765627\end{array}$ & $\begin{array}{r}\text { TBFF } \\
107039 \\
102998 \\
97839 \\
106855\end{array}$ & $\begin{array}{r}\text { TBFG } \\
146768 \\
103888 \\
114232 \\
116062\end{array}$ & $\begin{array}{l}\text { TBFH } \\
4475 \\
4105 \\
3337 \\
4182\end{array}$ & $\begin{array}{r}\text { TBFI } \\
18240 \\
17693 \\
17262 \\
16820\end{array}$ & $\begin{array}{r}\text { TBFJ } \\
480190 \\
478083 \\
480638 \\
496675\end{array}$ & $\begin{array}{r}\text { TBFK } \\
- \\
. . \\
. . \\
. .\end{array}$ & $\begin{array}{l}\text { TBFL } \\
1897 \\
1063 \\
1059 \\
1049\end{array}$ & $\begin{array}{r}\text { TBFM } \\
350687 \\
368051 \\
380757 \\
420623\end{array}$ & 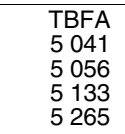 & $\begin{array}{l}\text { TBFN } \\
2263 \\
1993 \\
2563 \\
1860\end{array}$ \\
\hline $\begin{array}{r}2008 \text { Jan } \\
\text { Feb } \\
\text { Mar } \\
\text { Apr } \\
\text { May } \\
\text { Jun }\end{array}$ & $\begin{array}{l}92342 \\
86303 \\
90284 \\
89921 \\
88123 \\
85915\end{array}$ & $\begin{array}{l}2670 \\
3388 \\
4311 \\
2486 \\
2078 \\
2921\end{array}$ & $\begin{array}{r}12133 \\
8375 \\
9342 \\
8826 \\
8622 \\
8080\end{array}$ & $\begin{array}{l}766795 \\
765795 \\
777008 \\
765368 \\
759924 \\
764553\end{array}$ & $\begin{array}{l}102902 \\
104557 \\
108275 \\
107788^{\dagger} \\
104635 \\
109121\end{array}$ & $\begin{array}{l}123463 \\
127589 \\
119722 \\
134468 \\
134269 \\
123441\end{array}$ & $\begin{array}{l}3391 \\
32290 \\
4598 \\
5554 \\
5357 \\
4238\end{array}$ & $\begin{array}{l}15961 \\
14844 \\
13768 \\
15303 \\
16166 \\
16262\end{array}$ & $\begin{array}{l}500308 \\
504220 \\
512848 \\
530821 \dagger \\
544522 \\
576383\end{array}$ & $\begin{array}{l}. . \\
. . \\
. . \\
. . \\
. . \\
. .\end{array}$ & $\begin{array}{ll}1 & 035 \\
1 & 033 \\
1 & 018 \\
1 & 029 \\
1 & 030 \\
1 & 031\end{array}$ & $\begin{array}{l}432953 \\
429155 \\
428100 \\
451515 \\
394446 \\
397228\end{array}$ & $\begin{array}{l}5003 \\
4053 \\
5038 \\
5092 \\
5173 \\
5216\end{array}$ & $\begin{array}{ll}1 & 790 \\
1 & 831 \\
1 & 573 \\
1 & 494 \\
1 & 438 \\
1 & 547\end{array}$ \\
\hline $\begin{array}{l}\text { Jul } \\
\text { Aug } \\
\text { Sep } \\
\text { Oct } \\
\text { Nov }\end{array}$ & $\begin{array}{r}87433 \\
91589 \\
100002 \\
86659 \\
98189\end{array}$ & $\begin{array}{l}2015 \\
2335 \\
2748 \\
3708 \\
4903\end{array}$ & $\begin{array}{l}8541 \\
8151 \\
8373 \\
9391 \\
8946\end{array}$ & $\begin{array}{l}745519 \\
745980 \\
753822 \\
735618 \\
749686\end{array}$ & $\begin{array}{l}107658 \\
111736 \\
124431 \\
120574 \\
128402\end{array}$ & $\begin{array}{r}131096 \\
110562 \\
103632 \\
80373 \\
78821\end{array}$ & $\begin{array}{l}4939 \\
6493 \\
4840 \\
4697 \\
3485\end{array}$ & $\begin{array}{l}16566 \\
35423 \\
54495 \\
52200 \\
51170\end{array}$ & $\begin{array}{l}586837 \\
603131 \\
611969 \\
646403 \\
645791\end{array}$ & $\begin{array}{l}. . \\
. . \\
. . \\
. . \\
. .\end{array}$ & $\begin{array}{l}970 \\
831 \\
790 \\
790 \\
776\end{array}$ & $\begin{array}{l}395937 \\
408722 \\
393006 \\
381680 \\
373547\end{array}$ & $\begin{array}{l}5169 \\
5263 \\
5274 \\
5286 \\
5455\end{array}$ & $\begin{array}{ll}1 & 397 \\
1 & 357 \\
1469 \\
1386 \\
1351\end{array}$ \\
\hline $\begin{array}{r}2007 \text { Sep } \\
\text { Oct } \\
\text { Nov } \\
\text { Dec }\end{array}$ & $\begin{array}{r}\text { TBJL } \\
-1689 \\
-416 \\
3877 \\
-6398\end{array}$ & $\begin{array}{r}\text { TBJM } \\
624 \\
-154 \\
-241 \\
-498\end{array}$ & $\begin{array}{r}\text { TBJN } \\
1786 \\
-893 \\
-72 \\
-338\end{array}$ & $\begin{array}{r}\text { TBJO } \\
7792 \\
-4228 \\
-52 \\
1139\end{array}$ & $\begin{array}{r}\text { TBJP } \\
5541 \\
-4041 \\
-4376 \\
9016\end{array}$ & $\begin{array}{r}\text { TBJQ } \\
2786 \\
8785 \\
10344 \\
1830\end{array}$ & $\begin{array}{r}\text { TBJR } \\
1183 \\
-370 \\
-767 \\
844\end{array}$ & $\begin{array}{r}\text { TBJS } \\
-1430 \\
-547 \\
-430 \\
-443\end{array}$ & $\begin{array}{r}\text { TBJT } \\
-4758 \\
-1856 \\
2906 \\
16037\end{array}$ & $\begin{array}{r}\text { TBJU } \\
- \\
. . \\
. . \\
. .\end{array}$ & $\begin{array}{r}\text { TBJV } \\
30 \\
-833 \\
-4 \\
-11\end{array}$ & $\begin{array}{r}\text { TBJW } \\
-1837 \\
17364 \\
12354 \\
39866\end{array}$ & $\begin{array}{r}\text { TBJK } \\
6 \\
15 \\
77 \\
132\end{array}$ & $\begin{array}{r}\text { TBJX } \\
-28 \\
-270 \\
569 \\
-703\end{array}$ \\
\hline $\begin{array}{c}2008 \text { Jan } \\
\text { Feb } \\
\text { Mar } \\
\text { Apr } \\
\text { May } \\
\text { Jun }\end{array}$ & $\begin{array}{r}863 \\
-6040 \\
3981 \\
-363 \\
-1792 \\
-2208\end{array}$ & $\begin{array}{r}17 \\
718 \\
923 \\
-1825 \\
-408 \\
843\end{array}$ & $\begin{array}{r}3943 \\
-3759 \\
967 \\
-516 \\
-204 \\
-543\end{array}$ & $\begin{array}{r}2243 \\
-1000 \\
11213 \\
-11785 \\
520 \\
4629\end{array}$ & $\begin{array}{r}-4192 \\
1655 \\
3718 \\
-148 \\
-3153 \\
4485\end{array}$ & $\begin{array}{r}7400 \\
4126 \\
-7866 \\
14746 \\
-106 \\
-10828\end{array}$ & $\begin{array}{r}-790 \\
-101 \\
1108 \\
1156 \\
-198 \\
-1118\end{array}$ & $\begin{array}{r}-858 \\
-1118 \\
-1076 \\
1535 \\
842 \\
96\end{array}$ & $\begin{array}{r}3033 \\
3913 \\
7422 \\
17889 \\
7757 \\
31861\end{array}$ & $\begin{array}{l}. . \\
. . \\
. . \\
. . \\
. . \\
. .\end{array}$ & $\begin{array}{r}-14 \\
-2 \\
-15 \\
11 \\
1 \\
-\end{array}$ & $\begin{array}{r}12330 \\
-3799 \\
-1055 \\
23765 \\
-57069 \\
2782\end{array}$ & $\begin{array}{r}-262 \\
-51 \\
85 \\
54 \\
81 \\
42\end{array}$ & $\begin{array}{r}-70 \\
41 \\
-259 \\
-79 \\
-56 \\
109\end{array}$ \\
\hline $\begin{array}{l}\text { Jul } \\
\text { Aug } \\
\text { Sep } \\
\text { Oct } \\
\text { Nov }\end{array}$ & $\begin{array}{r}1519 \\
4155 \\
8414 \\
-13343 \\
11529\end{array}$ & $\begin{array}{r}-907 \\
320 \\
414 \\
959 \\
1195\end{array}$ & $\begin{array}{r}461 \\
-389 \\
222 \\
1018 \\
-445\end{array}$ & $\begin{array}{r}-19034 \\
461 \\
7842 \\
-18203 \\
14068\end{array}$ & $\begin{array}{r}-1463 \\
4078 \\
12519 \\
-3857 \\
8928\end{array}$ & $\begin{array}{r}7655 \\
-20534 \\
-6929 \\
-23259 \\
-1552\end{array}$ & $\begin{array}{r}700 \\
1554 \\
-1653 \\
-143 \\
-1212\end{array}$ & $\begin{array}{r}304 \\
18857 \\
19077 \\
-2280 \\
-1030\end{array}$ & $\begin{array}{r}10454 \\
16294 \\
8833 \\
34419 \\
-612\end{array}$ & $\begin{array}{l}. . \\
. . \\
. . \\
. . \\
. .\end{array}$ & $\begin{array}{r}-60 \\
-140 \\
-40 \\
- \\
-14\end{array}$ & $\begin{array}{r}-1292 \\
12785 \\
-16515 \\
-11326 \\
-9234\end{array}$ & $\begin{array}{r}-47 \\
94 \\
11 \\
12 \\
169\end{array}$ & $\begin{array}{r}-150 \\
-40 \\
112 \\
-83 \\
-35\end{array}$ \\
\hline
\end{tabular}

Sterling liabilities (continued)

\begin{tabular}{|c|c|c|c|c|c|c|c|c|c|c|c|c|c|}
\hline & \multicolumn{6}{|c|}{ Sterling liabilities:(UK)under sale and repurchase agreements } & \multicolumn{6}{|c|}{ Sterling liabilities } & \multirow[b]{2}{*}{$\begin{array}{r}\text { Total } \\
\text { sterling } \\
\text { liabiliti- } \\
\text { es }\end{array}$} \\
\hline & Banks & $\begin{array}{l}\text { Building } \\
\text { societies }\end{array}$ & $\begin{array}{l}\text { Public } \\
\text { sector }\end{array}$ & $\begin{array}{l}\text { Other UK } \\
\text { residents }\end{array}$ & $\begin{array}{r}\text { Non-resid- } \\
\text { ents }\end{array}$ & $\begin{array}{r}\text { Of which } \\
\text { British } \\
\text { government } \\
\text { securities }\end{array}$ & $\begin{array}{r}\text { CDs and } \\
\text { other } \\
\text { short term } \\
\text { paper } \\
\text { issued }\end{array}$ & $\begin{array}{r}\text { Total } \\
\text { sterling } \\
\text { deposits }\end{array}$ & $\begin{array}{r}\text { Sterling } \\
\text { items in } \\
\text { suspense } \\
\text { and } \\
\text { transmiss- } \\
\text { ion }\end{array}$ & $\begin{array}{r}\text { Net } \\
\text { derivativ- } \\
\text { es }\end{array}$ & $\begin{array}{c}\text { Accrued } \\
\text { amounts } \\
\text { payable }\end{array}$ & $\begin{array}{r}\text { Sterling } \\
\text { capital } \\
\text { and other } \\
\text { internal } \\
\text { funds }\end{array}$ & \\
\hline $\begin{array}{r}2007 \text { Sep } \\
\text { Oct } \\
\text { Nov } \\
\text { Dec }\end{array}$ & $\begin{array}{r}\text { TBFP } \\
188804 \\
176554 \\
176250 \\
167057\end{array}$ & $\begin{array}{r}\text { TBFQ } \\
501 \\
254 \\
400 \\
175\end{array}$ & $\begin{array}{r}\text { TBFR } \\
8079 \\
16044 \\
11458 \\
3792\end{array}$ & $\begin{array}{r}\text { TBFS } \\
64743 \\
66118 \\
69061 \\
71150\end{array}$ & $\begin{array}{r}\text { TBFT } \\
66760 \\
72107 \\
77466 \\
68660\end{array}$ & $\begin{array}{r}\text { TBFU } \\
238137 \\
. . \\
. . \\
. .\end{array}$ & $\begin{array}{r}\text { TBFV } \\
196334 \\
197971 \\
198590 \\
199834\end{array}$ & $\begin{array}{r}\text { TBFW } \\
2523553 \\
2476393 \\
2503898 \\
2541695\end{array}$ & $\begin{array}{r}\text { TBFX } \\
51856 \\
47712 \\
56427 \\
29469\end{array}$ & $\begin{array}{r}\text { TBFY } \\
-48522 \\
-40461 \\
-40977 \\
-25459\end{array}$ & & $\begin{array}{r}\text { TBGA } \\
291986 \\
275033 \\
290195 \\
275685\end{array}$ & $\begin{array}{r}\text { TBGB } \\
2863222 \\
2805367 \\
2860208 \\
2871564\end{array}$ \\
\hline $\begin{array}{r}2008 \text { Jan } \\
\text { Feb } \\
\text { Mar } \\
\text { Apr } \\
\text { May } \\
\text { Jun }\end{array}$ & $\begin{array}{l}176627 \\
188633 \\
178166 \\
164916 \\
150446 \\
147102\end{array}$ & $\begin{array}{r}- \\
- \\
160 \\
208 \\
2606 \\
201\end{array}$ & $\begin{array}{r}12704 \\
8917 \\
552 \\
4343 \\
1952 \\
620\end{array}$ & $\begin{array}{l}77723 \\
74900 \\
83289 \\
76211 \\
75732 \\
83394\end{array}$ & $\begin{array}{l}77507 \\
75660 \\
69525 \\
68063 \\
71813 \\
57377\end{array}$ & $\begin{array}{l}. . \\
. . \\
. . \\
. . \\
. .\end{array}$ & $\begin{array}{l}220515 \\
222538 \\
209822 \\
224703 \\
221062 \\
214130\end{array}$ & $\begin{array}{l}2619784 \\
2619995 \\
2611143 \\
2651987^{\dagger} \\
2583192 \\
2592513\end{array}$ & $\begin{array}{l}51252 \\
58551 \\
49769 \\
51199 \\
55367 \\
50654\end{array}$ & $\begin{array}{l}-31074 \\
-28684 \\
-15160 \\
-21934 \\
-27560 \\
-31294\end{array}$ & $\begin{array}{r}45016 \\
44015 \\
38226 \\
35109 \\
38182 \\
35031\end{array}$ & $\begin{array}{l}287737 \\
297376 \\
+300762 \\
289536^{\dagger} \\
288029 \\
302231\end{array}$ & $\begin{array}{r}2977718 \\
2996206 \\
2989778 \\
3010988 \\
2942383 \\
2954351\end{array}$ \\
\hline $\begin{array}{r}\text { Jul } \\
\text { Aug } \\
\text { Sep } \\
\text { Oct } \\
\text { Nov } \\
\text { Changes }\end{array}$ & $\begin{array}{l}143027 \\
146729 \\
197143 \\
177050^{\dagger} \\
186140\end{array}$ & $\begin{array}{r}181 \\
1900 \\
2934 \\
- \\
-\end{array}$ & $\begin{array}{r}8377 \\
3854 \\
1153 \\
17183 \\
17595\end{array}$ & $\begin{array}{r}86980 \\
94821^{\dagger} \\
104519 \\
137615 \\
141055\end{array}$ & $\begin{array}{l}59469 \\
60175 \\
60892 \\
48213 \\
39026\end{array}$ & $\begin{array}{l}. . \\
. . \\
. . \\
. .\end{array}$ & $\begin{array}{l}236918 \\
231884 \\
221943 \\
213420 \\
240300\end{array}$ & $\begin{array}{l}2622887 \\
2664840 \\
2747372 \\
2716171 \\
2768408\end{array}$ & $\begin{array}{l}45885 \\
40997 \\
61847 \\
51393 \\
52630\end{array}$ & $\begin{array}{r}-31262 \\
-2898 \\
-22799 \\
12696 \\
22178\end{array}$ & $\begin{array}{l}36984 \\
40347 \\
37562 \\
37976 \\
39489\end{array}$ & $\begin{array}{l}303686 \\
273795 \\
295972 \\
288658 \\
310001\end{array}$ & 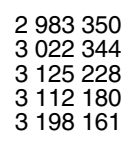 \\
\hline $\begin{array}{r}2007 \text { Sep } \\
\text { Oct } \\
\text { Nov } \\
\text { Dec }\end{array}$ & $\begin{array}{r}\text { TBJZ } \\
-4071 \\
-12250 \\
-304 \\
-9193\end{array}$ & $\begin{array}{r}\text { TBKA } \\
451 \\
-246 \\
146 \\
-225\end{array}$ & $\begin{array}{r}\text { TBKB } \\
-807 \\
7965 \\
-4586 \\
-7666\end{array}$ & $\begin{array}{r}\text { TBKC } \\
12190 \\
1375 \\
2942 \\
1710\end{array}$ & $\begin{array}{r}\text { TBKD } \\
-1035 \\
5348 \\
5359 \\
-8805\end{array}$ & $\begin{array}{r}\text { TBKE } \\
491 \\
. . \\
. . \\
. .\end{array}$ & $\begin{array}{r}\text { TBKF } \\
980 \\
1636 \\
619 \\
1244\end{array}$ & $\begin{array}{l}\text { TBKG } \\
17676 \\
17199 \\
28287 \\
37418\end{array}$ & $\begin{array}{r}\text { TBKH } \\
7254 \\
-4144 \\
8715 \\
-26957\end{array}$ & $\begin{array}{r}\text { TBKI } \\
-3715 \\
8061 \\
-516 \\
15518\end{array}$ & $\begin{array}{r}\text { TBKJ } \\
-2493 \\
2325 \\
3899 \\
-625\end{array}$ & $\begin{array}{r}\text { TBKK } \\
2509 \\
-17852 \\
14626 \\
-14551\end{array}$ & $\begin{array}{r}\text { TBKL } \\
21237 \\
5605 \\
55088 \\
10934\end{array}$ \\
\hline $\begin{array}{r}2008 \text { Jan } \\
\text { Feb } \\
\text { Mar } \\
\text { Apr } \\
\text { May } \\
\text { Jun }\end{array}$ & $\begin{array}{r}9570 \\
12007 \\
-10467 \\
-13250 \\
-14158 \\
-3345\end{array}$ & $\begin{array}{r}-175 \\
- \\
160 \\
48 \\
2398 \\
-2405\end{array}$ & $\begin{array}{r}8912 \\
-3787 \\
-8365 \\
3791 \\
-2391 \\
-1332\end{array}$ & $\begin{array}{r}6574 \\
-2823 \\
8389 \\
-7078 \\
-479 \\
7662\end{array}$ & $\begin{array}{r}8846 \\
-1847 \\
-6135 \\
-1462 \\
3750 \\
-14436\end{array}$ & $\begin{array}{l}. . \\
. . \\
. . \\
. \\
. \\
. .\end{array}$ & $\begin{array}{r}20682 \\
2022 \\
-12716 \\
14881 \\
-3641 \\
-6932\end{array}$ & $\begin{array}{r}78327 \\
210 \\
-10057 \\
41304 \\
-68384 \\
9321\end{array}$ & $\begin{array}{rl}21 & 782 \\
7 & 300 \\
-8 & 782 \\
1 & 430 \\
4 & 168 \\
-4 & 713\end{array}$ & $\begin{array}{r}-5615 \\
2391 \\
13524 \\
-6773 \\
-5 \\
-5 \\
-3734\end{array}$ & $\begin{array}{r}107 \\
-1001 \\
-5789 \\
-3118 \\
3073 \\
-2000^{\dagger}\end{array}$ & $\begin{array}{r}13555 \\
7249 \\
3954^{\dagger} \\
-5907 \\
2362 \\
17865\end{array}$ & $\begin{array}{r}107894 \\
+\quad 16098 \\
-7065 \\
26990 \\
-64325 \\
16780\end{array}$ \\
\hline $\begin{array}{l}\text { Jul } \\
\text { Aug } \\
\text { Sep } \\
\text { Oct } \\
\text { Nov }\end{array}$ & $\begin{array}{r}-4075 \\
3702 \\
50414 \\
-20093 \\
9090\end{array}$ & $\begin{array}{r}-20 \\
1719 \\
1034 \\
-2934 \\
-\end{array}$ & $\begin{array}{r}7757 \\
-4523 \\
-2701 \\
16030 \\
412\end{array}$ & $\begin{array}{rl} & 3585 \\
7 & 841^{\dagger} \\
9 & 698 \\
33096 \\
3440\end{array}$ & $\begin{array}{r}2092 \\
706 \\
717 \\
-12679 \\
-9187\end{array}$ & $\begin{array}{l}. . \\
. . \\
. . \\
. . \\
. .\end{array}$ & $\begin{array}{l}22787 \\
-5034 \\
-9941 \\
-8014 \\
26880\end{array}$ & $\begin{array}{r}30374 \\
41953 \\
81555 \\
-30691 \\
52236\end{array}$ & $\begin{array}{r}-4769 \\
-4888 \\
20553 \\
-10454 \\
1237\end{array}$ & $\begin{array}{r}33 \\
28364 \\
-19901 \\
35495 \\
9482\end{array}$ & $\begin{array}{r}1953 \\
3362 \\
-2311 \\
414 \\
1513\end{array}$ & $\begin{array}{r}-1444 \\
-34323 \\
32002 \\
-6160 \\
9136\end{array}$ & $\begin{array}{r}26101 \\
34563 \\
111910 \\
-11386 \\
73774\end{array}$ \\
\hline
\end{tabular}




\begin{tabular}{|c|c|c|c|c|c|c|c|c|c|c|}
\hline & \multicolumn{10}{|c|}{ Foreign currency liabilities } \\
\hline & \multicolumn{5}{|c|}{ Foreign currency liabilities:(UK)Sight and time deposits } & \multicolumn{5}{|c|}{ Foreign currency liabilities: (UK) Sale and repurchase agreements } \\
\hline & Banks & $\begin{array}{l}\text { Building } \\
\text { societies }\end{array}$ & Public sector & $\begin{array}{l}\text { Other UK } \\
\text { residents }\end{array}$ & Non-residents & Banks & $\begin{array}{c}\text { Building } \\
\text { societies }\end{array}$ & Public sector & $\begin{array}{l}\text { Other UK } \\
\text { residents }\end{array}$ & Non-residents \\
\hline $\begin{array}{r}2007 \text { Sep } \\
\text { Oct } \\
\text { Nov } \\
\text { Dec }\end{array}$ & $\begin{array}{r}\text { TBGC } \\
156091 \\
171087 \\
185187 \\
179964\end{array}$ & $\begin{array}{r}\text { TBGD } \\
1003 \\
1468 \\
933 \\
726\end{array}$ & $\begin{array}{r}\text { TBGE } \\
1256 \\
1036 \\
918 \\
616\end{array}$ & $\begin{array}{r}\text { TBGF } \\
198362 \\
195412 \\
212096 \\
207907\end{array}$ & $\begin{array}{r}\text { TBGG } \\
1801751 \\
1880045 \\
1911565 \\
1994229\end{array}$ & $\begin{array}{r}\text { TBGJ } \\
300814 \\
295294 \\
318562 \\
251972\end{array}$ & $\begin{array}{r}\text { TBGK } \\
- \\
- \\
- \\
-\end{array}$ & $\begin{array}{r}\text { TBGL } \\
1137 \\
1515 \\
1000 \\
972\end{array}$ & $\begin{array}{r}\text { TBGM } \\
91271 \\
93067 \\
105959 \\
108075\end{array}$ & $\begin{array}{r}\text { TBGN } \\
559901 \\
563368 \\
585562 \\
526493\end{array}$ \\
\hline $\begin{array}{r}2008 \text { Jan } \\
\text { Feb } \\
\text { Mar } \\
\text { Apr } \\
\text { May } \\
\text { Jun }\end{array}$ & $\begin{array}{l}214984 \\
205240 \\
214154 \\
218159^{\dagger} \\
197531 \\
195189\end{array}$ & $\begin{array}{r}710 \\
1212 \\
816 \\
896 \\
1062 \\
722\end{array}$ & $\begin{array}{l}740 \\
767 \\
639 \\
735 \\
854 \\
947\end{array}$ & $\begin{array}{l}229653 \\
232538 \\
245186 \\
239246 \\
231339 \\
232490\end{array}$ & $\begin{array}{l}1972321 \\
2017507 \\
2109274 \\
2031675^{\dagger} \\
2008810 \\
1930200\end{array}$ & $\begin{array}{l}308401 \\
323571 \\
282649 \\
254281 \\
255688 \\
208021\end{array}$ & $\begin{array}{l}- \\
- \\
- \\
- \\
-\end{array}$ & $\begin{array}{l}1309 \\
4498 \\
5221 \\
4656 \\
4230 \\
2387\end{array}$ & $\begin{array}{l}112456 \\
125826 \\
126502 \\
133358 \\
135288 \\
113729\end{array}$ & $\begin{array}{l}651986 \\
658587 \\
665574 \\
602877 \\
611326 \\
537627\end{array}$ \\
\hline $\begin{array}{l}\text { Jul } \\
\text { Aug } \\
\text { Sep } \\
\text { Oct } \\
\text { Nov }\end{array}$ & $\begin{array}{l}187082 \\
207513 \\
227423 \\
265468 \\
302929\end{array}$ & $\begin{array}{r}929 \\
1175 \\
1018 \\
732 \\
691\end{array}$ & $\begin{array}{ll}1 & 030 \\
1 & 044 \\
1 & 106 \\
1 & 100 \\
1 & 133\end{array}$ & $\begin{array}{l}228167 \\
232685 \\
229743 \\
254231 \\
292723\end{array}$ & $\begin{array}{l}1957466 \\
2009364 \\
2075116 \\
2303130 \\
2403089\end{array}$ & $\begin{array}{l}223433 \\
212119 \\
205355 \\
180757 \\
164260\end{array}$ & $\begin{array}{r}2 \\
3 \\
6 \\
8 \\
12\end{array}$ & $\begin{array}{ll}4 & 018 \\
3 & 555 \\
4 & 219 \\
1 & 146 \\
1 & 151\end{array}$ & $\begin{array}{r}109382 \\
116611 \\
99845 \\
105811 \\
98671\end{array}$ & $\begin{array}{l}562655 \\
597476 \\
621233 \\
531662 \\
512539\end{array}$ \\
\hline Changes & & & & & & & & & & \\
\hline $\begin{array}{r}2007 \text { Sep } \\
\text { Oct } \\
\text { Nov } \\
\text { Dec }\end{array}$ & $\begin{array}{r}\text { TBKM } \\
-12754 \\
16562 \\
11044 \\
-10755\end{array}$ & $\begin{array}{r}\text { TBKN } \\
395 \\
476 \\
-558 \\
-232\end{array}$ & $\begin{array}{r}\text { TBKO } \\
86 \\
-202 \\
-131 \\
-326\end{array}$ & $\begin{array}{r}\text { TBKP } \\
-2145 \\
-895 \\
13112 \\
-10386\end{array}$ & $\begin{array}{r}\text { TBKQ } \\
11773 \\
98827 \\
-1535 \\
23286\end{array}$ & $\begin{array}{r}\text { TBKT } \\
-409 \\
-5077 \\
18716 \\
-71287\end{array}$ & $\begin{array}{r}\text { TBKU } \\
- \\
- \\
- \\
-\end{array}$ & $\begin{array}{r}\text { TBKV } \\
175 \\
380 \\
-517 \\
-29\end{array}$ & $\begin{array}{r}\text { TBKW } \\
-5227 \\
1940 \\
11473 \\
-4982\end{array}$ & $\begin{array}{r}\text { TBKX } \\
-46778 \\
4098 \\
15151 \\
-66834\end{array}$ \\
\hline $\begin{array}{r}2008 \text { Jan } \\
\text { Feb } \\
\text { Mar } \\
\text { Apr } \\
\text { May } \\
\text { Jun }\end{array}$ & $\begin{array}{r}33318 \\
-12562 \\
3666 \\
4146 \\
-14598 \\
-2449\end{array}$ & $\begin{array}{r}-23 \\
488 \\
-425 \\
85 \\
166 \\
-342\end{array}$ & $\begin{array}{r}120 \\
21 \\
-139 \\
98 \\
120 \\
96\end{array}$ & $\begin{array}{r}19814 \\
-92 \\
8677 \\
-1824^{\dagger} \\
-6215 \\
1187\end{array}$ & $\begin{array}{r}-45957 \\
21467 \\
44065 \\
-60226 \\
-25963 \\
-77737\end{array}$ & $\begin{array}{r}52570 \\
9551 \\
-51077 \\
-24810 \\
3485 \\
-48369\end{array}$ & $\begin{array}{l}- \\
- \\
- \\
- \\
-\end{array}$ & $\begin{array}{r}325 \\
3128 \\
547 \\
-475 \\
-418 \\
-1823\end{array}$ & $\begin{array}{r}3116 \\
11485 \\
-3220 \\
8469 \\
1914 \\
-22008\end{array}$ & $\begin{array}{r}106374 \\
-2791 \\
-10989 \\
-55528 \\
8435 \\
-73556\end{array}$ \\
\hline $\begin{array}{l}\text { Jul } \\
\text { Aug } \\
\text { Sep } \\
\text { Oct } \\
\text { Nov }\end{array}$ & $\begin{array}{l}-7820 \\
10133 \\
20972 \\
25718 \\
23292\end{array}$ & $\begin{array}{r}210 \\
196 \\
-166 \\
-330 \\
-82\end{array}$ & $\begin{array}{r}82 \\
-53 \\
52 \\
-82 \\
-26\end{array}$ & $\begin{array}{l}-3991 \\
-8158 \\
-4625 \\
11477 \\
24846\end{array}$ & $\begin{array}{r}31328 \\
-57120 \\
51955 \\
101063 \\
-26637\end{array}$ & $\begin{array}{r}16161 \\
-20446 \\
-5467 \\
-32691 \\
-26437\end{array}$ & $\begin{array}{l}1 \\
2 \\
2 \\
1 \\
3\end{array}$ & $\begin{array}{r}1644 \\
-660 \\
649 \\
-3348 \\
-66\end{array}$ & $\begin{array}{r}-4032 \\
2545 \\
-15920 \\
2161 \\
-13028\end{array}$ & $\begin{array}{r}25716 \\
2153 \\
20772 \\
-126378 \\
-48621\end{array}$ \\
\hline
\end{tabular}

Foreign currency liabilities (continued)

\begin{tabular}{|c|c|c|c|c|c|c|c|c|c|}
\hline & $\begin{array}{r}\text { Acceptances } \\
\text { granted }\end{array}$ & $\begin{array}{r}\text { CDs and other } \\
\text { short term } \\
\text { paper issued }\end{array}$ & $\begin{array}{r}\text { Total foreign } \\
\text { currency } \\
\text { deposits }\end{array}$ & $\begin{array}{l}\text { Items in } \\
\text { suspense and } \\
\text { transmission }\end{array}$ & Net derivatives & $\begin{array}{r}\text { Accrued amounts } \\
\text { payable }\end{array}$ & $\begin{array}{r}\text { Capital and } \\
\text { other internal } \\
\text { funds }\end{array}$ & $\begin{array}{r}\text { Total foreign } \\
\text { currency } \\
\text { liabilities }\end{array}$ & $\begin{array}{r}\text { Total } \\
\text { liabilities }\end{array}$ \\
\hline $\begin{array}{r}2007 \text { Sep } \\
\text { Oct } \\
\text { Nov } \\
\text { Dec }\end{array}$ & $\begin{array}{l}\text { TBGH } \\
1324 \\
1317 \\
1583 \\
1394\end{array}$ & $\begin{array}{r}\text { TBGO } \\
520546 \\
532289 \\
532222 \\
530751\end{array}$ & $\begin{array}{r}\text { TBGP } \\
3633456 \\
3735899 \\
3855588 \\
3803098\end{array}$ & $\begin{array}{r}\text { TBGQ } \\
232952 \\
216374 \\
232583 \\
123779\end{array}$ & $\begin{array}{c}\text { TBGR } \\
50641 \\
60488 \\
47352 \\
29391\end{array}$ & $\begin{array}{r}\text { TBGS } \\
40572 \\
40651 \\
41842 \\
42646\end{array}$ & $\begin{array}{r}\text { TBGT } \\
94283 \\
101223 \\
88271 \\
93285\end{array}$ & $\begin{array}{r}\text { TBGU } \\
4051903 \\
4154634 \\
4265636 \\
4092199\end{array}$ & $\begin{array}{rr} & \text { TBGV } \\
6 & 915126 \\
6960001 \\
7125843 \\
6963763\end{array}$ \\
\hline $\begin{array}{c}2008 \text { Jan } \\
\text { Feb } \\
\text { Mar } \\
\text { Apr } \\
\text { May } \\
\text { Jun }\end{array}$ & $\begin{array}{l}1487 \\
1509 \\
1541 \\
1473 \\
1567 \\
1548\end{array}$ & $\begin{array}{l}560328 \\
566710 \\
577432 \\
587250 \\
594195 \\
572664\end{array}$ & $\begin{array}{l}4054374 \\
4137964 \\
4228989 \\
4074605 \\
4041889 \\
3795525\end{array}$ & $\begin{array}{l}247565 \\
267232 \\
210483 \\
250121^{\dagger} \\
227537 \\
189383\end{array}$ & $\begin{array}{r}13034 \\
7500 \\
-26398 \\
-14930 \\
1600 \\
-3876\end{array}$ & $\begin{array}{ll}39 & 783 \\
39 & 914 \\
36 & 445 \\
37 & 721^{\dagger} \\
38 & 310 \\
35 & 831\end{array}$ & $\begin{array}{l}102569 \\
117153 \\
100274 \\
134027^{\dagger} \\
116719 \\
127202\end{array}$ & $\begin{array}{l}4457325 \\
4569763 \\
4549792 \\
4481544 \\
4426055 \\
4144066\end{array}$ & $\begin{array}{lll}7 & 435 & 042 \\
7 & 565 & 969 \\
7 & 539 & 570 \\
7 & 492 & 532 \\
7 & 368 & 438 \\
7 & 098 & 417\end{array}$ \\
\hline $\begin{array}{l}\text { Jul } \\
\text { Aug } \\
\text { Sep } \\
\text { Oct } \\
\text { Nov }\end{array}$ & $\begin{array}{l}1751 \\
1906 \\
1944 \\
2076 \\
2067\end{array}$ & $\begin{array}{l}580729 \\
612900 \\
582979 \\
557466 \\
580627\end{array}$ & $\begin{array}{l}3856641 \\
3996352 \\
4049986 \\
4203586 \\
4359892\end{array}$ & $\begin{array}{l}200313 \\
201180 \\
232463 \\
222510 \\
194405\end{array}$ & $\begin{array}{r}-8106 \\
-33554 \\
-27436 \\
-112002 \\
-121774\end{array}$ & $\begin{array}{l}40100 \\
34475 \\
38655 \\
43762 \\
46446\end{array}$ & $\begin{array}{l}115981 \\
138596 \\
137791 \\
162735 \\
166725\end{array}$ & $\begin{array}{l}4204930 \\
4337048 \\
4431459 \\
4520592 \\
4645694\end{array}$ & $\begin{array}{l}7188279 \\
7359392 \\
7556 \quad 687 \\
7 \quad 632 \quad 771 \\
7 \quad 843 \quad 855\end{array}$ \\
\hline
\end{tabular}

\begin{tabular}{|c|c|c|c|c|c|c|c|c|c|}
\hline \multicolumn{10}{|l|}{ Changes } \\
\hline $\begin{array}{r}2007 \text { Sep } \\
\text { Oct } \\
\text { Nov } \\
\text { Dec }\end{array}$ & $\begin{array}{r}\text { TBKR } \\
157 \\
7 \\
248 \\
-229\end{array}$ & $\begin{array}{r}\text { TBKY } \\
14062 \\
17498 \\
-9706 \\
-17338\end{array}$ & $\begin{array}{r}\text { TBKZ } \\
-40665 \\
133612 \\
57297 \\
-159113\end{array}$ & $\begin{array}{r}\text { TBLA } \\
12781 \\
-16087 \\
13023 \\
-111436\end{array}$ & $\begin{array}{r}\text { TBLB } \\
-6214 \\
9922 \\
-14113 \\
-18495\end{array}$ & $\begin{array}{r}\text { TBLC } \\
917 \\
141 \\
693 \\
215\end{array}$ & $\begin{array}{r}\text { TBLD } \\
1347 \\
-3983 \\
-13654 \\
7053\end{array}$ & $\begin{array}{r}\text { TBLE } \\
-31834 \\
123605 \\
43246 \\
-281776\end{array}$ & $\begin{array}{r}\text { TBLF } \\
-10598 \\
129210 \\
98334 \\
-270842\end{array}$ \\
\hline $\begin{array}{r}2008 \text { Jan } \\
\text { Feb } \\
\text { Mar } \\
\text { Apr } \\
\text { May } \\
\text { Jun }\end{array}$ & $\begin{array}{r}85 \\
9 \\
6 \\
-60 \\
93 \\
-17\end{array}$ & $\begin{array}{r}24199 \\
-1013 \\
-3367 \\
14786 \\
6612 \\
-22022\end{array}$ & $\begin{array}{r}193940 \\
29690 \\
-12255 \\
-115339 \\
-26370 \\
-247041\end{array}$ & $\begin{array}{r}123066 \\
16268 \\
-62308 \\
41561^{\dagger} \\
-22733 \\
-38937\end{array}$ & $\begin{array}{r}-16784 \\
-6599 \\
-34539 \\
11752 \\
16704 \\
-5823\end{array}$ & $\begin{array}{r}-3168 \\
-397 \\
-4395 \\
1931^{\dagger} \\
592 \\
-2535\end{array}$ & $\begin{array}{r}7266 \\
-542 \\
-34170 \dagger \\
50038 \\
-11808 \\
19158\end{array}$ & $\begin{array}{r}304320 \\
38420 \\
-147667 \\
-10059 \\
-43615 \\
-275177\end{array}$ & $\begin{array}{r}412214 \\
54518 \\
-154731 \\
16932 \\
-107940 \\
-258397\end{array}$ \\
\hline $\begin{array}{l}\text { Jul } \\
\text { Aug } \\
\text { Sep } \\
\text { Oct } \\
\text { Nov }\end{array}$ & $\begin{array}{r}204 \\
59 \\
20 \\
-6 \\
-110\end{array}$ & $\begin{array}{r}9239 \\
1651 \\
-29333 \\
-51361 \\
-6913\end{array}$ & $\begin{array}{r}68741 \\
-69698 \\
38912 \\
-73777 \\
-73779\end{array}$ & $\begin{array}{r}11417 \\
-2186 \\
34059 \\
-10027 \\
-34516\end{array}$ & $\begin{array}{r}-3969 \\
-27010 \\
8193 \\
-85467^{\dagger} \\
-17925\end{array}$ & $\begin{array}{r}4364 \\
-6117 \\
6952 \\
5193 \\
1746\end{array}$ & $\begin{array}{r}-11815 \\
-6482 \\
36706 \\
24456 \\
-38666\end{array}$ & $\begin{array}{r}68739 \\
-111493 \\
124822 \\
-139622 \\
-163139\end{array}$ & $\begin{array}{r}94839 \\
-76930 \\
236731 \\
-151007 \\
-89365\end{array}$ \\
\hline
\end{tabular}

Also see footnotes in Bank of England Monetary and Financial Statistics tables B1.2 
Sterling Assets

\begin{tabular}{|c|c|c|c|c|c|c|c|c|c|c|c|}
\hline & \multicolumn{2}{|c|}{$\begin{array}{l}\text { Sterling assets:with UK } \\
\text { central bank }\end{array}$} & \multicolumn{5}{|c|}{ Market loans UK } & \multicolumn{3}{|c|}{ Advances(UK) } & \multirow[b]{2}{*}{$\begin{array}{r}\text { Notes and } \\
\text { coin }\end{array}$} \\
\hline & $\begin{array}{r}\text { Cash ratio } \\
\text { deposits }\end{array}$ & Other & Banks & Bank CDs & $\begin{array}{r}\text { Commercial } \\
\text { paper }\end{array}$ & $\begin{array}{r}\text { Building } \\
\text { societies } \\
\text { CDs etc and } \\
\text { deposits }\end{array}$ & $\begin{array}{r}\text { Non-residen- } \\
\text { ts }\end{array}$ & $\begin{array}{l}\text { Public } \\
\text { sector }\end{array}$ & $\begin{array}{l}\text { Other UK } \\
\text { residents }\end{array}$ & $\begin{array}{r}\text { Non-residen- } \\
\text { ts }\end{array}$ & \\
\hline $\begin{array}{r}2007 \text { Sep } \\
\text { Oct } \\
\text { Nov } \\
\text { Dec }\end{array}$ & $\begin{array}{l}\text { TBGX } \\
2405 \\
2299 \\
2415 \\
2599\end{array}$ & $\begin{array}{r}\text { TBGY } \\
21712 \\
17501 \\
15754 \\
21268\end{array}$ & $\begin{array}{r}\text { TBGZ } \\
248618 \\
186193 \\
191715 \\
185890\end{array}$ & $\begin{array}{l}\text { TBHB } \\
63290 \\
61996 \\
52927 \\
50856\end{array}$ & $\begin{array}{r}\text { TBHC } \\
1 \\
1394 \\
544 \\
399\end{array}$ & $\begin{array}{l}\text { TBHD } \\
8125 \\
8247 \\
7840 \\
7827\end{array}$ & $\begin{array}{r}\text { TBHE } \\
227288 \\
231313 \\
236074 \\
268221\end{array}$ & $\begin{array}{l}\text { TBHU } \\
9950 \\
9915 \\
9980 \\
9443\end{array}$ & $\begin{array}{r}\text { TBHV } \\
1531556 \\
1554156 \\
1550899 \\
1555938\end{array}$ & $\begin{array}{l}\text { TBHW } \\
77500 \\
77104 \\
78824 \\
81118\end{array}$ & $\begin{array}{r}\text { TBGW } \\
8641 \\
6124 \\
8941 \\
7798\end{array}$ \\
\hline $\begin{array}{c}2008 \text { Jan } \\
\text { Feb } \\
\text { Mar } \\
\text { Apr } \\
\text { May } \\
\text { Jun }\end{array}$ & $\begin{array}{l}2599 \\
2599 \\
2599 \\
2599 \\
2587 \\
2011\end{array}$ & $\begin{array}{l}16735 \\
14893 \\
26130 \\
21880 \\
21708 \\
26449\end{array}$ & $\begin{array}{l}198585 \\
198215 \\
193588 \\
210070 \dagger \\
204464 \\
195377\end{array}$ & $\begin{array}{l}63870 \\
60159 \\
51347 \\
51556 \\
49879 \\
40856\end{array}$ & $\begin{array}{r}605 \\
559 \\
665 \\
1265 \\
1268 \\
996\end{array}$ & $\begin{array}{l}8288 \\
8454 \\
7885 \\
8131 \\
7935 \\
7367\end{array}$ & $\begin{array}{l}276591 \\
292983 \\
271503 \\
287852 \\
227519 \\
231354\end{array}$ & $\begin{array}{r}9859 \\
9655 \\
9832 \\
10022 \\
10032 \\
10392\end{array}$ & $\begin{array}{l}1577231 \\
1594607 \\
1605219 \\
1616137 \\
1634625 \\
1644803\end{array}$ & $\begin{array}{l}79251 \\
82 \quad 453 \\
85 \quad 910 \\
87175 \\
84 \\
83071 \\
83086\end{array}$ & $\begin{array}{l}6409 \\
9223 \\
6329 \\
6035 \\
9762 \\
5882\end{array}$ \\
\hline $\begin{array}{l}\text { Jul } \\
\text { Aug } \\
\text { Sep } \\
\text { Oct } \\
\text { Nov }\end{array}$ & $\begin{array}{ll}2 & 011 \\
2 & 011 \\
2 & 011 \\
2 & 011 \\
2 & 015\end{array}$ & $\begin{array}{l}25965 \\
22345 \\
79986 \\
48450 \\
40805\end{array}$ & $\begin{array}{l}203839 \\
203112 \\
207957 \\
167746 \\
175272\end{array}$ & $\begin{array}{l}50691 \\
46187 \\
43321 \\
45681 \\
51888\end{array}$ & $\begin{array}{r}1116 \\
1205 \\
1222 \\
896 \\
739\end{array}$ & $\begin{array}{l}7591 \\
7599 \\
6684 \\
4528 \\
3895\end{array}$ & $\begin{array}{l}225360 \\
228353 \\
232191 \\
231517 \\
243278\end{array}$ & $\begin{array}{r}10700 \\
9689 \\
9711 \\
10274 \\
9851\end{array}$ & $\begin{array}{l}1643735 \\
1643317 \\
1664734 \\
1707114 \\
1715151\end{array}$ & $\begin{array}{l}84020 \\
83541 \\
86198 \\
86390 \\
91269\end{array}$ & $\begin{array}{l}6342 \\
9621 \\
6072 \\
9388 \\
9167\end{array}$ \\
\hline $\begin{array}{r}\text { Changes } \\
2007 \text { Sep } \\
\text { Oct } \\
\text { Nov } \\
\text { Dec }\end{array}$ & $\begin{array}{r}\text { TBLH } \\
-\overline{-} \\
-106 \\
116 \\
184\end{array}$ & $\begin{array}{r}\text { TBLI } \\
7303 \\
-4211 \\
-1747 \\
5514\end{array}$ & $\begin{array}{r}\text { TBLJ } \\
-4684 \\
1657 \\
5522 \\
-5833\end{array}$ & $\begin{array}{r}\text { TBLL } \\
-3727 \\
-1294 \\
-9069 \\
-2071\end{array}$ & $\begin{array}{l}\text { TBLM } \\
-291 \\
1393 \\
-849 \\
-146\end{array}$ & $\begin{array}{r}\text { TBLN } \\
-1319 \\
122 \\
-407 \\
-12\end{array}$ & $\begin{array}{r}\text { TBLO } \\
-19933 \\
4025 \\
5491 \\
32059\end{array}$ & $\begin{array}{r}\text { TBME } \\
-101 \\
-35 \\
65 \\
-537\end{array}$ & $\begin{array}{r}\text { TBMF } \\
13232 \\
22425 \\
-2799 \\
6241\end{array}$ & $\begin{array}{r}\text { TBMG } \\
6230 \\
-397 \\
1720 \\
2292\end{array}$ & $\begin{array}{r}\text { TBLG } \\
-1180 \\
-2517 \\
2817 \\
-1143\end{array}$ \\
\hline $\begin{array}{c}2008 \text { Jan } \\
\text { Feb } \\
\text { Mar } \\
\text { Apr } \\
\text { May } \\
\text { Jun }\end{array}$ & $\begin{array}{r}- \\
- \\
- \\
- \\
-12 \\
-576\end{array}$ & $\begin{array}{r}-4533 \\
-1842 \\
11237 \\
-4250 \\
-171 \\
4741\end{array}$ & $\begin{array}{r}12665 \\
-370 \\
-4627 \\
16592^{\dagger} \\
-5574 \\
-9087\end{array}$ & $\begin{array}{r}13014 \\
-3711 \\
-8813 \\
210 \\
-1677 \\
-9023\end{array}$ & $\begin{array}{r}207 \\
-46 \\
106 \\
600 \\
3 \\
-272\end{array}$ & $\begin{array}{r}461 \\
166 \\
-569 \\
246 \\
-196 \\
-568\end{array}$ & $\begin{aligned} 8124 \\
16392 \\
-20480 \\
16703^{\dagger} \\
-60334 \\
3836\end{aligned}$ & $\begin{array}{r}416 \\
-204 \\
177 \\
191 \\
10 \\
360\end{array}$ & $\begin{array}{ll}21 & 861 \\
17 & 459 \\
11 & 206 \\
11 & 808^{\dagger} \\
19 & 011 \\
10 & 834\end{array}$ & $\begin{array}{r}-1863 \\
3206 \\
3461 \\
1272 \\
-494 \\
-1252\end{array}$ & $\begin{array}{r}-1380 \\
281 \\
-289 \\
-29 \\
3727 \\
-3880\end{array}$ \\
\hline $\begin{array}{l}\text { Jul } \\
\text { Aug } \\
\text { Sep } \\
\text { Oct } \\
\text { Nov }\end{array}$ & $\begin{array}{l}- \\
- \\
- \\
- \\
3\end{array}$ & $\begin{array}{r}-484 \\
-3619 \\
57641 \\
-31536 \\
-7645\end{array}$ & $\begin{array}{r}8461 \\
-726 \\
5781 \\
-40211 \\
7526\end{array}$ & $\begin{array}{r}9835 \\
-4504 \\
-2866 \\
2360 \\
6207\end{array}$ & $\begin{array}{r}120 \\
89 \\
17 \\
-326 \\
-157\end{array}$ & $\begin{array}{r}224 \\
8 \\
-915 \\
-2157 \\
-632\end{array}$ & $\begin{array}{r}-5994 \\
2993 \\
3838 \\
-674 \\
11762\end{array}$ & $\begin{array}{r}308 \\
-1012 \\
22 \\
564 \\
-423\end{array}$ & $\begin{array}{r}-1709 \\
134 \\
19305 \\
45119 \\
8717\end{array}$ & $\begin{array}{r}956 \\
-455 \\
2680 \\
215 \\
4902\end{array}$ & $\begin{array}{r}460 \\
327 \\
-3550 \\
3317 \\
-22\end{array}$ \\
\hline
\end{tabular}

Sterling assets (continued)

\begin{tabular}{lll}
\hline Sterling assets:(UK)Acceptances granted & Bills (UK) Claims under sale and repurchase agreements(UK)
\end{tabular}

Of which

British

governme-

\begin{tabular}{|c|c|c|c|c|c|c|c|c|c|c|c|c|c|c|c|}
\hline & $\begin{array}{l}\text { Building } \\
\text { societies }\end{array}$ & $\begin{array}{l}\text { Public } \\
\text { sector }\end{array}$ & $\begin{array}{l}\text { Other UK } \\
\text { residents }\end{array}$ & $\begin{array}{r}\text { Non-resi- } \\
\text { dents }\end{array}$ & $\begin{array}{r}\text { Treasury } \\
\text { bills }\end{array}$ & $\begin{array}{r}\text { UK bank } \\
\text { bills }\end{array}$ & $\begin{array}{l}\text { Building } \\
\text { societies }\end{array}$ & Other & $\begin{array}{r}\text { Non-resi- } \\
\text { dents }\end{array}$ & Banks & $\begin{array}{l}\text { Building } \\
\text { societies }\end{array}$ & $\begin{array}{l}\text { Public } \\
\text { sector }\end{array}$ & $\begin{array}{l}\text { Other UK } \\
\text { residents }\end{array}$ & $\begin{array}{r}\text { Non-resi- } \\
\text { dents }\end{array}$ & $\begin{array}{r}\mathrm{nt} \\
\text { securiti- } \\
\text { es }\end{array}$ \\
\hline $\begin{array}{r}2007 \text { Sep } \\
\text { Oct } \\
\text { Nov } \\
\text { Dec }\end{array}$ & $\begin{array}{r}\text { TBHF } \\
- \\
- \\
- \\
-\end{array}$ & $\begin{array}{r}\text { TBHG } \\
- \\
- \\
- \\
-\end{array}$ & $\begin{array}{l}\text { TBHH } \\
1071 \\
1117 \\
1298 \\
1032\end{array}$ & $\begin{array}{r}\text { TBHI } \\
1192 \\
876 \\
1264 \\
828\end{array}$ & $\begin{array}{l}\text { TBHJ } \\
4635 \\
3776 \\
4229 \\
4837\end{array}$ & $\begin{array}{r}\text { TBHA } \\
570 \\
53 \\
49 \\
51\end{array}$ & $\begin{array}{r}\text { TBHK } \\
230 \\
- \\
- \\
-\end{array}$ & $\begin{array}{r}\text { TBHL } \\
535 \\
-\quad 336 \\
-\quad 351 \\
-\quad 320\end{array}$ & $\begin{array}{r}\text { TBHM } \\
2832 \\
1305 \\
1863 \\
4099\end{array}$ & $\begin{array}{r}\text { TBHO } \\
153688 \\
149595 \\
157818 \\
140814\end{array}$ & $\begin{array}{l}\text { TBHP } \\
1540 \\
1715 \\
2285 \\
4650\end{array}$ & $\begin{array}{r}\text { TBHQ } \\
2470 \\
2003 \\
1973 \\
8025\end{array}$ & $\begin{array}{r}\text { TBHR } \\
104599 \\
98981 \\
100271 \\
102677\end{array}$ & $\begin{array}{r}\text { TBHS } \\
67945 \\
67560 \\
69083 \\
68570\end{array}$ & $\begin{array}{r}\text { TBHT } \\
261304\end{array}$ \\
\hline $\begin{array}{r}2008 \text { Jan } \\
\text { Feb } \\
\text { Mar } \\
\text { Apr } \\
\text { May } \\
\text { Jun }\end{array}$ & $\begin{array}{l}- \\
- \\
- \\
- \\
- \\
-\end{array}$ & $\begin{array}{l}- \\
- \\
- \\
- \\
- \\
-\end{array}$ & $\begin{array}{r}990 \\
1001 \\
917 \\
858 \\
806 \\
793\end{array}$ & $\begin{array}{l}800 \\
830 \\
655 \\
636 \\
632 \\
755\end{array}$ & $\begin{array}{l}4272 \\
4779 \\
4212 \\
6343 \\
5051 \\
4028\end{array}$ & $\begin{array}{l}33 \\
34 \\
32 \\
22 \\
36 \\
36\end{array}$ & $\begin{array}{l}- \\
- \\
- \\
- \\
-\end{array}$ & $\begin{array}{r}638 \\
-\quad 605 \\
-\quad 515 \\
-\quad 592 \\
-\quad 732 \\
-\quad 475\end{array}$ & $\begin{array}{l}3986 \\
3611 \\
3906 \\
3773 \\
3669 \\
4054\end{array}$ & $\begin{array}{l}152592 \\
162479 \\
146511 \\
133882 \\
117304 \\
109712\end{array}$ & $\begin{array}{l}5200 \\
5634 \\
3670 \\
2605 \\
3650 \\
4386\end{array}$ & $\begin{array}{r}4169 \\
5841 \\
7018 \\
10007 \\
9422 \\
3450\end{array}$ & $\begin{array}{l}107695 \\
111088 \\
113186 \\
118043 \\
108483 \\
119367\end{array}$ & $\begin{array}{r}74128 \\
76940 \\
68686 \\
+\quad 68714 \\
73893^{\dagger} \\
66163\end{array}$ & .. \\
\hline $\begin{array}{l}\text { Jul } \\
\text { Aug } \\
\text { Sep } \\
\text { Oct } \\
\text { Nov }\end{array}$ & $\begin{array}{l}- \\
- \\
- \\
-\end{array}$ & $\begin{array}{l}- \\
- \\
- \\
-\end{array}$ & $\begin{array}{l}791 \\
757 \\
757 \\
730 \\
715\end{array}$ & $\begin{array}{l}606 \\
600 \\
712 \\
656 \\
636\end{array}$ & $\begin{array}{ll}1 & 240 \\
1 & 338 \\
1 & 607 \\
2 & 629 \\
2 & 546\end{array}$ & $\begin{array}{r}36 \\
37 \\
42 \\
17545 \\
46224\end{array}$ & $\begin{array}{l}- \\
- \\
- \\
-\end{array}$ & $\begin{array}{r}600 \\
-\quad 470 \\
-\quad 416 \\
-\quad 355 \\
-\quad 739\end{array}$ & $\begin{array}{l}4323 \\
3809 \\
5365 \\
3938 \\
3051\end{array}$ & $\begin{array}{c}112088 \\
109831 \\
114039 \\
92329 \\
85159\end{array}$ & $\begin{array}{l}4197 \\
4179 \\
4700 \\
4327 \\
4567\end{array}$ & $\begin{array}{ll}5 & 459 \\
6 & 178 \\
7 & 973 \\
4 & 426 \\
2 & 437\end{array}$ & $\begin{array}{l}116894 \\
126695 \\
130317 \\
135160 \\
128606\end{array}$ & $\begin{array}{l}66718 \\
65493 \\
66166 \\
57219 \\
51946\end{array}$ & $\begin{array}{l}. . \\
. \\
. . \\
. \\
.\end{array}$ \\
\hline $\begin{array}{r}2007 \text { Sep } \\
\text { Oct } \\
\text { Nov } \\
\text { Dec }\end{array}$ & $\begin{array}{r}\text { TBLP } \\
- \\
- \\
- \\
-\end{array}$ & $\begin{array}{r}\text { TBLQ } \\
- \\
- \\
- \\
-\end{array}$ & $\begin{array}{r}\text { TBLR } \\
-6 \\
46 \\
181 \\
-266\end{array}$ & $\begin{array}{r}\text { TBLS } \\
-22 \\
-316 \\
388 \\
-437\end{array}$ & $\begin{array}{r}\text { TBLT } \\
-451 \\
-860 \\
454 \\
607\end{array}$ & $\begin{array}{r}\text { TBLK } \\
201 \\
-517 \\
-5 \\
3\end{array}$ & $\begin{array}{r}\text { TBLU } \\
- \\
-230 \\
- \\
-\end{array}$ & $\begin{array}{r}\text { TBLV } \\
-340 \\
-199 \\
-\quad 16 \\
-\quad-31\end{array}$ & $\begin{array}{r}\text { TBLW } \\
-1319 \\
-1528 \\
558 \\
2236\end{array}$ & $\begin{array}{r}\text { TBLY } \\
-12048 \\
-4093 \\
8223 \\
-17005\end{array}$ & $\begin{array}{r}\text { TBLZ } \\
1048 \\
175 \\
570 \\
2365\end{array}$ & $\begin{array}{r}\text { TBMA } \\
446 \\
-468 \\
-30 \\
6052\end{array}$ & $\begin{array}{r}\text { TBMB } \\
16059 \\
-5618 \\
1290 \\
2406\end{array}$ & $\begin{array}{r}\text { TBMC } \\
2904 \\
-384 \\
1523 \\
-513\end{array}$ & $\begin{array}{r}\text { TBMD } \\
7375 \\
. .\end{array}$ \\
\hline $\begin{array}{r}2008 \text { Jan } \\
\text { Feb } \\
\text { Mar } \\
\text { Apr } \\
\text { May } \\
\text { Jun }\end{array}$ & $\begin{array}{l}- \\
- \\
- \\
- \\
- \\
-\end{array}$ & $\begin{array}{l}- \\
- \\
- \\
- \\
- \\
-\end{array}$ & $\begin{array}{r}-42 \\
11 \\
-84 \\
-60 \\
-52 \\
-13\end{array}$ & $\begin{array}{r}-28 \\
30 \\
-175 \\
-19 \\
-3 \\
122\end{array}$ & $\begin{array}{r}-564 \\
506 \\
-567 \\
2131 \\
-1292 \\
-1024\end{array}$ & $\begin{array}{r}-18 \\
-2 \\
-10 \\
14 \\
-\end{array}$ & $\begin{array}{l}- \\
- \\
- \\
- \\
- \\
-\end{array}$ & $\begin{array}{r}318 \\
-\quad-33 \\
-\quad-90 \\
-\quad 77 \\
-\quad 140 \\
-\quad-257\end{array}$ & $\begin{array}{r}-113 \\
-375 \\
295 \\
-133 \\
-104 \\
385\end{array}$ & $\begin{array}{r}11778 \\
9886 \\
-15967 \\
-12629 \\
-16441 \\
-7592\end{array}$ & $\begin{array}{r}550 \\
634 \\
-2164 \\
-1065 \\
446 \\
1335\end{array}$ & $\begin{array}{r}-3856 \\
1672 \\
1177 \\
2989 \\
-585 \\
-5972\end{array}$ & $\begin{array}{r}4920 \\
3394 \\
2098 \\
4856 \\
-9560^{\dagger} \\
10884\end{array}$ & $\begin{array}{r}5656 \\
2812 \\
-8254 \\
+\quad 28 \\
5180^{\dagger} \\
-7730\end{array}$ & $\begin{array}{l}. . \\
. . \\
. . \\
. . \\
. . \\
. .\end{array}$ \\
\hline $\begin{array}{l}\text { Jul } \\
\text { Aug } \\
\text { Sep } \\
\text { Oct } \\
\text { Nov }\end{array}$ & $\begin{array}{l}- \\
- \\
- \\
-\end{array}$ & $\begin{array}{l}- \\
- \\
- \\
-\end{array}$ & $\begin{array}{r}-2 \\
-33 \\
- \\
-27 \\
-15\end{array}$ & $\begin{array}{r}-148 \\
-6 \\
112 \\
-56 \\
-20\end{array}$ & $\begin{array}{r}-2788 \\
98 \\
270 \\
1021 \\
-82\end{array}$ & $\begin{array}{r}1 \\
1 \\
5 \\
17504 \\
28679\end{array}$ & $\begin{array}{l}- \\
- \\
-\end{array}$ & $\begin{array}{r}126 \\
-\quad-130 \\
-\quad-54 \\
-\quad-61 \\
-\quad 384\end{array}$ & $\begin{array}{r}270 \\
-514 \\
1556 \\
-1427 \\
-887\end{array}$ & $\begin{array}{r}1798 \\
-2257 \\
4209 \\
-21710^{\dagger} \\
-7170\end{array}$ & $\begin{array}{r}-188 \\
-18 \\
521 \\
-373 \\
240\end{array}$ & $\begin{array}{r}2009 \\
719 \\
1795 \\
-3547 \\
-1989\end{array}$ & $\begin{array}{r}-2473 \\
9802 \\
3622 \\
4842 \\
-6554\end{array}$ & $\begin{array}{r}1133 \\
-1226 \\
673 \\
-8947 \\
-5273\end{array}$ & .. \\
\hline
\end{tabular}




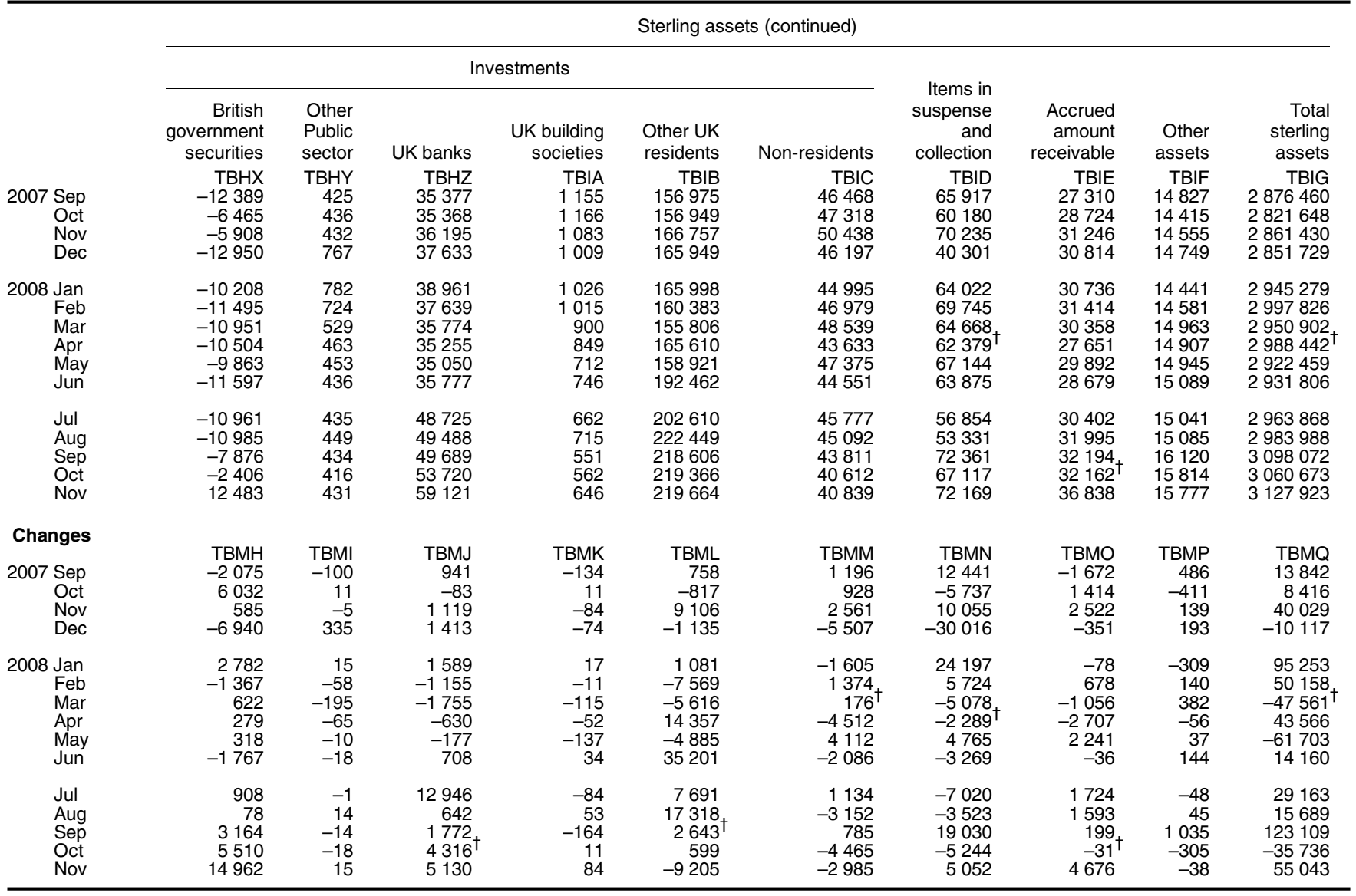


Foreign currency assets






\begin{tabular}{|c|c|c|c|c|c|c|c|c|c|c|c|c|c|}
\hline & \multicolumn{13}{|c|}{ Sterling liabilities } \\
\hline & \multicolumn{4}{|c|}{ Sight deposits } & \multicolumn{5}{|c|}{ Time deposits } & \multicolumn{4}{|c|}{ Sterling liabilities continued } \\
\hline & $\begin{array}{r}\text { UK Banks \& } \\
\text { Building } \\
\text { societies }\end{array}$ & $\begin{array}{r}\text { UK Public } \\
\text { sector }\end{array}$ & $\begin{array}{l}\text { Other UK } \\
\text { residents }\end{array}$ & $\begin{array}{r}\text { Non-resid- } \\
\text { ents }\end{array}$ & $\begin{array}{r}\text { UK Banks \& } \\
\text { Building } \\
\text { societies }\end{array}$ & $\begin{array}{l}\text { UK Public } \\
\text { sector }\end{array}$ & $\begin{array}{l}\text { Other UK } \\
\text { residents }\end{array}$ & $\begin{array}{l}\text { Of which } \\
\text { cash ISAs }\end{array}$ & $\begin{array}{r}\text { Non-resid- } \\
\text { ents }\end{array}$ & $\begin{array}{r}\text { Liabiliti- } \\
\text { es under } \\
\text { sale and } \\
\text { repurchase } \\
\text { agreements }\end{array}$ & $\begin{array}{r}\text { CDs and } \\
\text { other } \\
\text { short term } \\
\text { paper } \\
\text { issued } \\
\end{array}$ & $\begin{array}{r}\text { Other } \\
\text { liabiliti- } \\
\text { es }\end{array}$ & $\begin{array}{r}\text { Total } \\
\text { sterling } \\
\text { liabiliti- } \\
\text { es } \\
\end{array}$ \\
\hline \multicolumn{14}{|l|}{ Changes } \\
\hline $\begin{array}{c}2008 \text { Feb } \\
\text { Mar } \\
\text { Apr } \\
\text { May } \\
\text { Jun }\end{array}$ & $\begin{array}{r}\text { B33E } \\
89 \\
-14 \\
-127 \\
186 \\
242\end{array}$ & $\begin{array}{r}\text { B34E } \\
- \\
- \\
- \\
- \\
-\end{array}$ & $\begin{array}{r}\text { B35E } \\
671 \\
1012 \\
-541 \\
-419 \\
-982\end{array}$ & $\begin{array}{r}\text { B36E } \\
166 \\
70 \\
164 \\
560 \\
528\end{array}$ & $\begin{array}{r}\text { B37E } \\
384 \\
549 \\
-401 \\
-211 \\
470\end{array}$ & $\begin{array}{r}\text { B38E } \\
-965 \\
-39 \\
1459 \\
739 \\
63\end{array}$ & $\begin{array}{r}\text { B39E } \\
1138 \\
4043 \\
3020 \\
1966 \\
536\end{array}$ & $\begin{array}{r}\text { I6BC } \\
270 \\
1921 \\
2882 \\
176 \\
351\end{array}$ & $\begin{array}{r}\mathrm{B} 42 \mathrm{E} \\
328 \\
-52 \\
220 \\
-185 \\
-23\end{array}$ & $\begin{array}{r}\text { B43E } \\
567 \\
-706 \\
681 \\
-503 \\
208\end{array}$ & $\begin{array}{r}\text { B44E } \\
-256 \\
-1004 \\
240 \\
-972 \\
-1803\end{array}$ & $\begin{array}{r}\text { B45E } \\
1966 \\
-3380 \\
522 \\
532 \\
-123\end{array}$ & $\begin{array}{r}\text { B46E } \\
4090 \\
479 \\
5237 \\
1694 \\
-884\end{array}$ \\
\hline $\begin{array}{l}\text { Jul } \\
\text { Aug } \\
\text { Sep } \\
\text { Oct } \\
\text { Nov }\end{array}$ & $\begin{array}{r}-275 \\
-237 \\
61 \\
-123 \\
-3\end{array}$ & $\begin{array}{r}1 \\
-1 \\
-\overline{15} \\
-13\end{array}$ & $\begin{array}{r}-1734 \\
-731 \\
-196 \\
-1102 \\
-26\end{array}$ & $\begin{array}{r}-323 \\
-85 \\
116 \\
-666 \\
319\end{array}$ & $\begin{array}{r}-36 \\
330 \\
-296 \\
342 \\
246\end{array}$ & $\begin{array}{l}-76 \\
-234 \\
-470 \\
-469 \\
-740\end{array}$ & $\begin{array}{r}2067 \\
1936 \\
16490 \\
1600 \\
1766\end{array}$ & $\begin{array}{r}430^{\dagger} \\
97 \\
-39 \\
-225 \\
72\end{array}$ & $\begin{array}{r}-6 \\
-89 \\
-221 \\
-284 \\
24\end{array}$ & $\begin{array}{r}-2373 \\
1319 \\
6987 \\
2287 \\
2792\end{array}$ & $\begin{array}{r}935 \\
475 \\
-1654 \\
-2478 \\
55\end{array}$ & $\begin{array}{c}-80^{\dagger} \\
945 \\
-267 \\
412 \\
506\end{array}$ & $\begin{array}{r}-1900^{\dagger} \\
3628 \\
20552 \\
-465 \\
4926\end{array}$ \\
\hline \multicolumn{14}{|c|}{ Amounts outstanding } \\
\hline $\begin{array}{c}2008 \text { Feb } \\
\text { Mar } \\
\text { Apr } \\
\text { May } \\
\text { Jun }\end{array}$ & $\begin{array}{r}\text { B83E } \\
501 \\
487 \\
360 \\
546 \\
788\end{array}$ & $\begin{array}{r}\mathrm{B} 84 \mathrm{E} \\
- \\
- \\
- \\
- \\
-\end{array}$ & $\begin{array}{l}\text { B85E } \\
87784 \\
88796 \\
88255 \\
87836 \\
86854\end{array}$ & $\begin{array}{l}\text { B } 86 E \\
3904 \\
3974 \\
4139 \\
4699 \\
5227\end{array}$ & $\begin{array}{l}\text { B87E } \\
3946 \\
4495 \\
4093 \\
3883 \\
4352\end{array}$ & $\begin{array}{r}\text { B88E } \\
10476 \\
10437 \\
11896 \\
12635 \\
12690\end{array}$ & $\begin{array}{r}\text { B2R2 } \\
144683 \\
148726 \\
151746 \\
153713 \\
154257\end{array}$ & $\begin{array}{r}\text { I6BD } \\
54474 \\
56395 \\
59277 \\
59454 \\
59804\end{array}$ & $\begin{array}{l}\text { B2R3 } \\
3396 \\
3 \quad 344 \\
3564 \\
35379 \\
3357\end{array}$ & $\begin{array}{l}\text { B2R4 } \\
9934 \\
9228 \\
9909 \\
9406 \\
9614\end{array}$ & $\begin{array}{r}\text { B2R5 } \\
20602 \\
19599 \\
19839 \\
18867 \\
17064\end{array}$ & $\begin{array}{r}\text { B2R6 } \\
27126 \\
23742 \\
24258 \\
24784 \\
24656\end{array}$ & $\begin{array}{r}\text { B2R7 } \\
312353 \\
312827 \\
318059 \\
319747 \\
318858\end{array}$ \\
\hline $\begin{array}{l}\text { Jul } \\
\text { Aug } \\
\text { Sep } \\
\text { Oct } \\
\text { Nov }\end{array}$ & $\begin{array}{l}513 \\
276 \\
337 \\
214 \\
211\end{array}$ & $\begin{array}{r}1 \\
- \\
15 \\
2\end{array}$ & $\begin{array}{l}85120 \\
84389 \\
84193 \\
83091 \\
83065\end{array}$ & $\begin{array}{l}4904 \\
4819 \\
4935 \\
4269 \\
4588\end{array}$ & $\begin{array}{l}4317 \\
4647 \\
4351 \\
4694 \\
4940\end{array}$ & $\begin{array}{l}12614 \\
12381 \\
11911 \\
11443 \\
10702\end{array}$ & $\begin{array}{l}156324 \\
158260 \\
174750 \\
176349 \\
178115\end{array}$ & $\begin{array}{l}60234^{\dagger} \\
60331 \\
60292 \\
60067 \\
60139\end{array}$ & $\begin{array}{l}3350 \\
3 \text { 261 } \\
3041 \\
2757 \\
2781\end{array}$ & $\begin{array}{r}7241 \\
8559 \\
15546 \\
17833 \\
20625\end{array}$ & $\begin{array}{l}17998 \\
18473 \\
16819 \\
14341 \\
14396\end{array}$ & $\begin{array}{l}24562 \\
25732 \\
25450 \\
25848 \\
26340\end{array}$ & $\begin{array}{l}316943 \\
320797 \\
341334 \\
340855 \\
345766\end{array}$ \\
\hline
\end{tabular}

Foreign currency liabilities (including euro)

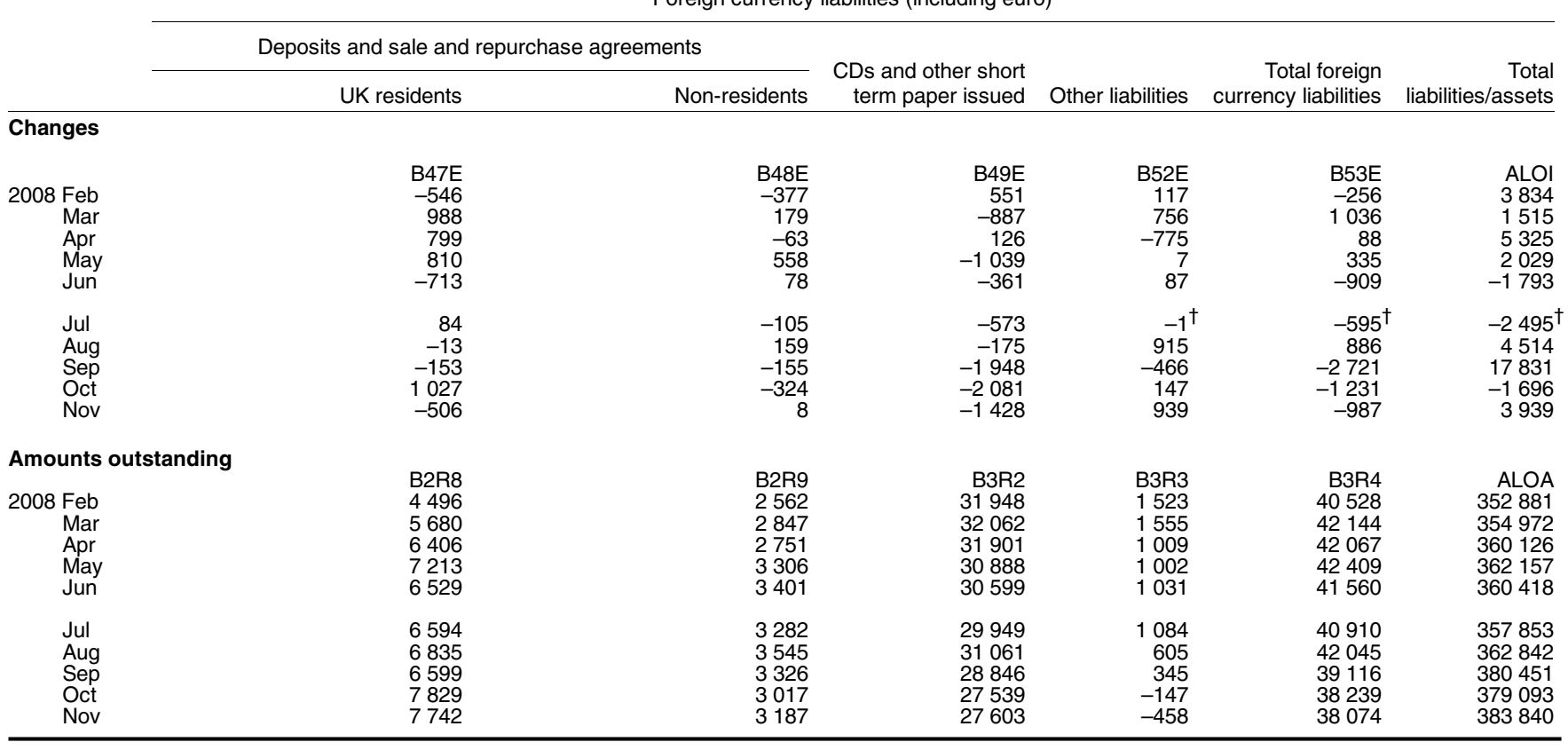

Source: Bank of England 


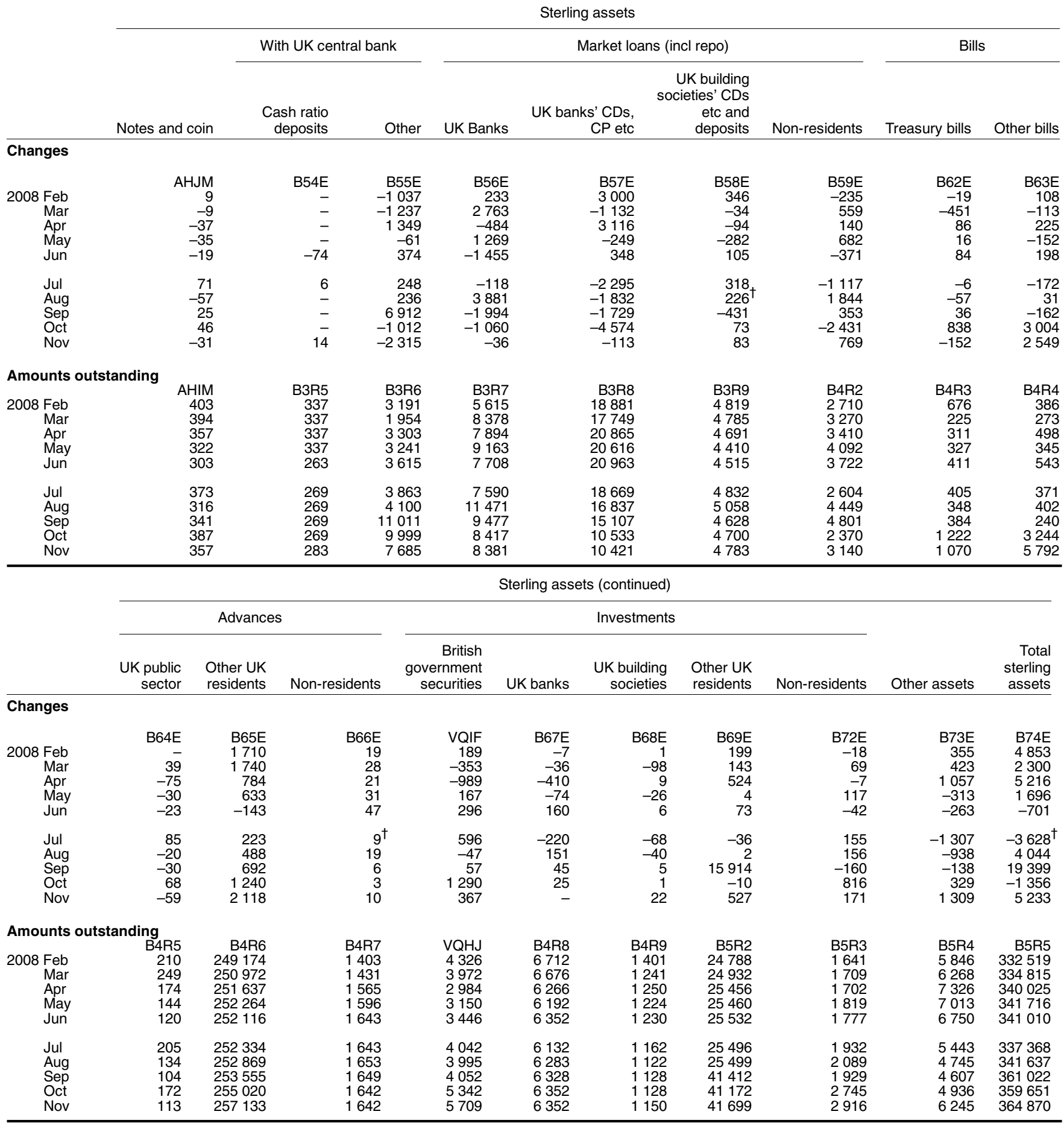


Foreign currency assets (including euro)

Market loans and advances (including reverse repos)

Changes

2008 Feb
Mar
Apr
May
Jun

Jul
Aug
Sep
Oct
Nov

B75E

-604
-505
233

349

$-968$

$1016^{\dagger}$

563

-889
-97

$-890$

Amounts outstanding

2008 Feb

Mar

Apr

Jun

Jul

Aug

Sep

Oct

$\begin{array}{lr}\text { B5R6 } & \text { B5R8 } \\ 4242 & 15514 \\ 3891 & 15785 \\ 4079 & 15461 \\ 4427 & 15471 \\ 3479 & 15438 \\ & \\ 4473 & 15541 \\ 5143 & 15875 \\ 4174 & 15145 \\ 4149 & 15192 \\ 3464 & 15368\end{array}$

$\mathrm{B} 78 \mathrm{E}$
-242
-144
87
-19
-54
-18
38
-75
-9
31

B79E

-1019
-785

109

$-1092$

$1132^{\dagger}$

1132
469
-1568

$-1568$

-340
-1294

See Supplementary Information

\begin{tabular}{rr} 
B5R9 & B6R2 \\
605 & 20361 \\
481 & 20157 \\
561 & 20101 \\
542 & 20440 \\
492 & 19409 \\
471 & \\
187 & 20485 \\
109 & 21205 \\
102 & 19429 \\
139 & 19442 \\
& 18970 \\
\hline
\end{tabular}

Source: Bank of England 


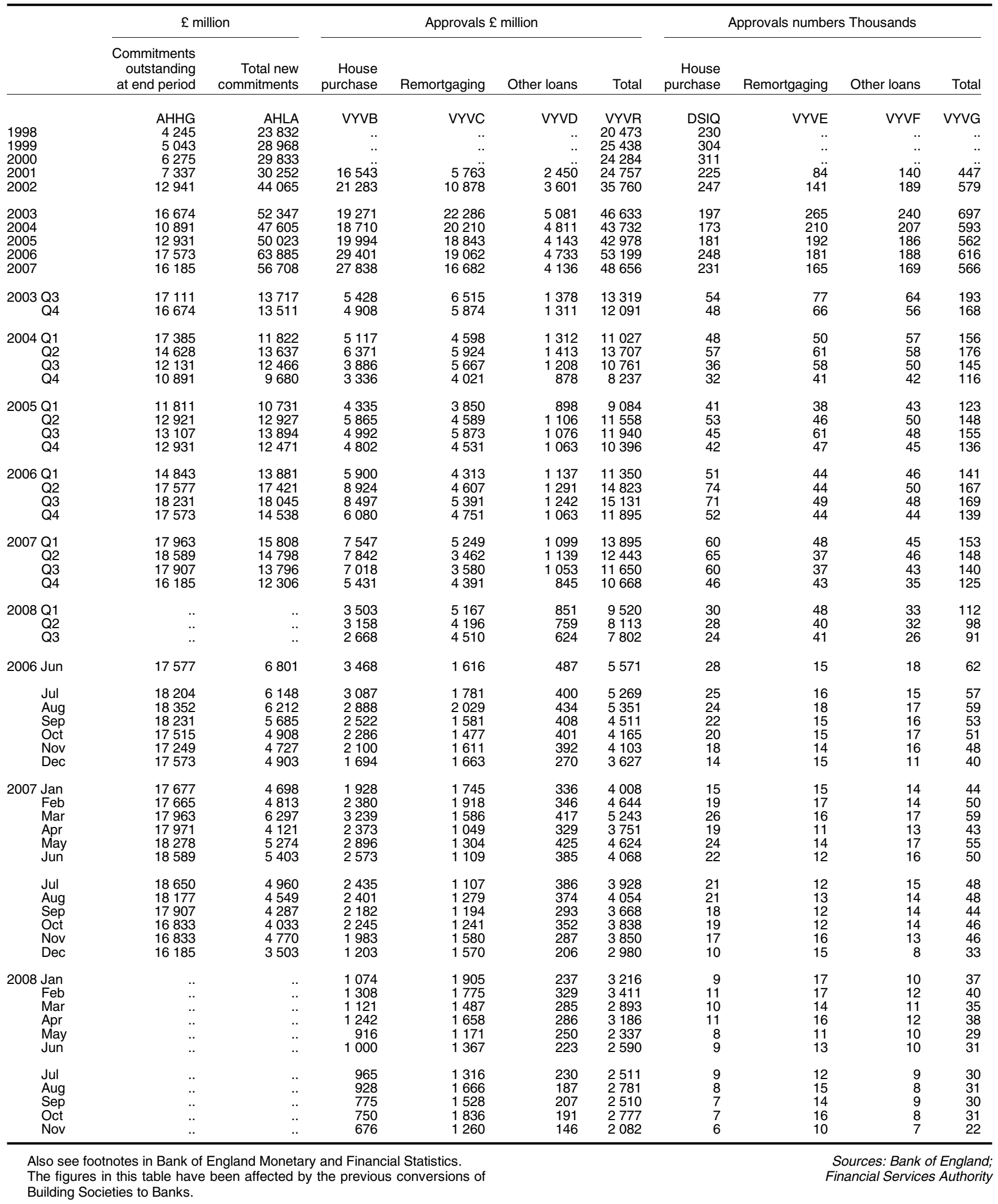


$£$ million

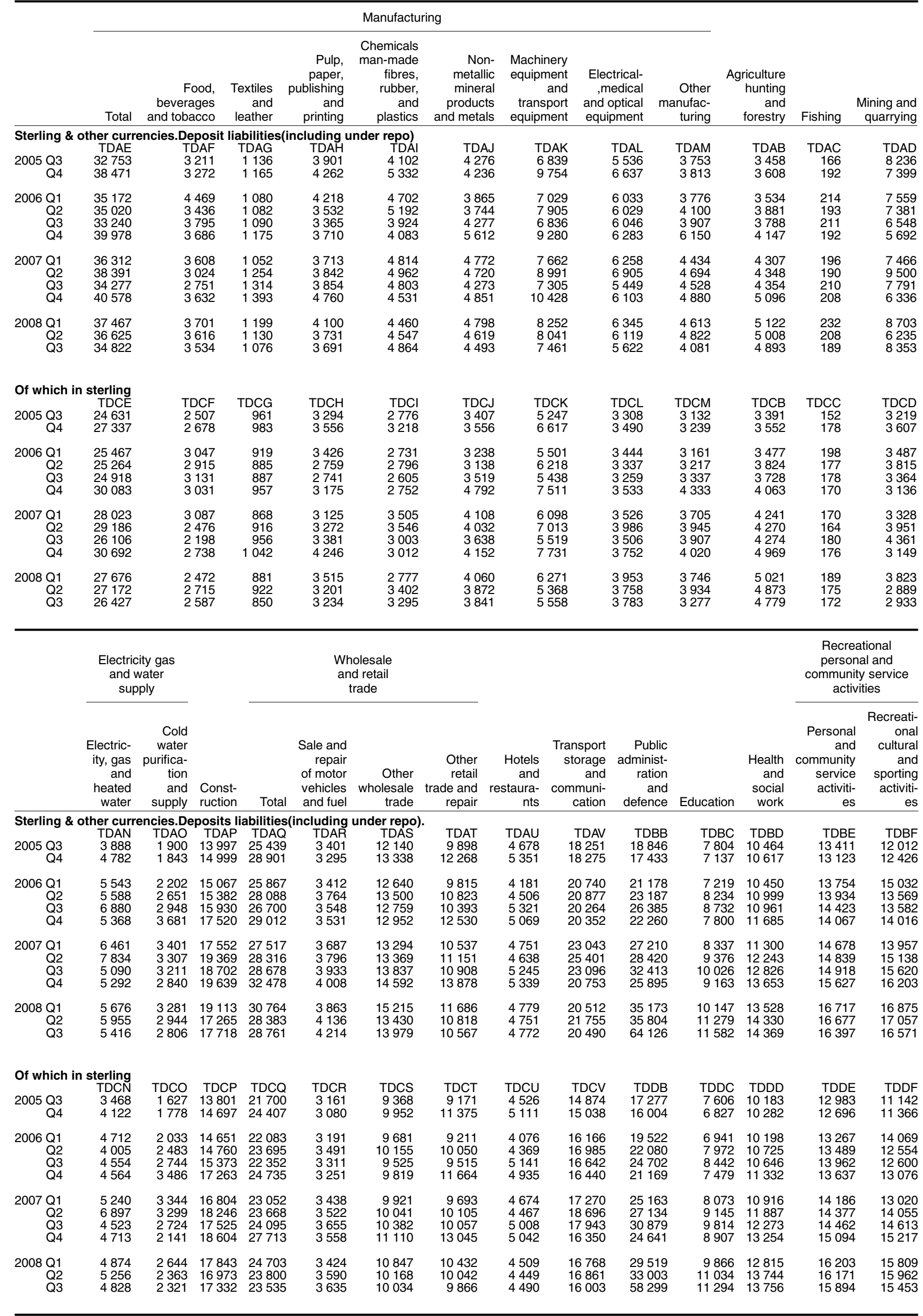


Financial intermediation (excluding insurance and pension funds)

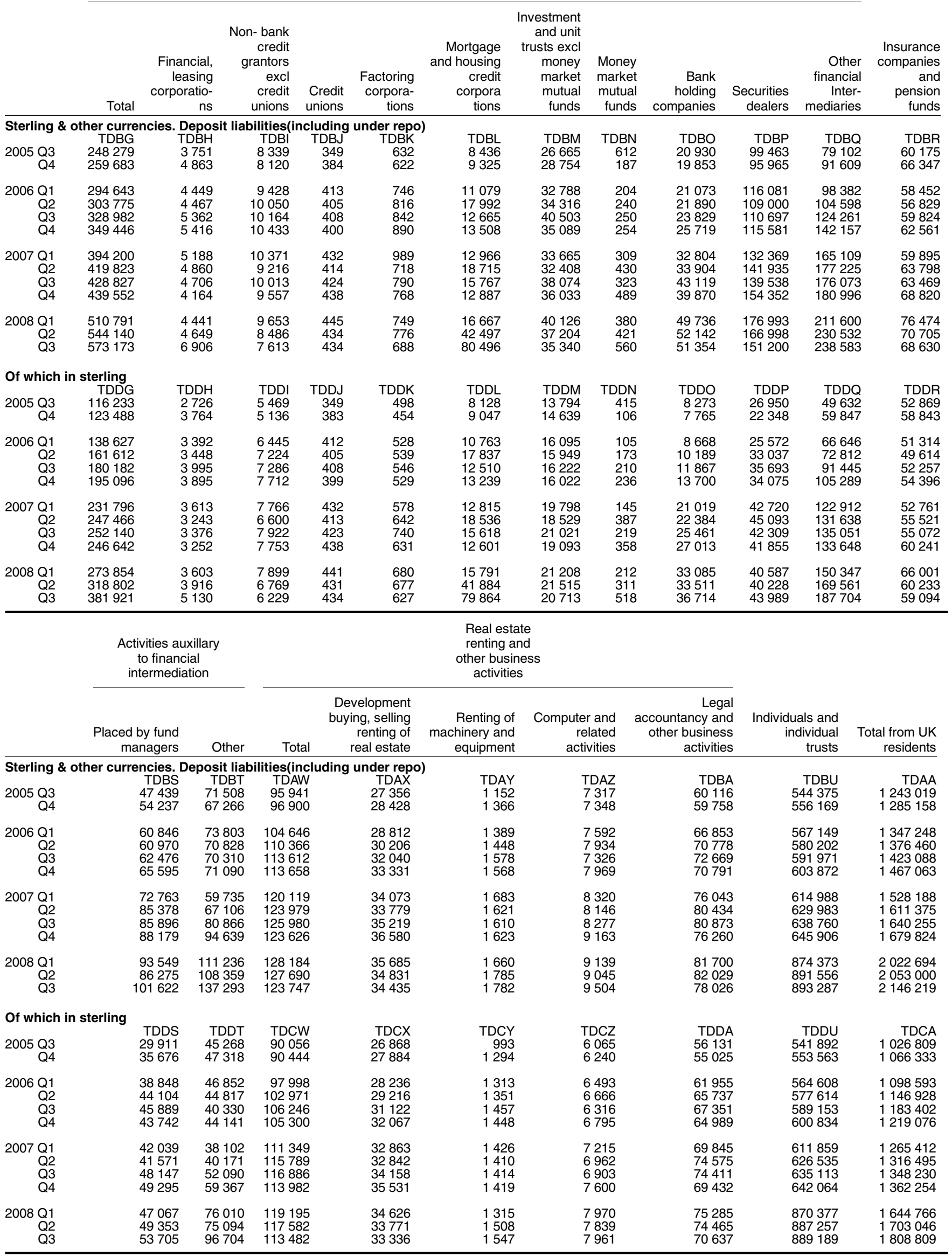

Also see footnotes in Bank of England Monetary and Financial Statistics.

1 The analysis of deposits includes sale and repurchase agreements(repo)

2 Changes in reporting population in the quarter to end-December 1997, in-

cluding the entry of Northern Rock plc, account for an increase of $110.0 \mathrm{bn}$ in total sterling deposits. Other currency deposits were unchanged. Changes data have been adjusted to reflect only the new business undertaken by Northern Rock plc during the quarter. 
Manufacturing

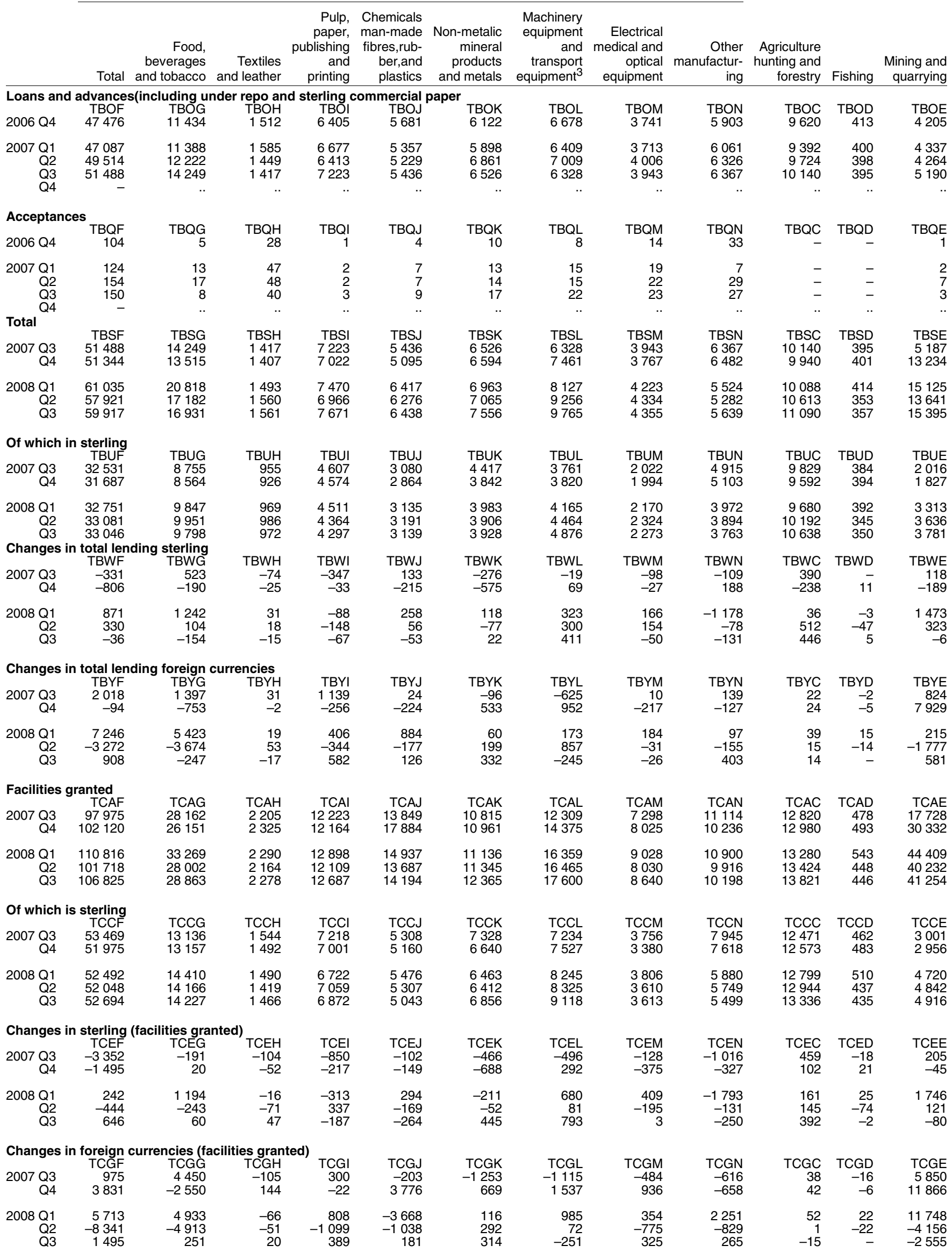

See Supplementary Information

1 Comprises loans advances(including under reverse repos),finance leasing, acceptances,facilities and holdings of sterling commercial paper, and also euro commercial paper. Holdings of investments and bills and adjustments for transit items are not included.
2 Changes in the reporting population including four building societies conversions to banks, in the six months to end-September 1997 account for an approximate net increase of $£ 134 \mathrm{bn}$ in total sterling lending; other currency lending increased by approximately £370mn. 


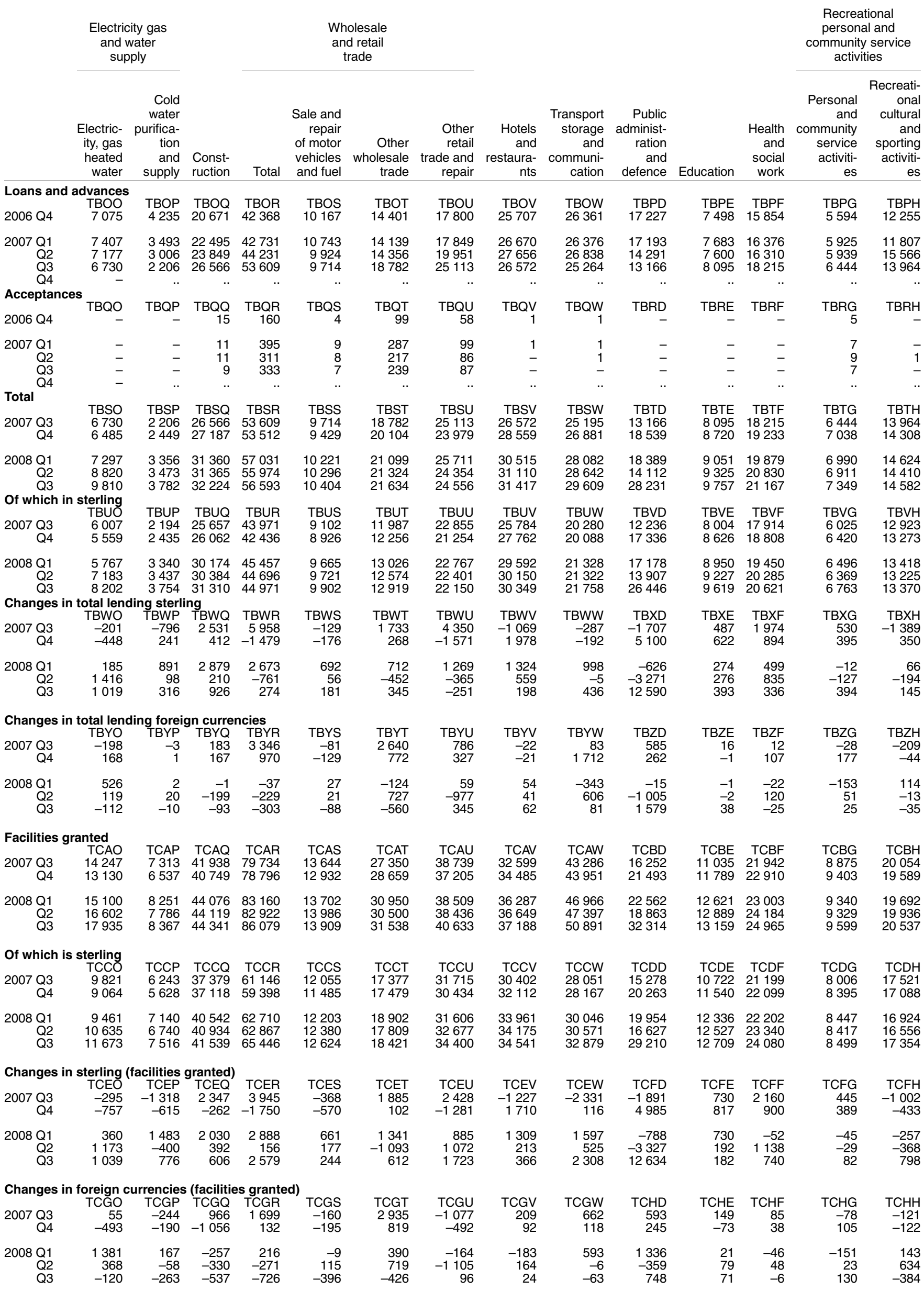

See Supplementary Information 
Financial intermediation (excluding insurance and pension funds)

\begin{tabular}{|c|c|c|c|c|c|c|c|c|c|c|c|c|}
\hline & Total & $\begin{array}{r}\text { Financial, } \\
\text { leasing } \\
\text { corporatio- } \\
\text { ns }\end{array}$ & $\begin{array}{r}\text { Non- bank } \\
\text { credit } \\
\text { grantors } \\
\text { excl } \\
\text { credit } \\
\text { unions }\end{array}$ & $\begin{array}{r}\text { Credit } \\
\text { unions }\end{array}$ & $\begin{array}{r}\text { Factoring } \\
\text { corpora- } \\
\text { tions }\end{array}$ & $\begin{array}{r}\text { Mortgage } \\
\text { and housing } \\
\text { credit } \\
\text { corpora } \\
\text { tions }\end{array}$ & $\begin{array}{r}\text { Investment } \\
\text { and unit } \\
\text { trusts excl } \\
\text { money } \\
\text { market } \\
\text { mutual } \\
\text { funds }\end{array}$ & $\begin{array}{c}\text { Money } \\
\text { market } \\
\text { mutual } \\
\text { funds }\end{array}$ & $\begin{array}{r}\text { Bank } \\
\text { holding } \\
\text { companies }\end{array}$ & $\begin{array}{r}\text { Securities } \\
\text { dealers }\end{array}$ & $\begin{array}{r}\text { Other } \\
\text { financial } \\
\text { Inter- } \\
\text { mediaries }\end{array}$ & $\begin{array}{r}\text { Insurance } \\
\text { companies } \\
\text { and } \\
\text { pension } \\
\text { funds }\end{array}$ \\
\hline \multicolumn{13}{|c|}{ Loans and advances } \\
\hline 2006 Q4 & $\begin{array}{r}\text { TBPI } \\
491121\end{array}$ & $\begin{array}{r}\text { TBPJ } \\
41068\end{array}$ & $\begin{array}{r}\text { TBPK } \\
21496\end{array}$ & $\begin{array}{r}\text { TBPL } \\
60\end{array}$ & $\begin{array}{l}\text { TBPM } \\
5593\end{array}$ & $\begin{array}{r}\text { TBPN } \\
84959\end{array}$ & $\begin{array}{r}\text { TBPO } \\
20131\end{array}$ & $\begin{array}{r}\text { TBPP } \\
674\end{array}$ & $\begin{array}{r}\text { TBPQ } \\
17969\end{array}$ & $\begin{array}{r}\text { TBPR } \\
183551\end{array}$ & $\begin{array}{r}\text { TBPS } \\
115620\end{array}$ & $\begin{array}{r}\text { TBPT } \\
26355\end{array}$ \\
\hline $\begin{array}{r}2007 \text { Q1 } \\
\text { Q2 } \\
\text { Q3 } \\
\text { Q4 }\end{array}$ & $\begin{array}{l}612141 \\
625647 \\
649856\end{array}$ & $\begin{array}{l}40089 \\
41173 \\
41848\end{array}$ & $\begin{array}{l}22341 \\
22612 \\
22485\end{array}$ & $\begin{array}{l}64 \\
75 \\
65\end{array}$ & $\begin{array}{l}5692 \\
6288 \\
6441\end{array}$ & $\begin{array}{r}90688 \\
96276 \\
103919\end{array}$ & $\begin{array}{l}16438 \\
16202 \\
19164\end{array}$ & $\begin{array}{l}282 \\
286 \\
343\end{array}$ & $\begin{array}{l}34055 \\
34509 \\
33777\end{array}$ & $\begin{array}{l}222199 \\
224741 \\
210590\end{array}$ & $\begin{array}{l}180294 \\
183486 \\
211223\end{array}$ & $\begin{array}{l}25092 \\
25255 \\
27968\end{array}$ \\
\hline
\end{tabular}

$\begin{array}{crrrrr}\text { Acceptances } & & & & & \\ 2006 \text { Q4 } & \text { TBRI } & \text { TBRJ } & \text { TBRK } & \text { TBRL } & \text { TBRM } \\ 2007 \text { Q1 } & 90 & - & 15 & 5 & - \\ \text { Q2 } & 51 & - & 16 & 5 & 1 \\ \text { Q3 } & 50 & - & 16 & 5 & - \\ \text { Q4 } & - & - & 16 & 5 & - \\ & & . . & . . & . . & . .\end{array}$

Total

$\begin{array}{rr}\text { Total } & \\ 2007 \text { Q3 } & \text { TBT } \\ \text { Q4 } & 66212 \\ & \\ 2008 \text { Q1 } & 742670 \\ \text { Q2 } & 717036 \\ \text { Q3 } & 75165\end{array}$

TBTJ

41848

42290

44030

43594

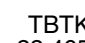

22465

24934

24501
24721

TBTL

TBTL
65
80

TBTM

6441

$83 \quad 6531$

$\begin{array}{rr}4 & 6879 \\ 81 & 6852\end{array}$

6852

Of which in sterling

2007 Q3 $\quad 364164$

TBVJ

35502

TBVK

21063
21443

TBVL

TBVL
64
80

TBVM

5683
5520

2008 Q1 391845

36491

22600
22197

83

83
4
80

5518

35232

22025

Changes in total lending sterling

Changes in total lending sterling
$\begin{array}{ccc}\text { TBXI } & \text { TBX } \\ 2007 \text { Q3 } & 24306 & 293 \\ \text { Q4 } & -3417 & -33\end{array}$

5688

TBXK TBXL TBXM

-140
380

1066

2008 Q1 10595

Q2 26394

876
-598

-598
-831

-403
-172

Changes in total lending foreign currencies

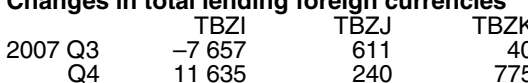

2008 Q1 $\quad 26973$

$\begin{array}{ll}\text { Q2 } & -43359 \\ \text { Q3 } & -33902\end{array}$

443
198

198
674

55
-25
191

-10
15

3
-79
77

140
-163

-25
175
-6

TBZ

$\begin{array}{rr}\text { BZL } & \text { TBZM } \\ - & -7 \\ - & 202\end{array}$

$\begin{array}{ll}- & -61 \\ - & 180\end{array}$

Facilities granted

$\begin{array}{rr} & \text { TCBI } \\ 2007 \text { Q3 } & 719717 \\ \text { Q4 } & 750335\end{array}$

TCBJ

44762
44850

$\begin{array}{lll}\text { TCBK } & \text { TCBL } & \text { TCBM }\end{array}$

$\begin{array}{lrl}24771 & 97 & 6770\end{array}$

25847

93

6857
6892

26977

27066
27098

$\begin{array}{rr}94 & 6892 \\ 8 & 7224 \\ 95 & 7177\end{array}$

47371
47721

27098

7224
7177

TBTN

103919

99231

119062

123274
151409

TBVN

88923
82577

100802

106003

129760

TBXN

2326
856

1839

5201

23757

TBZN
467

467
868

188
-843

-843
4247

TCBN

111192

105225

124029

128384
154692

$\begin{array}{ll}\text { Q2 } & 794671 \\ \text { Q3 } & 830720\end{array}$

Of which in sterling

$\begin{array}{rr} & \text { TCDI } \\ 2007 \text { Q3 } & 396338 \\ \text { Q4 } & 383376\end{array}$

TCDJ

38008

TCDK TCDL TCDM

$\begin{array}{lll}22793 & 97 & 5956\end{array}$

TCDN

95915

88024

$23977 \quad 93 \quad 5810$

$\begin{array}{rr}2008 \text { Q1 } & 420406 \\ \text { Q2 } & 448444\end{array}$

38831

39426
38510

23715

105203

110622
132504

Changes in sterling (facilities granted)

$\begin{array}{lrr} & \text { TCFI } & \text { TCFJ } \\ 2007 \text { Q3 } & 28900 & 575 \\ & & -5764\end{array}$

$\begin{array}{rr}\text { TCFK } & \text { TCF } \\ -430 & -7 \\ 325 & -7\end{array}$

5940

TCFN

7236
-688

TCFM
108
-170

$-688$

2008 Q1

8991

8991
28446

1000
594

$\begin{array}{rr}762 & 3 \\ 174 & -85 \\ -437 & 86\end{array}$

1
173
-43

775
5419

5419
21882

$\begin{array}{rr}\text { TBTO } & \text { TBTP } \\ 19164 & 193 \\ 20980 & 32 \\ & \\ 18732 & 295 \\ 12588 & 575 \\ 13480 & 174\end{array}$

TBTQ

33777

44392

50842

53723
54335

210590

228447
197970

170710

TBVQ

24900

$\begin{array}{rr}\text { TBVO } & \text { TBVP } \\ 6892 & 110 \\ 6133 & 77\end{array}$

6004

6004

5979
6499

67
370
50

38267

41109

41407

$\begin{array}{rr}\text { TBXO } & \text { TBXP } \\ 677 & 28 \\ -759 & -33\end{array}$

TBXQ

-2023
7463

5752

$-168$

-168
-25
520

-10
302

302
-319

284

$\begin{array}{rr}\text { TBZO } & \text { TBZP } \\ 2163 & -122 \\ 2052 & 158\end{array}$

TBZQ

$-2730 \quad-33$

$-6077 \quad-20$

$-10 \quad-92$

32988

$48565 \quad 400$

45530

39425

391

TBZQ
1156
2715

TBVR

36975

27680

27039

27907

TBX

-384
-4743

$-9405$

$-641$

868

-44
109

TBZR

-16247
5463

4283
-838

8750

-28593
-35517

20405

-8287
-2993

TCBQ

34747

45288

TCBR

219886

232192

TCBS

244172

241017

52369

55891
56492

234035

203570
177393

282313

285045

318374

TCDO TCDP TCDQ

$13872 \quad 113$

TCDR

TCDR

TCDS

151859
145212

$\begin{array}{lll}12911 & 78 & 38683\end{array}$

$12635 \quad 379 \quad 42382$

2879

166140

$27923-184935$

209619

$\begin{array}{rrr}\text { TCFO } & \text { TCFP } & \text { TCFO } \\ 959 & 28 & -1937\end{array}$

959
-958

TCFQ
-1930

TCF

-444
-4630

TCFS

22792

$-6650$

$\begin{array}{rr}-70 & -11 \\ -276 & 30\end{array}$

6026

$-9396$

9902

19203

23933

-5122
-2652

Changes in foreign currencies (facilities granted)

\begin{tabular}{|c|c|c|c|c|c|c|c|c|c|c|c|c|}
\hline \multicolumn{13}{|c|}{ Changes in foreign currencies (facilities granted) } \\
\hline $\begin{array}{r}2007 \text { Q3 } \\
\text { Q4 }\end{array}$ & $\begin{array}{r}\text { TCHI } \\
-8155 \\
30118\end{array}$ & $\begin{array}{r}\text { TCHJ } \\
666 \\
177\end{array}$ & $\begin{array}{r}\text { TCHK } \\
171 \\
671\end{array}$ & $\begin{array}{r}\mathrm{TCHL} \\
-421 \\
3\end{array}$ & $\begin{array}{r}\mathrm{TCHM} \\
-16 \\
211\end{array}$ & $\begin{array}{r}\mathrm{TCHN} \\
590 \\
1114\end{array}$ & $\begin{array}{r}\mathrm{TCHO} \\
1813 \\
15239\end{array}$ & $\begin{array}{r}\mathrm{TCHP} \\
-78 \\
82\end{array}$ & $\begin{array}{r}\mathrm{TCHQ} \\
1651 \\
2697\end{array}$ & $\begin{array}{r}\text { TCHR } \\
-17198 \\
9616\end{array}$ & $\begin{array}{r}\text { TCHS } \\
4668 \\
309\end{array}$ & $\begin{array}{r}\text { TCHT } \\
189 \\
11317\end{array}$ \\
\hline $\begin{array}{r}2008 \text { Q1 } \\
\text { Q2 } \\
\text { Q3 }\end{array}$ & $\begin{array}{r}14645 \\
-44061 \\
-31666\end{array}$ & $\begin{array}{l}290 \\
236 \\
758\end{array}$ & $\begin{array}{l}210 \\
-75 \\
216\end{array}$ & $\begin{array}{r}-3 \\
- \\
-\end{array}$ & $\begin{array}{l}-64 \\
166 \\
-24\end{array}$ & $\begin{array}{r}174 \\
-914 \\
4276\end{array}$ & $\begin{array}{r}-4529 \\
-5676 \\
-279\end{array}$ & $\begin{array}{r}-12 \\
-2 \\
-99\end{array}$ & $\begin{array}{r}267 \\
-102 \\
-126\end{array}$ & $\begin{array}{r}37 \\
-28443 \\
-34585\end{array}$ & $\begin{array}{r}18275 \\
-18766 \\
15994\end{array}$ & $\begin{array}{r}-1433 \\
1298 \\
401\end{array}$ \\
\hline
\end{tabular}

See Supplementary Information 


\begin{tabular}{|c|c|c|c|c|c|c|c|c|c|c|c|c|}
\hline & \multicolumn{2}{|c|}{$\begin{array}{l}\text { Activities auxillary } \\
\text { to financial } \\
\text { intermediation }\end{array}$} & \multicolumn{5}{|c|}{$\begin{array}{l}\text { Real estate } \\
\text { renting and } \\
\text { other business } \\
\text { activities }\end{array}$} & \multicolumn{3}{|c|}{$\begin{array}{l}\text { Individuals and } \\
\text { individual trusts }\end{array}$} & \multicolumn{2}{|c|}{ Total to UK residents } \\
\hline & $\begin{array}{r}\text { Fund } \\
\text { management } \\
\text { activities }\end{array}$ & Other & Total & $\begin{array}{r}\text { Development } \\
\text { buying, } \\
\text { selling } \\
\text { renting of } \\
\text { real estate }\end{array}$ & $\begin{array}{r}\text { Renting of } \\
\text { machinery } \\
\text { and } \\
\text { equipment }\end{array}$ & $\begin{array}{r}\text { Computer } \\
\text { and } \\
\text { related } \\
\text { activities }\end{array}$ & $\begin{array}{r}\text { Legal } \\
\text { accountancy } \\
\text { and } \\
\text { other } \\
\text { business } \\
\text { activities }\end{array}$ & Total & $\begin{array}{r}\text { Lending } \\
\text { secured on } \\
\text { dwellings } \\
\text { incl } \\
\text { bridging } \\
\text { finance }\end{array}$ & $\begin{array}{r}\text { Other loans } \\
\text { and } \\
\text { advances }\end{array}$ & Total & $\begin{array}{l}\text { Of which in } \\
\text { sterling }\end{array}$ \\
\hline \multicolumn{13}{|c|}{ Loans and advances } \\
\hline $\begin{array}{r}2007 \text { Q3 } \\
\text { Q4 }\end{array}$ & $\begin{array}{r}\text { TBPU } \\
54857 \\
. .\end{array}$ & $\begin{array}{r}\text { TBPV } \\
77162 \\
. .\end{array}$ & $\begin{array}{r}\text { TBOX } \\
242872 \\
. .\end{array}$ & $\begin{array}{r}\text { TBOY } \\
188212 \\
. .\end{array}$ & $\begin{array}{r}\text { TBPA } \\
8845 \\
. .\end{array}$ & $\begin{array}{r}\text { TBPB } \\
4826 \\
. .\end{array}$ & $\begin{array}{r}\text { TBPC } \\
40989 \\
. .\end{array}$ & $\begin{array}{r}\text { TBPW } \\
740243 \\
749174\end{array}$ & $\begin{array}{r}\text { TBPX } \\
598760 \\
605198\end{array}$ & $\begin{array}{r}\text { TBPY } \\
141482 \\
144014\end{array}$ & $\begin{array}{r}\text { TBOA } \\
2061002\end{array}$ & $\begin{array}{r}\text { TBOB } \\
1648779\end{array}$ \\
\hline $\begin{array}{r}2008 \text { Q1 } \\
\text { Q2 } \\
\text { Q3 }\end{array}$ & $\begin{array}{l}. . \\
. . \\
. .\end{array}$ & $\begin{array}{l}. . \\
. . \\
. .\end{array}$ & $\begin{array}{l}. . \\
. . \\
. .\end{array}$ & $\begin{array}{l}. . \\
. . \\
. .\end{array}$ & $\begin{array}{l}. . \\
. . \\
. .\end{array}$ & $\begin{array}{l}. . \\
. . \\
. .\end{array}$ & $\begin{array}{l}. . \\
. . \\
. .\end{array}$ & $\begin{array}{l}959483 \\
962583 \\
942140\end{array}$ & $\begin{array}{l}813136 \\
815239 \\
792601\end{array}$ & $\begin{array}{l}146347 \\
147345 \\
149539\end{array}$ & $\begin{array}{l}. . \\
. . \\
. .\end{array}$ & $\begin{array}{l}. . \\
. . \\
. .\end{array}$ \\
\hline
\end{tabular}

$\begin{array}{crrr}\text { Acceptances } & \text { TBRU } & \text { TBRV } & \text { TBQX } \\ 2006 \text { Q4 } & - & - & 812 \\ 2007 \text { Q1 } & - & - & 905 \\ \text { Q2 } & - & - & 772 \\ \text { Q3 } & - & - & 948 \\ \text { Q4 } & - & . . & . . \\ \text { Total } & & & \\ \text { 2007 Q3 } & \text { TBTU } & \text { TBTV } & \text { TBSX } \\ \text { Q4 } & 52748 & 93162 & 242872 \\ \text { 2008 Q1 } & 63480 & 124807 & 288254 \\ \text { Q2 } & 43662 & 132902 & 298065 \\ \text { Q3 } & 61150 & 152803 & 306330 \\ & & & \\ \text { Of which in sterling } & & & \\ \text { 2007 Q3 } & 20459 & 43262 & 231596 \\ \text { Q4 } & 15774 & 58154 & 241030 \\ \text { 2008 Q1 } & 20037 & 69844 & 274392 \\ \text { Q2 } & 17059 & 79030 & 283581 \\ \text { Q3 } & 16903 & 88494 & 290524\end{array}$

$\begin{array}{rrrr}\text { TBQY } & \text { TBRA } & \text { TBRB } & \text { TBRC } \\ 800 & - & - & 12 \\ 891 & 1 & - & 13 \\ 756 & - & 1 & 14 \\ 929 & 1 & - & 19\end{array}$

TBSY 196183

229241 237365 245684

\section{TBTA TBTB} 8845
9125

9
9922
10377

TBUY

185891
193064

224694

232148
240129

240129

Changes in total lending sterling

$\begin{array}{rrrr}\text { Changes in total lending sterling } & \\ & \text { TBXU } & \text { TBXV } & \text { TBWX } \\ 2007 \text { Q3 } & 6568 & 10301 & 14703 \\ \text { Q4 } & -4688 & 14891 & 9429 \\ & & & \\ 2008 \text { Q1 } & 4184 & 11377 & 9830 \\ \text { Q2 } & . . & 9185 & 8562 \\ \text { Q3 } & . . & 9201 & 5785\end{array}$

TBWY
10857
8094
9143
6826
6824

TBVA

7459
7629

8066

8566
8778

\section{TBXA TBXB}

TBXA
251
170

Changes in total lending foreign currencies

\begin{tabular}{rrrr}
\multicolumn{4}{c}{ Changes in total lending } \\
& TBZU & TBZV & TBY currencies \\
2007 Q3 & 3775 & 2106 & 1220 \\
Q4 & 1299 & -375 & 118 \\
& & & \\
2008 Q1 & 4994 & 16177 & 226 \\
Q2 & -16695 & -700 & 709 \\
Q3 & 15174 & 4917 & 799
\end{tabular}

Facilities granted

\begin{tabular}{rrrr}
\multicolumn{2}{l}{ Facilities granted } & & \\
& TCBU & TCBV & TCAX \\
2007 Q3 & 58014 & 80907 & 311359 \\
Q4 & 56988 & 96108 & 318035 \\
2008 Q1 & 74731 & 127928 & 361106 \\
Q2 & 52172 & 137180 & 369459 \\
Q3 & 70666 & 156301 & 376468
\end{tabular}

TBYY

237
-271

TBZA

131

702
244

TCAY

232209

278101

286134

293576

TCBA

10572

10682

10930

11949

12831

TCCY

224844
232906

\section{TCDA TCDB}

$\begin{array}{rrrr}\text { Of which is sterling } & & \\ & \text { TCDU } & \text { TCDV } & \text { TCCX } \\ \text { 2007 Q3 } & 21764 & 45506 & 289451 \\ \text { Q4 } & 17865 & 59923 & 295544 \\ & & & \\ \text { 2008 Q1 } & 22785 & 71525 & 335258 \\ \text { Q2 } & 19172 & 81066 & 343792 \\ \text { Q3 } & 18681 & 90546 & 348893\end{array}$

276293
282849

8599
8683

9153

9980
10406

TCEY

11182

8057

TCFA TCFB

10835

6414
5165 188212

$\begin{array}{lll}18681 & 90546 & 348893\end{array}$

269251
9281

4826
4590

4686

4686
4616
4832

TBVB

3216

2829

2924

3035
3104

393

500
213

158
46

-365
149

149
207

1406
84

TBTC

111
69

TBZB
88
83
-100
-169
86

4405

$\begin{array}{rr}410 & -154 \\ 826 & 11\end{array}$

$\begin{array}{ll}826 & 11 \\ 426 & 97\end{array}$
$4089 \quad 740243$

$45047 \quad 959483$

46162
45437

45437

TBVC

35955

37508

38708

$\begin{array}{ll}39833 & 960219 \\ 38512 & 939863\end{array}$

\section{TBXC TBXW}

$\begin{array}{ll}\text { TBXC } & \text { TBXW } \\ 3434 & 11148\end{array}$

1552

213

1125
-1321

15212
3934

$\begin{array}{rr}\text { TBZC } & \text { TBZW } \\ 737 & 112 \\ 261 & -464 \\ & \\ 559 & 57 \\ 27 & 331 \\ 262 & -169\end{array}$

TCB

61247 TCBW

$60156 \quad 865188$

$64760 \quad 1087369$

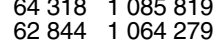

TCDC TCDW

$\begin{array}{ll}51259 & 859131 \\ 49524 & 863182\end{array}$

$52556 \quad 1084927$

$53211 \quad 1083077$

512331061530

TBTX
598760
605198
813136
815239
792601

TBVX

597894

604674

812356

814257
791769

\section{TBXX}

8866

14327

14327
2601

$-23821$

TBZX
-24
-363

$-363$

17

209
-171

TCBX

668623

883660

882315

853921

TCDX

667746

666897

882852

881305

853061

TCFC TCFW

$4311 \quad 15188$

$-1736 \quad-3502$

TCFX

TCFX
10983
-7797

$\begin{array}{rr}1945 & 18385\end{array}$

$\begin{array}{rr}655 & -700 \\ -1978 & -23930\end{array}$

15667

15667
-848
-29577

$\begin{array}{rr}\text { TBQA } & \text { TBQB } \\ 1190 & 956 \\ & \\ 1499 & 1044 \\ 1317 & 897 \\ 1520 & 1071\end{array}$

TBTY TBSA

1414822060660

1440142128450

1463472521555

1473452491018

TBVY TBUA

$140267 \quad 1649850$

1428531676084

$145080 \quad 1986840$

1459632030094

1480942093896

TBXY TBWA

$\begin{array}{ll}2282 & 75834 \\ 3069 & 28278\end{array}$

$885 \quad 60651$

$1333 \quad 44185$

$1083 \quad 58979$

$$
\begin{array}{rr}
\text { TBZY } & \text { TBYA } \\
136 & 6339 \\
-101 & 23355 \\
& \\
40 & 57154 \\
123 & -64513 \\
2 & -10203
\end{array}
$$

TCBY TCAA 1929172499070

2037083013694

2035042967571

2103583060753

TCDY TCCA 140267
1428531960266
1977125

2020752302537 2017732339948

2084692402656

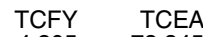

$4205 \quad 78845$

$4294 \quad 16488$

$2718 \quad 62830$

$\begin{array}{rl}2718 & 38342 \\ 5647 & 57623\end{array}$

Changes in foreign currencies (facilities granted)

\begin{tabular}{rrrr}
\multicolumn{4}{c}{ Changes in foreign currencies (facilities granted) } \\
TCHU & TCHV & TCGX \\
2007 Q3 & 3910 & 2367 & 1828 \\
Q4 & 1479 & -900 & -274 \\
& & & \\
2008 Q1 & 11186 & 16541 & 1049 \\
Q2 & -18766 & 114 & -15 \\
Q3 & 15994 & 4042 & 729 \\
\hline
\end{tabular}

TCGY
448

$\begin{array}{rr}\text { TCHA } & \text { TC } \\ 120 & -53 \\ -57 & 287 \\ -332 & -114 \\ 205 & -250 \\ 385 & -68\end{array}$

See Supplementary Information

$\begin{array}{rrrrr}\text { TCHC } & \text { TCHW } & \text { TCHX } & \text { TCHY } & \text { TCGA } \\ 1304 & 240 & -22 & 262 & 11200 \\ 262 & -482 & -370 & -113 & 55784 \\ & & & & \\ 1017 & 113 & 39 & 74 & 62856 \\ -1020 & 318 & 209 & 108 & -73337 \\ -147 & -97 & -172 & 75 & -12800\end{array}$


$£$ million

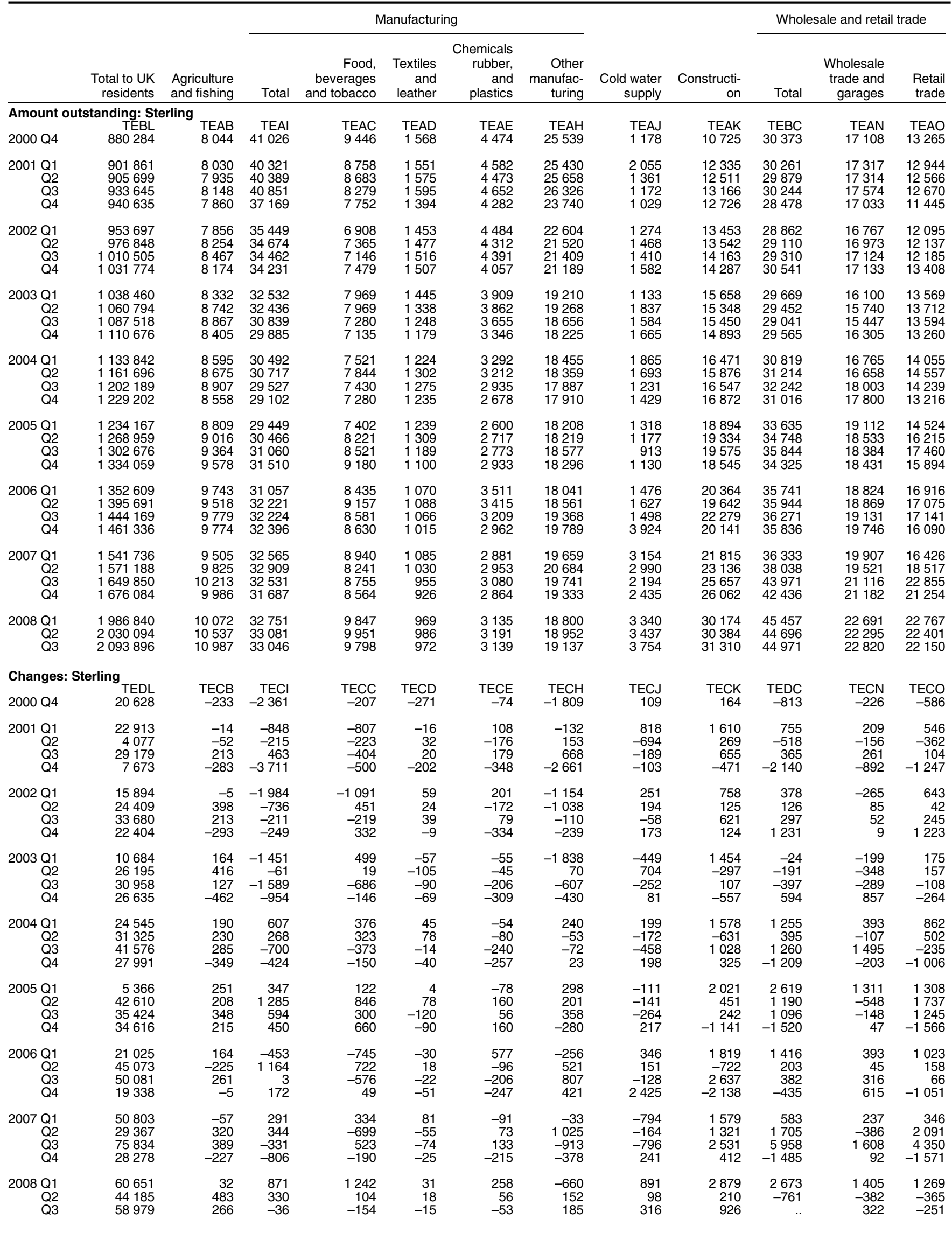




\begin{tabular}{|c|c|c|c|c|c|c|c|c|c|c|c|c|c|}
\hline & & & & & Finan & ncial interme & ediation & & & & Individ & and Individue & al trusts \\
\hline & $\begin{array}{r}\text { Hotel and } \\
\text { restauran- } \\
\text { ts }\end{array}$ & $\begin{array}{r}\text { storage } \\
\text { and } \\
\text { communica- } \\
\text { tion }\end{array}$ & $\begin{array}{r}\text { Real } \\
\text { estate }\end{array}$ & Total & $\begin{array}{r}\text { Financial } \\
\text { leasing }\end{array}$ & $\begin{array}{r}\text { Securities } \\
\text { dealers }\end{array}$ & $\begin{array}{r}\text { Investmen- } \\
\text { ts and } \\
\text { Unit } \\
\text { trusts }\end{array}$ & $\begin{array}{r}\text { Other } \\
\text { financial }\end{array}$ & $\begin{array}{r}\text { Insurance } \\
\text { cos and } \\
\text { pension } \\
\text { funds }\end{array}$ & $\begin{array}{r}\text { unclassif- } \\
\text { ied } \\
\text { industrial } \\
\text { categories }\end{array}$ & Total & $\begin{array}{r}\text { Lending } \\
\text { secured on } \\
\text { dwellings }\end{array}$ & other \\
\hline mount & tstanding & Sterling & & & & & & & & & & & \\
\hline 2000 Q4 & $\begin{array}{r}\text { TEAP } \\
13952\end{array}$ & $\begin{array}{r}\text { TEAR } \\
14892\end{array}$ & $\begin{array}{r}\text { TEAS } \\
56121\end{array}$ & $\begin{array}{r}\text { TEBA } \\
144389\end{array}$ & $\begin{array}{r}\text { TEAT } \\
35086\end{array}$ & $\begin{array}{r}\text { TEAU } \\
33750\end{array}$ & $\begin{array}{r}\text { TEAW } \\
15803\end{array}$ & $\begin{array}{r}\text { TEAZ } \\
59749\end{array}$ & $\begin{array}{r}\text { TEBB } \\
18441\end{array}$ & $\begin{array}{r}\text { TEBF } \\
70227\end{array}$ & $\begin{array}{r}\text { TEBJ } \\
470917\end{array}$ & $\begin{array}{r}\text { TEBH } \\
377028\end{array}$ & $\begin{array}{r}\text { TEBI } \\
93888\end{array}$ \\
\hline $\begin{array}{r}2001 \text { Q1 } \\
\text { Q2 } \\
\text { Q3 } \\
\text { Q4 }\end{array}$ & $\begin{array}{l}14734 \\
15689 \\
14829 \\
15366\end{array}$ & $\begin{array}{l}16732 \\
18021 \\
18686 \\
18539\end{array}$ & $\begin{array}{l}59761 \\
62669 \\
66433 \\
70330\end{array}$ & $\begin{array}{l}157891 \\
145645 \\
152539 \\
148272\end{array}$ & $\begin{array}{l}34657 \\
34677 \\
34609 \\
34871\end{array}$ & $\begin{array}{l}44389 \\
30292 \\
37609 \\
33478\end{array}$ & $\begin{array}{l}16731 \\
18540 \\
18019 \\
18292\end{array}$ & $\begin{array}{l}62114 \\
62136 \\
62302 \\
61630\end{array}$ & $\begin{array}{l}17632 \\
16452 \\
17207 \\
14792\end{array}$ & $\begin{array}{l}66309 \\
65609 \\
68481 \\
71271\end{array}$ & $\begin{array}{l}475800 \\
489539 \\
501887 \\
514802\end{array}$ & $\begin{array}{ll}381 & 417 \\
390 & 054 \\
399 & 119 \\
407 & 365\end{array}$ & $\begin{array}{r}94383 \\
99485 \\
102768 \\
107437\end{array}$ \\
\hline $\begin{array}{r}2002 \text { Q1 } \\
\text { Q2 } \\
\text { Q3 } \\
\text { Q4 }\end{array}$ & $\begin{array}{l}15752 \\
16210 \\
16430 \\
16078\end{array}$ & $\begin{array}{l}20086 \\
21321 \\
22717 \\
25644\end{array}$ & $\begin{array}{l}73296 \\
75731 \\
81014 \\
85627\end{array}$ & $\begin{array}{l}152539 \\
155257 \\
155398 \\
149872\end{array}$ & $\begin{array}{l}34652 \\
34310 \\
36295 \\
35508\end{array}$ & $\begin{array}{l}36266 \\
36240 \\
30414 \\
22238\end{array}$ & $\begin{array}{l}18998 \\
20389 \\
19935 \\
20421\end{array}$ & $\begin{array}{l}62623 \\
64318 \\
68753 \\
71705\end{array}$ & $\begin{array}{l}11931 \\
10854 \\
13282 \\
12728\end{array}$ & $\begin{array}{l}67546 \\
69830 \\
73707 \\
77191\end{array}$ & $\begin{array}{l}525653 \\
540597 \\
560146 \\
575819\end{array}$ & $\begin{array}{l}416102 \\
427946 \\
442235 \\
455055\end{array}$ & $\begin{array}{l}109551 \\
112652 \\
117910 \\
120764\end{array}$ \\
\hline $\begin{array}{r}2003 \text { Q1 } \\
\text { Q2 } \\
\text { Q3 } \\
\text { Q4 }\end{array}$ & $\begin{array}{l}17268 \\
18401 \\
18677 \\
18980\end{array}$ & $\begin{array}{l}25286 \\
25413 \\
21990 \\
22246\end{array}$ & $\begin{array}{l}90411 \\
94344 \\
97259 \\
98963\end{array}$ & $\begin{array}{l}158073 \\
158795 \\
164989 \\
168140\end{array}$ & $\begin{array}{l}35285 \\
35778 \\
36439 \\
35336\end{array}$ & $\begin{array}{l}23742 \\
23568 \\
27090 \\
27279\end{array}$ & $\begin{array}{l}20542 \\
20562 \\
21915 \\
21357\end{array}$ & $\begin{array}{l}78505 \\
78888 \\
79544 \\
84169\end{array}$ & $\begin{array}{l}13032 \\
13260 \\
15721 \\
16594\end{array}$ & $\begin{array}{l}73722 \\
74840 \\
76903 \\
81085\end{array}$ & $\begin{array}{l}573342 \\
587926 \\
606197 \\
620255\end{array}$ & $\begin{array}{l}458253 \\
469236 \\
484820 \\
497389\end{array}$ & $\begin{array}{l}115089 \\
118691 \\
121377 \\
122866\end{array}$ \\
\hline $\begin{array}{r}2004 \text { Q1 } \\
\text { Q2 } \\
\text { Q3 } \\
\text { Q4 }\end{array}$ & $\begin{array}{l}19679 \\
19778 \\
21282 \\
21658\end{array}$ & $\begin{array}{l}16704 \\
15251 \\
17549 \\
16888\end{array}$ & $\begin{array}{l}103631 \\
109324 \\
112867 \\
114936\end{array}$ & $\begin{array}{l}164934 \\
163841 \\
190894 \\
194870\end{array}$ & $\begin{array}{l}32732 \\
33098 \\
31475 \\
31547\end{array}$ & $\begin{array}{l}29718 \\
22676 \\
24049 \\
24094\end{array}$ & $\begin{array}{l}21170 \\
20991 \\
17246 \\
16850\end{array}$ & $\begin{array}{r}81314 \\
87076 \\
118124 \\
122378\end{array}$ & $\begin{array}{l}16266 \\
18049 \\
21197 \\
18895\end{array}$ & $\begin{array}{r}93417 \\
99872 \\
99506 \\
108161\end{array}$ & & $\begin{array}{l}505275 \\
517060 \\
516803 \\
529546\end{array}$ & $\begin{array}{l}125693 \\
130345 \\
133637 \\
137270\end{array}$ \\
\hline $\begin{array}{r}2005 \text { Q1 } \\
\text { Q2 } \\
\text { Q3 } \\
\text { Q4 }\end{array}$ & $\begin{array}{l}21733 \\
22446 \\
22165 \\
23568\end{array}$ & $\begin{array}{l}16986 \\
17158 \\
16236 \\
16531\end{array}$ & $\begin{array}{l}122513 \\
127892 \\
133278 \\
135928\end{array}$ & $\begin{array}{l}189902 \\
199075 \\
202126 \\
206104\end{array}$ & $\begin{array}{l}30718 \\
31944 \\
32713 \\
32472\end{array}$ & & & $\begin{array}{l}119975 \\
124013 \\
128170 \\
131982\end{array}$ & & $\begin{array}{l}104847 \\
114047 \\
125582 \\
134753\end{array}$ & & $\begin{array}{l}527488 \\
532509 \\
547007 \\
558615\end{array}$ & $\begin{array}{l}139204 \\
141176 \\
141571 \\
141888\end{array}$ \\
\hline $\begin{array}{r}2006 \text { Q1 } \\
\text { Q2 } \\
\text { Q3 } \\
\text { Q4 }\end{array}$ & $\begin{array}{l}24399 \\
24573 \\
24810 \\
25042\end{array}$ & $\begin{array}{l}16607 \\
18306 \\
22519 \\
21589\end{array}$ & $\begin{array}{l}142366 \\
149088 \\
155411 \\
160970\end{array}$ & $\begin{array}{l}216508 \\
233198 \\
247756 \\
246302\end{array}$ & $\begin{array}{l}33139 \\
33763 \\
34655 \\
35832\end{array}$ & & $\begin{array}{l}18771 \\
19508 \\
19550 \\
19535\end{array}$ & & $\begin{array}{l}16581 \\
17624 \\
19259 \\
24373\end{array}$ & $\begin{array}{l}144714 \\
148021 \\
153147 \\
152932\end{array}$ & & $\begin{array}{l}073 \\
863 \\
720 \\
643\end{array}$ & $\begin{array}{l}139982 \\
141068 \\
141496 \\
141413\end{array}$ \\
\hline $\begin{array}{r}2007 \text { Q1 } \\
\text { Q2 } \\
\text { Q3 } \\
\text { Q4 }\end{array}$ & $\begin{array}{l}25950 \\
26859 \\
25784 \\
27762\end{array}$ & $\begin{array}{l}21473 \\
21998 \\
20280 \\
20088\end{array}$ & $\begin{array}{l}166995 \\
175429 \\
185891 \\
193064\end{array}$ & $\begin{array}{l}326993 \\
335982 \\
364164 \\
353327\end{array}$ & $\begin{array}{l}34700 \\
35485 \\
35502 \\
35470\end{array}$ & $\begin{array}{l}38584 \\
42102 \\
41717 \\
36975\end{array}$ & $\begin{array}{l}33041 \\
33219 \\
32051 \\
38573\end{array}$ & $\begin{array}{l}220669 \\
225176 \\
254894 \\
242308\end{array}$ & $\begin{array}{l}22875 \\
23017 \\
25519 \\
27965\end{array}$ & $\begin{array}{l}147365 \\
153686 \\
175486 \\
193744\end{array}$ & & $\begin{array}{l}587268 \\
588087 \\
597894 \\
604674\end{array}$ & $\begin{array}{l}139445 \\
139232 \\
140267 \\
142853\end{array}$ \\
\hline $\begin{array}{r}2008 \text { Q1 } \\
\text { Q2 } \\
\text { Q3 }\end{array}$ & $\begin{array}{l}29592 \\
30150 \\
30349\end{array}$ & $\begin{array}{l}21328 \\
21322 \\
21758\end{array}$ & $\begin{array}{l}224694 \\
232148 \\
240129\end{array}$ & $\begin{array}{l}391845 \\
417831 \\
467898\end{array}$ & $\begin{array}{l}36491 \\
35894 \\
35232\end{array}$ & $\begin{array}{l}27680 \\
27039 \\
27907\end{array}$ & $\begin{array}{l}44339 \\
47457 \\
47957\end{array}$ & $\begin{array}{l}283335 \\
307441 \\
356802\end{array}$ & & $\begin{array}{l}214151 \\
221353 \\
244592\end{array}$ & & & $\begin{array}{l}145080 \\
145963 \\
148094\end{array}$ \\
\hline Cha & rling & & & & & & & & & & & & \\
\hline & $\begin{array}{r}\text { TËCP } \\
672\end{array}$ & $\begin{array}{r}\text { TECR } \\
-1024\end{array}$ & $\begin{array}{l}\text { TECS } \\
3944\end{array}$ & $\begin{array}{l}\text { TEDA } \\
4485\end{array}$ & $\begin{array}{r}\text { TECT } \\
83\end{array}$ & $\begin{array}{r}\text { TECU } \\
560\end{array}$ & $\begin{array}{r}\text { TECW } \\
1247\end{array}$ & $\begin{array}{l}\text { TECZ } \\
2595\end{array}$ & $\begin{array}{r}\text { TEDB } \\
248\end{array}$ & $\begin{array}{l}\text { TEDF } \\
8775\end{array}$ & $\begin{array}{l}\text { TEDJ } \\
6661\end{array}$ & $\begin{array}{l}\text { TEDH } \\
2583\end{array}$ & $\begin{array}{l}\text { TEDI } \\
4078\end{array}$ \\
\hline $\begin{array}{r}2001 \mathrm{Q} 1 \\
\text { Q2 } \\
\text { Q3 } \\
\text { Q4 }\end{array}$ & $\begin{array}{r}673 \\
1124 \\
-815 \\
493\end{array}$ & $\begin{array}{r}1860 \\
1228 \\
665 \\
-146\end{array}$ & $\begin{array}{l}2773 \\
1970 \\
4112 \\
3933\end{array}$ & $\begin{array}{r}14222 \\
-10731 \\
6894 \\
-3758\end{array}$ & $\begin{array}{r}-339 \\
93 \\
-67 \\
407\end{array}$ & $\begin{array}{r}10783 \\
-13941 \\
7317 \\
-4089\end{array}$ & $\begin{array}{r}1048 \\
1993 \\
-522 \\
282\end{array}$ & $\begin{array}{r}2729 \\
1124 \\
166 \\
-357\end{array}$ & $\begin{array}{r}-808 \\
-1141 \\
755 \\
-2407\end{array}$ & $\begin{array}{r}-3772 \\
-531 \\
2767 \\
3032\end{array}$ & & & $\begin{array}{l}1735 \\
4782 \\
4203 \\
5263\end{array}$ \\
\hline $\begin{array}{r}2002 \text { Q1 } \\
\text { Q2 } \\
\text { Q3 } \\
\text { Q4 }\end{array}$ & $\begin{array}{r}400 \\
458 \\
221 \\
-353\end{array}$ & $\begin{array}{l}1572 \\
1264 \\
1397 \\
2928\end{array}$ & $\begin{array}{l}2956 \\
2183 \\
4426 \\
4589\end{array}$ & $\begin{array}{r}4072 \\
2860 \\
-924 \\
-5508\end{array}$ & $\begin{array}{l}-657 \\
-181 \\
2096 \\
-788\end{array}$ & $\begin{array}{r}2779 \\
219 \\
-6762 \\
-8176\end{array}$ & $\begin{array}{r}702 \\
1390 \\
-523 \\
486\end{array}$ & $\begin{array}{l}1249 \\
1431 \\
4265 \\
2970\end{array}$ & $\begin{array}{r}-971 \\
-1077 \\
2429 \\
-554\end{array}$ & $\begin{array}{r}-3641 \\
2354 \\
5607 \\
3484\end{array}$ & & $\begin{array}{r}8491 \\
12060 \\
14303 \\
12835\end{array}$ & $\begin{array}{l}3617 \\
4199 \\
5358 \\
3 \quad 997\end{array}$ \\
\hline $\begin{array}{r}2003 \text { Q1 } \\
\text { Q2 } \\
\text { Q3 } \\
\text { Q4 }\end{array}$ & $\begin{array}{r}1202 \\
1095 \\
280 \\
303\end{array}$ & $\begin{array}{r}-273 \\
64 \\
-3402 \\
256\end{array}$ & $\begin{array}{l}4894 \\
3765 \\
32224 \\
2274\end{array}$ & $\begin{array}{r}3367 \\
998 \\
6213 \\
2519\end{array}$ & $\begin{array}{r}-222 \\
515 \\
669 \\
-1213\end{array}$ & $\begin{array}{r}1281 \\
-548 \\
3523 \\
188\end{array}$ & $\begin{array}{r}120 \\
38 \\
1359 \\
-559\end{array}$ & $\begin{array}{r}2189 \\
992 \\
662 \\
4103\end{array}$ & $\begin{array}{r}304 \\
236 \\
2464 \\
873\end{array}$ & $\begin{array}{r}-3506 \\
3086 \\
2285 \\
4176\end{array}$ & & $\begin{array}{r}3493 \\
12016 \\
17843 \\
13187\end{array}$ & $\begin{array}{l}1509 \\
4364 \\
4056 \\
4345\end{array}$ \\
\hline $\begin{array}{r}2004 \text { Q1 } \\
\text { Q2 } \\
\text { Q3 } \\
\text { Q4 }\end{array}$ & $\begin{array}{r}699 \\
99 \\
1532 \\
376\end{array}$ & $\begin{array}{r}-5542 \\
-1453 \\
2557 \\
-661\end{array}$ & $\begin{array}{l}4696 \\
5706 \\
3418 \\
2530\end{array}$ & $\begin{array}{r}-2330 \\
-632 \\
12873 \\
4376\end{array}$ & $\begin{array}{r}-2235 \\
366 \\
174 \\
72\end{array}$ & $\begin{array}{r}2421 \\
-7002 \\
1374 \\
45\end{array}$ & $\begin{array}{r}217 \\
-179 \\
6210 \\
-395\end{array}$ & $\begin{array}{r}-2732 \\
6183 \\
5115 \\
4654\end{array}$ & $\begin{array}{r}-303 \\
1782 \\
3157 \\
-2302\end{array}$ & $\begin{array}{r}12354 \\
7230 \\
570 \\
8641\end{array}$ & & & $\begin{array}{l}3137 \\
5887 \\
5495 \\
4502\end{array}$ \\
\hline $\begin{array}{r}2005 \text { Q1 } \\
\text { Q2 } \\
\text { Q3 } \\
\text { Q4 }\end{array}$ & $\begin{array}{r}75 \\
717 \\
-281 \\
1403\end{array}$ & $\begin{array}{r}98 \\
243 \\
-922 \\
295\end{array}$ & $\begin{array}{l}7577 \\
6858 \\
5494 \\
4355\end{array}$ & $\begin{array}{r}-7042 \\
10869 \\
3051 \\
3723\end{array}$ & $\begin{array}{r}-828 \\
1226 \\
769 \\
-241\end{array}$ & $\begin{array}{r}-3016 \\
5168 \\
-1779 \\
-1690\end{array}$ & $\begin{array}{r}1279 \\
-669 \\
-96 \\
1842\end{array}$ & $\begin{array}{r}-4477 \\
5144 \\
4157 \\
3812\end{array}$ & $\begin{array}{r}495 \\
536 \\
-1961 \\
3629\end{array}$ & $\begin{array}{r}-3314 \\
11897 \\
11534 \\
9171\end{array}$ & $\begin{array}{r}2351 \\
8498 \\
16492 \\
13818\end{array}$ & $\begin{array}{r}-833 \\
5010 \\
14352 \\
11465\end{array}$ & $\begin{array}{ll}3 & 183 \\
3 & 488 \\
2 & 141 \\
2 & 353\end{array}$ \\
\hline $\begin{array}{r}2006 \text { Q1 } \\
\text { Q2 } \\
\text { Q3 } \\
\text { Q4 }\end{array}$ & $\begin{array}{l}831 \\
174 \\
237 \\
232\end{array}$ & $\begin{array}{r}76 \\
1698 \\
4214 \\
-930\end{array}$ & $\begin{array}{l}6398 \\
6722 \\
6323 \\
5560\end{array}$ & $\begin{array}{l}10404 \\
15767 \\
13439 \\
-1454\end{array}$ & $\begin{array}{r}667 \\
624 \\
192 \\
1177\end{array}$ & $\begin{array}{r}1042 \\
5150 \\
4797 \\
-9060\end{array}$ & $\begin{array}{r}-321 \\
737 \\
41 \\
-14\end{array}$ & $\begin{array}{l}9016 \\
9256 \\
8408 \\
6443\end{array}$ & $\begin{array}{r}-5003 \\
1043 \\
1635 \\
5114\end{array}$ & $\begin{array}{l}9961 \\
3307 \\
6247 \\
-215\end{array}$ & $\begin{array}{l}-4935 \\
15790 \\
14833 \\
11012\end{array}$ & $\begin{array}{r}-5877 \\
12430 \\
12800 \\
8814\end{array}$ & $\begin{array}{rl} & 942 \\
3 & 360 \\
2 & 034 \\
2 & 198\end{array}$ \\
\hline $\begin{array}{r}2007 \text { Q1 } \\
\text { Q2 } \\
\text { Q3 } \\
\text { Q4 }\end{array}$ & $\begin{array}{r}958 \\
909 \\
-1069 \\
1978\end{array}$ & $\begin{array}{r}223 \\
525 \\
-287 \\
-192\end{array}$ & $\begin{array}{r}6078 \\
8403 \\
10857 \\
8094\end{array}$ & $\begin{array}{r}35164 \\
8338 \\
24306 \\
-3417\end{array}$ & $\begin{array}{r}-1117 \\
785 \\
293 \\
-33\end{array}$ & $\begin{array}{r}12964 \\
2868 \\
-384 \\
-4743\end{array}$ & $\begin{array}{r}217 \\
178 \\
-1168 \\
6671\end{array}$ & $\begin{array}{r}23101 \\
4507 \\
25564 \\
-5313\end{array}$ & $\begin{array}{r}-1588 \\
143 \\
2503 \\
2466\end{array}$ & $\begin{array}{r}7022 \\
6321 \\
20624 \\
18264\end{array}$ & $\begin{array}{r}1344 \\
1201 \\
11148 \\
2940\end{array}$ & $\begin{array}{r}1507 \\
-195 \\
8866 \\
-129\end{array}$ & $\begin{array}{r}-163 \\
1396 \\
2282 \\
3069\end{array}$ \\
\hline $\begin{array}{r}2008 \text { Q1 } \\
\text { Q2 } \\
\text { Q3 }\end{array}$ & $\begin{array}{r}1324 \\
559 \\
198\end{array}$ & $\begin{array}{r}998 \\
-5 \\
436\end{array}$ & $\begin{array}{l}9143 \\
6826 \\
6824\end{array}$ & $\begin{array}{l}10595 \\
26394 \\
49146\end{array}$ & $\begin{array}{r}876 \\
-598 \\
-831\end{array}$ & $\begin{array}{r}-9405 \\
-641 \\
868\end{array}$ & $\begin{array}{r}5574 \\
3119 \\
500\end{array}$ & $\begin{array}{l}13550 \\
24515 \\
48610\end{array}$ & $\begin{array}{l}-2075 \\
-1066\end{array}$ & $\begin{array}{r}18107 \\
7202 \\
22877\end{array}$ & $\begin{array}{r}15212 \\
3934 \\
-22738\end{array}$ & $\begin{array}{r}14327 \\
2601 \\
-23821\end{array}$ & $\begin{array}{r}885 \\
1333 \\
1083\end{array}$ \\
\hline
\end{tabular}

